\title{
MODEL DEVELOPER'S APPENDIX . TO THE MODEL DOCUMENTATION REPORT: NEMS MACROECONOMIC ACTIVITY MODULE
}

July $15 ; 1994$

Office of Integrated Analysis and Forecasting Energy Information Administration

U.S. Department of Energy Washington, DC

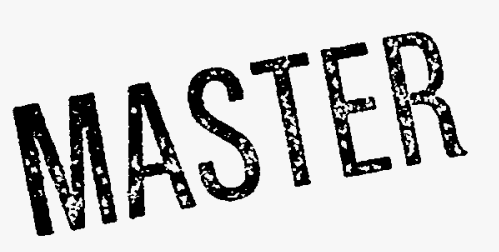

DISTRIBUTION OF THIS DOCUMENT IS UAVLRITED W ZFCEIVED

MAR 201995

OSTI 
Released for Printing: March 3, 1995 


\section{DISCLAIMER}

This report was prepared as an account of work sponsored by an agency of the United States Government. Neither the United States Government nor any agency thereof, nor any of their employees, make any warranty, express or implied, or assumes any legal liability or responsibility for the accuracy, completeness, or usefulness of any information, apparatus, product, or process disclosed, or represents that its use would not infringe privately owned rights. Reference herein to any specific commercial product, process, or service by trade name, trademark, manufacturer, or otherwise does not necessarily constitute or imply its endorsement, recommendation, or favoring by the United States Government or any agency thereof. The views and opinions of authors expressed herein do not necessarily state or reflect those of the United States Government or any agency thereof. 


\section{DISCLAIMER}

Portions of this document may be illegible in electronic image products. Images are produced from the best available original document. 


\section{Table of Contents}

1. Properties of the Mathematical Solution

1.1. Solution Methodology 1

1.2 Theoretical Considerations 3

Domain of Module Solution 3

Module Stability $\quad 3$

2. NEMS MAM Empirical Basis . 5

2.1 Scenario Design Methodology 5

2.2 Relevant Output Variables for Scenario Analysis 7

3. Scenario Analysis : 8

3.1. Expectations for Scenario Analysis 8 .

Gross Domestic Product (GDP) ， 8

Disposable Income (YD87) 9

Unit Sales of Automobiles, Domestic (SQTRCAR.SDOM) , 9

Consumer Price Index (CPI) '. 9

Utility Bond Interest Rate (RMPUAANS) . 10

Unemployment Rate (RUC) . . 10

3.2. Historical World Oil Price Scenario

First Set of Comparisons: MAM Historical World Oil Price Scenario . vs. MAM Base Scenario 11

Second Set of Comparisons: MAM Historical World Oil Price - Scenario vs. DRI Historical World Oil Price Scenario 16

3.3. AEO94 High World Oil Price Scenario 23

First Set of Comparisons: MAM AE094 High World Oil Price Scenario vs. MAM Base Scenario ' 23

Second Set of Comparisons: MAM AEO94 High World Oil Price Scenario vs. DRI AEO94 High World Oil Price Scenario 28

3.4. AEO94 Low World Oil Price Scenario . 35

First Set of Comparisons: MAM AE094 Low. World Oil Price Scenario vs. MAM Base Scenario $\quad 35$

Second Set of Comparisons: MAM AEO94 Low World Oil Price

Scenario vs. DRI AEO94 Low World Oil Price Scenario $\quad 40$

3.5. Immediate Increase World Oil Price Scenario 47

First Set of Comparisons: MAM Ramped Decline World Oil Price Scenario vs: MAM Base Scenario $\quad 47$

Second Set of Comparisons: MAM Ramped Decline World Oil Price Scenario vs.'DRI Ramped Decline World Oil Price Scenario 52

Energy Information Administration

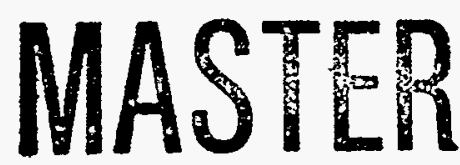

Model Developer's Appendix to the NEMS Macroeconomic Activity Module Documintation Report 
3.6. Ramped Decline World Oil Price Scenario

First Set of Comparisons: MAM Immediate Increase World Oil Price Sceriario vs. MAM Base Scenario.

Second Set of Comparisons: MAM Immediate Increase World Oil Price

Scenario vs. DRI AEO94 Immediate Increase World Oil Price

Scenario

Appendix 


\section{Properties of the Mathematical Solution}

\subsection{Solution Methodology}

The NEMS Macroeconomic Activity Module (MAM) tested here was used to generate the Annuai Energy Outlook 1994 (AEO94). MAM is a response surface model, not a structural model, composed of three submodules: the National Submodule, the Interindustry Submodule, and the Regional Submodule. The National Submodule and the Interindustry Submodule are response surface approximations of two larger, proprietary econometric models that have been developed and maintained by McGraw-Hill/Data Resources, Incorporated (DRI), namely, the DRI U.S. Quarterly and Interindustry Models, respectively. The Regional Submodule of the MAM is composed of a set of shares that vary by Census division, combined with an algorithm to share the national level results of the National and Interindustry Submodules out to the Census division level of detail for those variables that are required by other modules of the NEMS system. The regional shares used to generate the AEO94 were developed by simulating the DRI Regional Model, a proprietary econometric model that has been developed and maintained by DRI in conjunction with the U.S. Quarterly and Interindustry Models. The response surface equations and regional shares used to develop the MAM forecasts for the AEO94 are designed to accept a range of inputs and generate their corresponding solution values. The response surface model is a macroeconomic feedback model that responds to changes in energy prices, specifically the wholesale purchased fuel price index. The user is given a macroeconomic baseline and when energy prices change, the MAM estimates the energy price impact and calculates a new macroeconomic solution ${ }^{2}$. Since MAM is a response surface model, and not a structural model, the validation of MAM involves testing MAM's performance compared to the full structural DRI model's performance under comparable scenarios. The validation of the full

1 The report titled, Model Documentation Report: Macroeconomic Activity Module of the National Energy Modeling System (NEMS). Final Report prepared by Decision Analysis Corporation of Virginia, Contract No. DE-AC01-92EI21946, Task 93-060, March 31, 1994, provides a detailed description of the process by which MAM arrives at its solution.

Energy Information Administration Model Developer's Appendix to the NEMS Macroeconomic Activity Module Documentation Report 
DRI model is documented in the report, Documentation of the DRI Model of the U.S. Economy, DOE/EIA-M061, December, 1993. 


\subsection{Theoretical Considerations}

\section{Domain of Module Solution}

The MAM is a sequential structured algorithm in the following sense: the National Submodule is solved first, and the results of the National Submodule are passed to the Interindustry Submodule as inputs. The subset of results of both submodules that are required at the Census division level of disaggregation are then passed to the Regional Submodule, and the corresponding regional shares are applied to generate Census division level results. Because of the direct solution algorithm, and because all of the functions in the MAM are continuous and differentiable in the domain of applicability of the model, the model always converges to produce a unique solution. The solution domain is all real values for the solution variables as functions of macroeconomic driver variables, buildings sector economic activity measures, and industrial sector variables at the required levels of detail, either national or Census division: As described in the main documentation of this module ${ }^{2}$, some of the inputs to the MAM may be correlated, such as certain macroeconomic activity variables, and if inconsistent pairs of such inputs or negative prices are chosen, then the model may produce anomalous results.

\section{Module Stability"}

A frequently employed method of model assessment is to investigate output response to a variety of different input data and parameter assumptions. The structure of the rnodel should be such that the output responds in a manner that reflects the underlying physical and behavioral tenets of the model. This implies that reasonable changes in inputs do not cause catastrophic model results that would indicate a structural flaw in the model design.

As described previously, MAM is a response surface approximation to the DRI U.S. Quarterly and Interindustry Models. Consequently, sensitivity cases of the MAM are designed to measure 
the degree to which MAM scenario results mirror compàrable scenario results generated using the full DRI models, in addition to verifying the absence of catastrophic behavior described above. Meaningful scenario design focuses upon the performance as a function of a key driver variable of the MAM: the wholesale purchased fuel price index, WPI05, which is composed using price information for the fuel classes of electricity; natural gas; fuel oil 'and coal; gasoline and oil in the MAM. The methodolegical design for the scenarios, and the scenario assumptions for this analysis, are disclissed in the next section of this report. 


\section{NEMS MAM Empiriçal Basis}

This section presents the scenario design methodology and empirical basis for the sensitivity analysis of the MAM. Five scenarios are presented in which WRI05 is varied by systematically modifying the Real World Oil Price. The MAM is calculated using WPI05 as the energy price variable that triggers macroeconomic feedback. To assess the degree to which MAM performance approximates the DRI model results, the same percentage change in WPI05 from the base values are effectively used as inputs to both the DRI and MAM simulations. It must be emphasized that the forecasts presented in this volume are designed only to test the MAM, and do not necessarily represent the official Department of Energy or Energy Information Administration forecasts. These forecasts are used only for examining the responsiveness of the NEMS MAM under a variety of input assumpiions.

\subsection{Scenario Design Methodology}

The previous section of this report describes the relationship between the.DRI full models and the MAM, emphasizing the need to design scenarios that contain parallel assumptions for the DRI full models and the MAM. The assumptions that define the five scenarios are summarized in Table 1.

In order to develop DRI and MAM scenario results, the world oil price (in real terms) assumptions described in Table 1 were first implemented in the DRI model input files beginning with the year 1993 (the first forecast year), and the DRI full models were then executed. The changes in WPI05 corresponding to the real world oil price changes were then incorporated into the MAM. The MAM was executed next, and the forecast values generated through this exercise are comparable to the corresponding values.projected by the DFI full models. 


\section{Table 1. DRI Real World Oil Price Assumptions to Generate}

\section{Corresponding MAM WPI05 Assumptions}

\begin{tabular}{|c|c|}
\hline Scenario Title & Scenario Assumptions \\
\hline $\begin{array}{l}\text { Repeat Historical } \\
\text { World Oil Price } \\
\begin{array}{l}\text { Path } \\
\therefore\end{array}\end{array}$ & $\begin{array}{l}\text { 1. Trends in real world oil prices from the most recent } 20 \text { - } \\
\text { year historical period are repeated for the forecast. This } \\
\text { scenario measures model performance under periods of } \\
\text { increasing prices and decreasing prices. }\end{array}$ \\
\hline $\begin{array}{ll}\text { 2. } & \text { Annual Energy } \\
. & \text { Outlook (AEO) } \\
. & \text { High Oil Price }\end{array}$ & $\begin{array}{l}\text { Real world oil price is set to the AEO High Oil Price } \\
\text { case for the forecast period. This scenario measures } \\
\text { model performance under a high price scenario and tests } \\
\text { the bounds corresponding to the published AEO case. }\end{array}$ \\
\hline $\begin{array}{ll}\text { 3. Annual Energy } \\
\text { Outlook (AEO) } \\
\text { Low Oil Price }\end{array}$ & $\begin{array}{l}\text { Real world oil price is set to the AEO Low Oil Price } \\
\text { case for the forecast period. This scenario measures } \\
\text { model performance under a low price scenario and tests } \\
\text { the bounds corresponding to the published AEO case. }\end{array}$ \\
\hline \begin{tabular}{|l} 
4. \\
Immediate $20 \%$ \\
Increase in World \\
Oil Price
\end{tabular} & $\begin{array}{l}\text { For the entire forecast period of } 1993-2010 \text {, real world } \\
\text { oil price is increased by } 20 \% \text { over the baseline. This } \\
\text { scenario measures model performance under sustained } \\
\text { higher price levels compared to the baseline. }\end{array}$ \\
\hline $\begin{array}{l}\text { 5. } \text { Ramped } 18 \% \\
\text { Decline in World } \\
\text { Oil Price }\end{array}$ & $\begin{array}{l}\text { 5. This scenario implements a gradual decrease in prices, } \\
\text { reaching } 18 \% \text { below base case levels by the year } 2010 \text {. } \\
\text { In other words, in the } x^{\text {th }} \text { year of the forecast, real world } \\
\text { oil price is } x \% \text { lower under this scenario than under the } \\
\text { baseline. As a result, in the year } 2010 \text {, which is the } 18^{\text {th }} \\
\text { year of the forecast, real world oil price is } 18 \% \text { lower } \\
\text { than the baseline } 2010 \text { real world oil price value. }\end{array}$ \\
\hline
\end{tabular}




\subsection{Relevant Output Variables for Scenario Analysis}

The output variables of greatest relevance to scenario comparisons are provided in Table 2.

\section{Table 2. DRI and MAM Model Outputs for Scenario Comparison}

\begin{tabular}{||l|c|}
\hline Variable Description & Variable Name \\
\hline Gross Domestic Product measured in 1987 dollars & GDP87 $^{3}$ \\
\hline Disposable Income measured in 1987 dollars. & YD87 \\
\hline Unit Sales of Automobiles, Domestic & SQTRCARSDOM \\
\hline Consumer Price Index & CPI \\
\hline Utility Bond.Interest Rate . & RMPUAANS \\
\hline Unemployment Rate & RUC \\
\hline
\end{tabular}

Summary forecast results for the relevant output variables are provided and interpreted in Chapter 3 of this report. Chapter 3 also compares the results obtained using the DRI full model with the MAM response surface results. Percentage changes within and across scenarios are computed where applicable, and absolute differences are computed for the interest rate and unemployment rate variables. Forecasted energy prices under all scenarios are provided for reference and to facilitate price impact calculations. Detailed tables containing the above listed information are provided in Tables A-1 through A-12 in the Appendix to this report.

3 The calculated sum of the components of Gross Domestic Product (denoted GDPSUM in the MAM code) is used where applicable. Otherwise, Gross Domestic Product measured in constant $\$ 1987$ is used (denoted by GDP87 in the DRI code). The two measures are conceptually identical. 


\section{Scenario Analysis}

\subsection{Expectations for Scenario Analysis}

The analysis is composed of two stages. First, MAM results are evaluated from the standpoint of ensuring that the forecasts respond to input variable changes and reflect the underlying physical and behavioral tenets of the model. Second, because the MAM is a response surface approximation of the DRI U.S. Quarterly and. Interindustry Models, MAM outputs arë compared to results generated under an analogous scenario executed using the full DRI model.

The output variables most relevant to scenario comparisons are provided in Table 2 of Chapter 2 in this report. It is expected that under various world oil price scenarios, these output variables will change in a manner that is consistent with macroeconomic theory. A basic discussion of expected impacts with respect to each of the output variables of interest is presented in the sections below: This discussion can be skipped by users familiar with the macroeconomic treatment of oil price variations.

\section{Gross Domestic Product (GDP).}

Oil price fluctuations are a key driver of GDP. Economic theory postulates an inverse relationship between world oil prices and growth in GDP in an expanding economy. Several reasons support this relationship. For illustrative purposes, assume that oil prices increase. Because the U.S. imports nearly one-half of its oil supplies, more payments must beinade to:foreign suppliers when prices increase. In addition, the only industry in the U.S. that benefits from oil price increases is the "upstream" oil industry and related service providers. In all other industries, an increase in oil prices results in increased costs for their goods. If this increase is passed on to consumers, demand for these goods will decrease (according to the principles of market supply and demand), thus slowing down the growth of the economy. In all recent past oil 
crises, economic growth has been slowed by the increase in prices.

\section{Disposable Income (YD87)}

The relationship between disposable income and oil prices is very similar to the relationship between GDP and oil prices. When oil prices risè, production costs for a. wide range of goods increase, since oil is an important factor of production in the economy. Rising production costs are generally passed on to consumers in the form of higher retail prices, so that real disposable income declines. The opposite effect occurs when oil prices decrease. Real disposable income rises because consumers are able to purchase the same amount of energy and goods for a smaller percentage of their disposable income. Thus, they may use some of the remaining disposable income to purchase other goods, which increases the rate of growth in the economy. This increased rate of growth in turn increases disposable income.

\section{Unit Sales of Automobiles, Domestic (SQTRCARSDOM)}

The economic principle of complementary goods postulates that a rise in the price of a good results in a reduction in the quantity demanded of a complementary good. In the case of world oil price and domestic automobiles, a rise in world oil price is almost always accompanied by a rise in retail-motor gasoline prices, with potential impacts on domestic automobile sales.

\section{Consumer Price Index (CPI)}

Macroeconomic theory postulates a direct relationship between oil price increases and the CPI. The CPI is a measure of the average price of commodities commonly bought by households. If oil prices rise, the CPI also rises, since oil and related energy prices are included as a part of the market-basket of consumer goods used to measure consumer price movements. Because oil and related energy products are a component of the CPI, increases in oil prices increase the CPI. In addition, because nearly all sectors of the economy use oil as an input, the price of most other goods will also increase in response to increases in the cost of energy. These secondary effects will also contribute to the CPI increase when oil prices rise. 


\section{Utility Bond Interest Rate (RMPUAANS)}

The utility bond interest rate varies with oil prices in a manner similar to the CPI. This is. because the $\mathrm{CPI}$ is often used as a measure of the inflationary pressure in the economy. If the CPI increases, inflation is then increasing. This increase in inflation causes interest rates to rise. A similar relationship exists between decreases in oil prices and decreases in interest rates. Decreases in oil prices will cause the utility bond interest rate to fall, due to an easing of inflationary pressures. In the case of severe oil price increases; the utility bond interest rate may be pushed up even further.

\section{Unemployment Rate (RUC)}

A direct relationship between the unemployment rate and world oil prices is postulated in traditional macroeconomic theory. An increase in world oil prices is expected to result in a rise in the unemployment rate, and a decrease in world oil prices is expected to decrease the unemployment rate. When oil prices increase, consumers have less money to spend on other goods. This causes a short-term contraction in the economy which slows GNP and increases unemployment. 


\subsection{Historical World Oil Price Scenario}

As described in Table 1, the Historical World Oil Price path scenario repeats world oil price trends from the most recent 20-year historical period for the forecasted values of world oil price. This scenario measures the performance of MAM within periods of price fluctuation. The scenario also tests the robustness of the MAM; over the past 20 years, world oil prices have shown more volatility than any other cash commodity. Real world oil prices in this scenario range from a low of $\$ 13.82$ per barrel to a high of $\$ 66.34$ per barrel. The values used for world oil prices in this scenario and the resulting model outputs are shown in Tables A-1 and A-3 of the appendix to this report.

\section{First Set of Comparisons: MAM Historical World Oil Price Sienario vs. MAM Base Sceniario}

Figures 1 through 3 illustrate the changes in the relevant MAM output variables in relation to the changes in world oil price. As evident from these graphs, changes in the output variables are consistent with the macroeconomic theories described previously in this section of the report. GDP decreases correspondingly as oil prices increase from reference case values. In quantitative terms, WPI05 is increased by $82 \%$ in 1995 , and GDP is $1.41 \%$ lower than in the reference case. The percent increase from the reference case for the oil price index reaches its peak at $270 \%$ higher than the reference case, in the year 2002. This increase causes the GDP to be $5.92 \%$ lower than the forecast in the reference case. In all forecast years, changes in personal income track closely to changes in GDP as expected. 
Figure 1. MAM Base Compared to MAM Historical World Oil Price Scenario

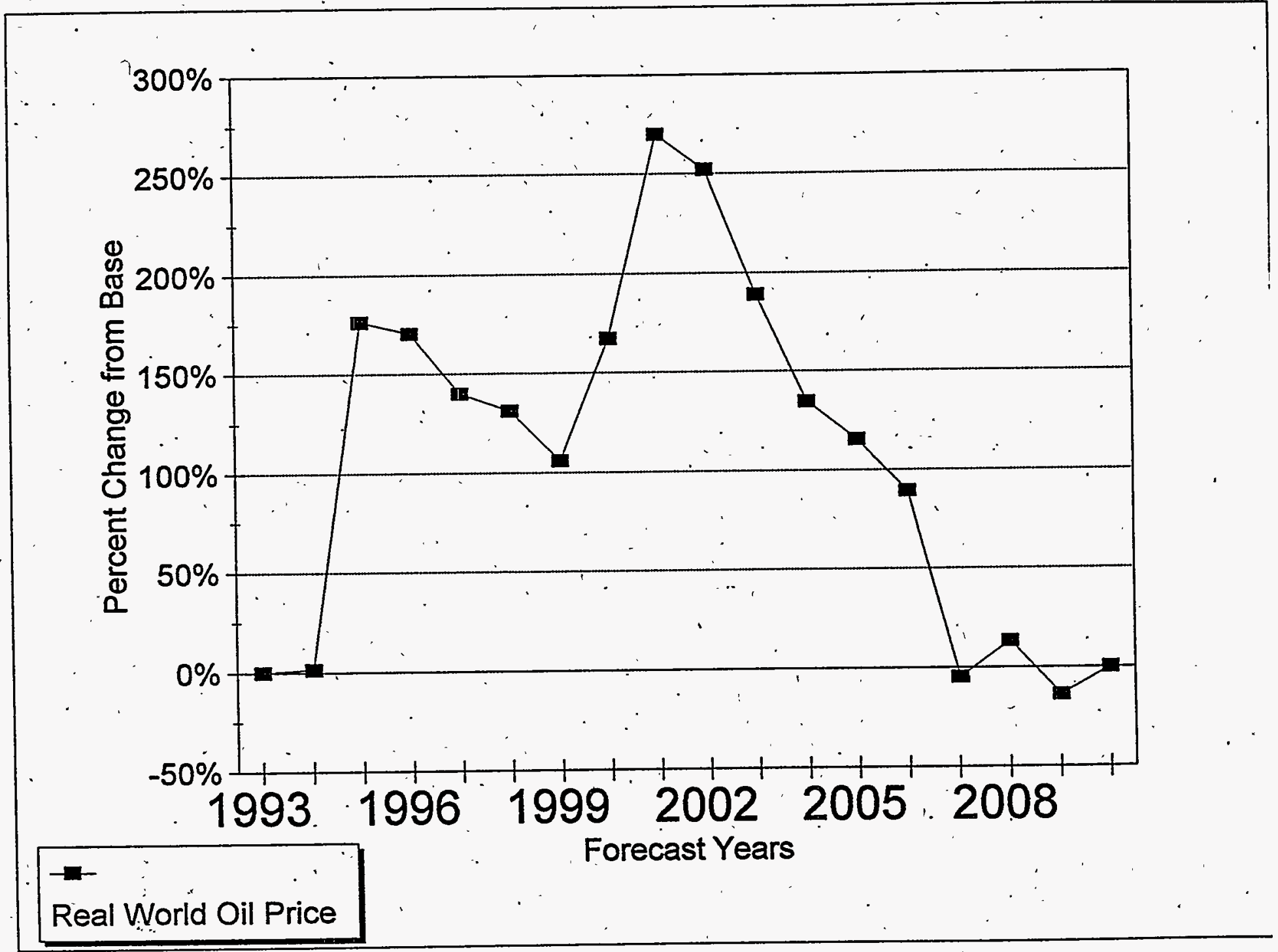


Figure 2. MAM Base Compared to MAM Historical World Oil Price Scenario

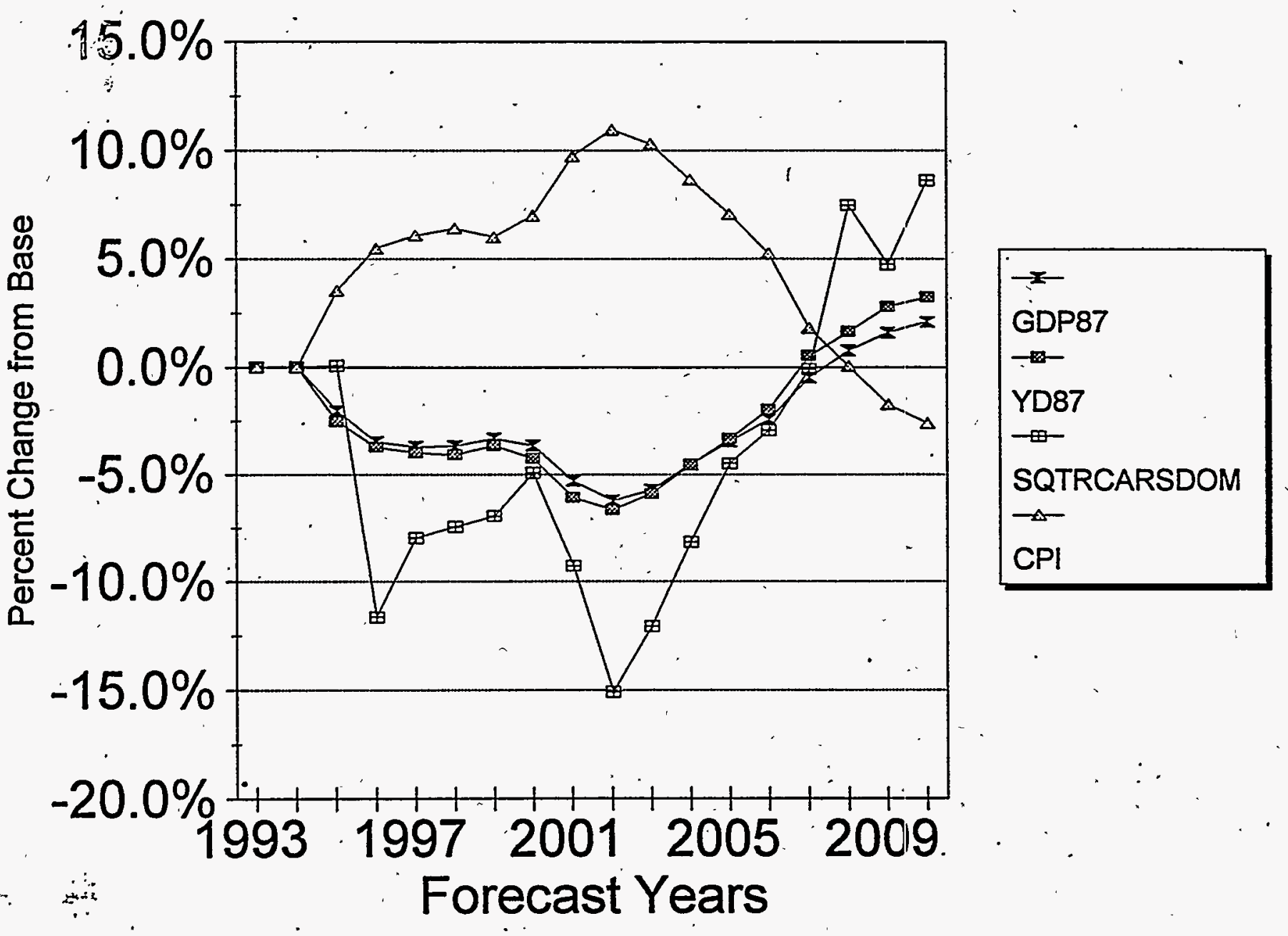


As the reference case real world oil price increases over the period of 1993-2002, the CPI is slightly higher than the reference case CPI values. Similarly, as the oil price decreases over the period of 2003-2010, the CPI also decreases. The utility bond interest rate follows a path similar to the CPI: As the real world oil price increases above the reference value, the utility bond interest rate also increases. In the later years of the forecast (post-2003), utility bond interest rate changes dônot track the real world oil price as closely. As an example, by the year 2007, WPI05 has fallen from its peak of $164 \%$ above the reference forecast to $15 \%$ above the reference forecast. During this same period, the utility bond interest rate actually rises from $1.17 \%$ to $1.62 \%$ above the reference case forecast.

Finally, the unemployment rate moves directly with changes in WPI05. Increases in oil prices exert upward pressure on the inflation rate, and decreases exert downward pressure on the inflation rate, in the forecast as expected. 
Figure 3. MAM Base Compared to MAM Historical World Oil Price

\section{Scenario}

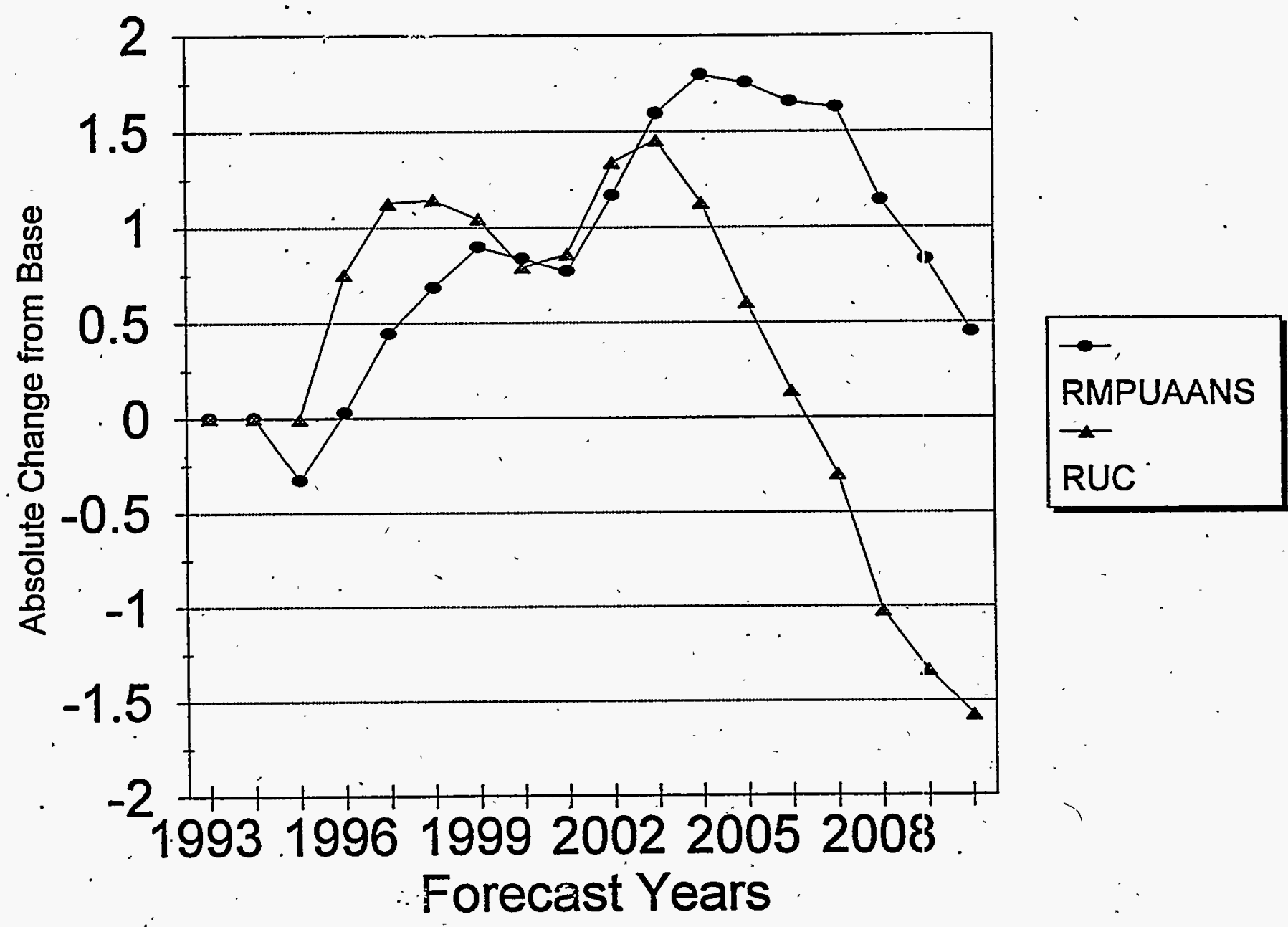


Second Set of Comparisons: MAM Historical World Oil Price Scenario vs. DRI

\section{Historical World Oil Price Scenario}

In the historical world oil price path scenario, the world oil price is varied from a low of $13.7 \%$ below the reference case to a high of $270 \%$ above the reference case. Over this range, the key outputs of the NEMS MAM differ by $3.25 \%$ or less from the outputs of the full DRI model. When the world oil price is restricted within $100 \%$ of the reference case value, the values of the MAM and the DRI forecasts are no more than 1.3\% apart for the same key variables. This range is similar to the differences between MAMand DRI in the reference case. In summary, MAM produces results that closely poirror DRI full rnodel results under the historical world oil price path scenario. Figures 4 through 9 compare the MAM scenario results to the DRI scenario results for the key output variables listed in Table 2 of this report. 
Figure 4. Historical World Oil Price Scenario: Percent Change in Constant $\$ 1987$ Gross Domestic Product

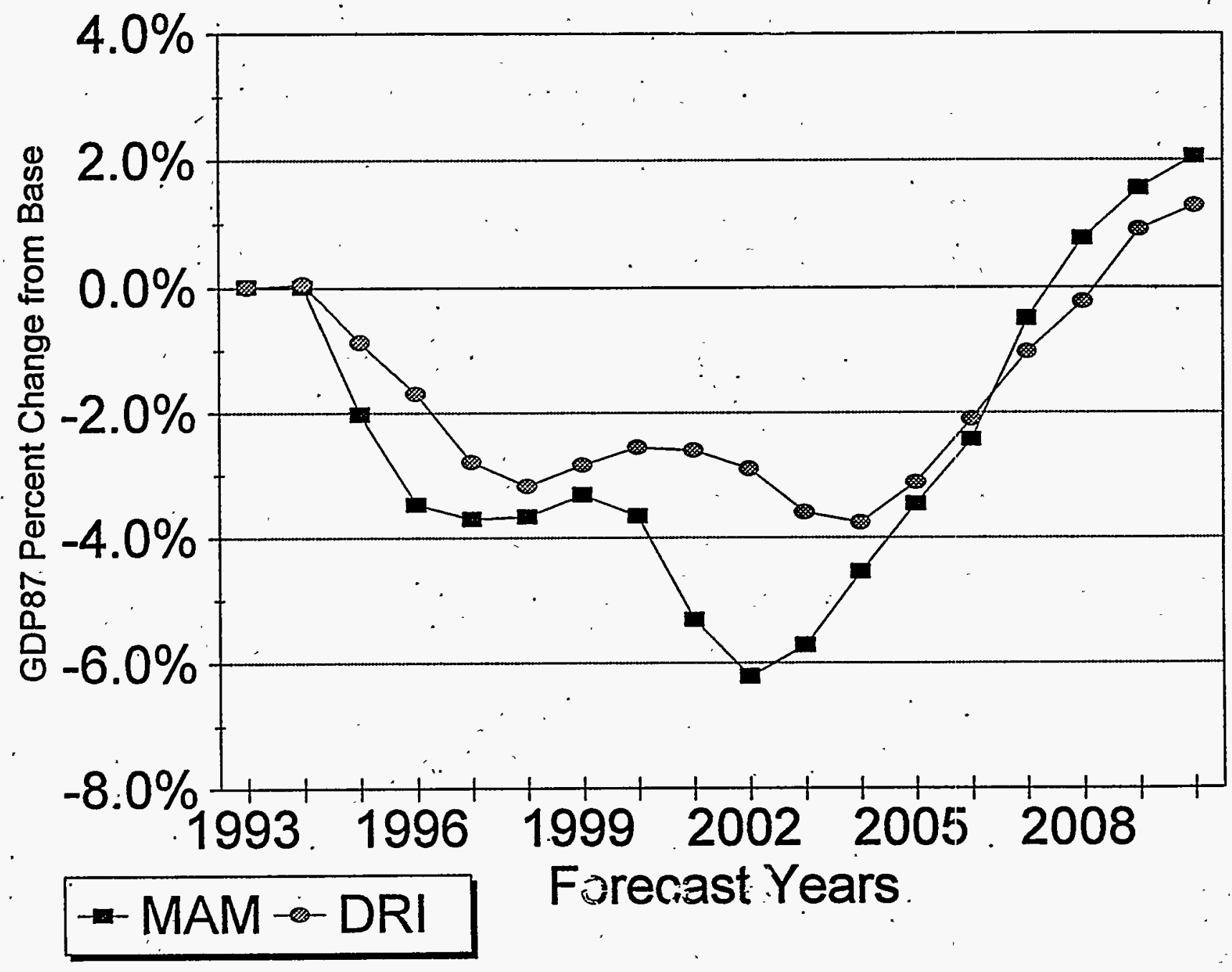


Figure 5. Historical World Oil Price Scenario: Percent Change in - Constant \$1987 Disposable Income

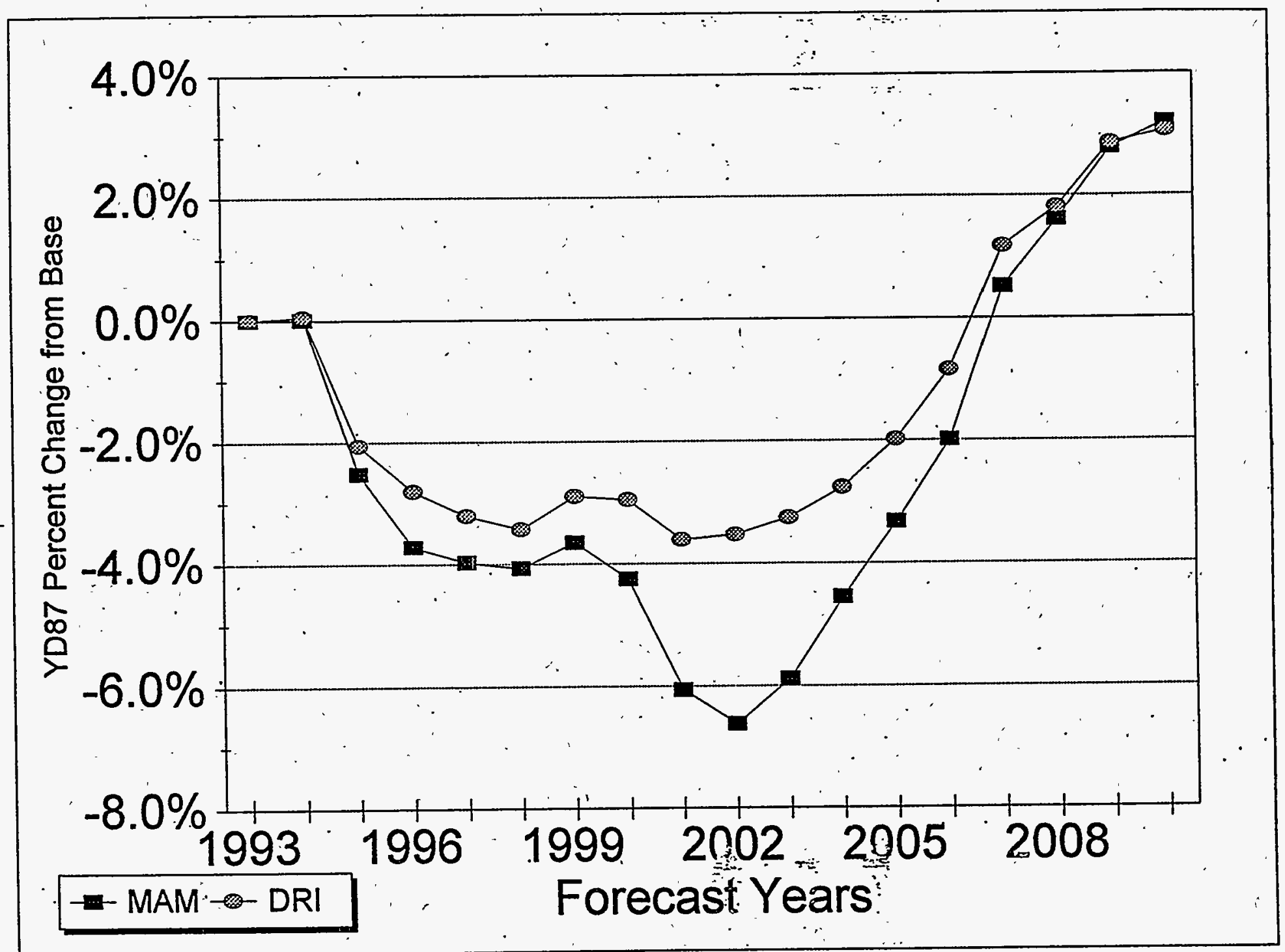


Figure 6. Historical World Oil Price Scenario: Percent Change in Unit $\therefore$ Sales of Domestic Automobiles

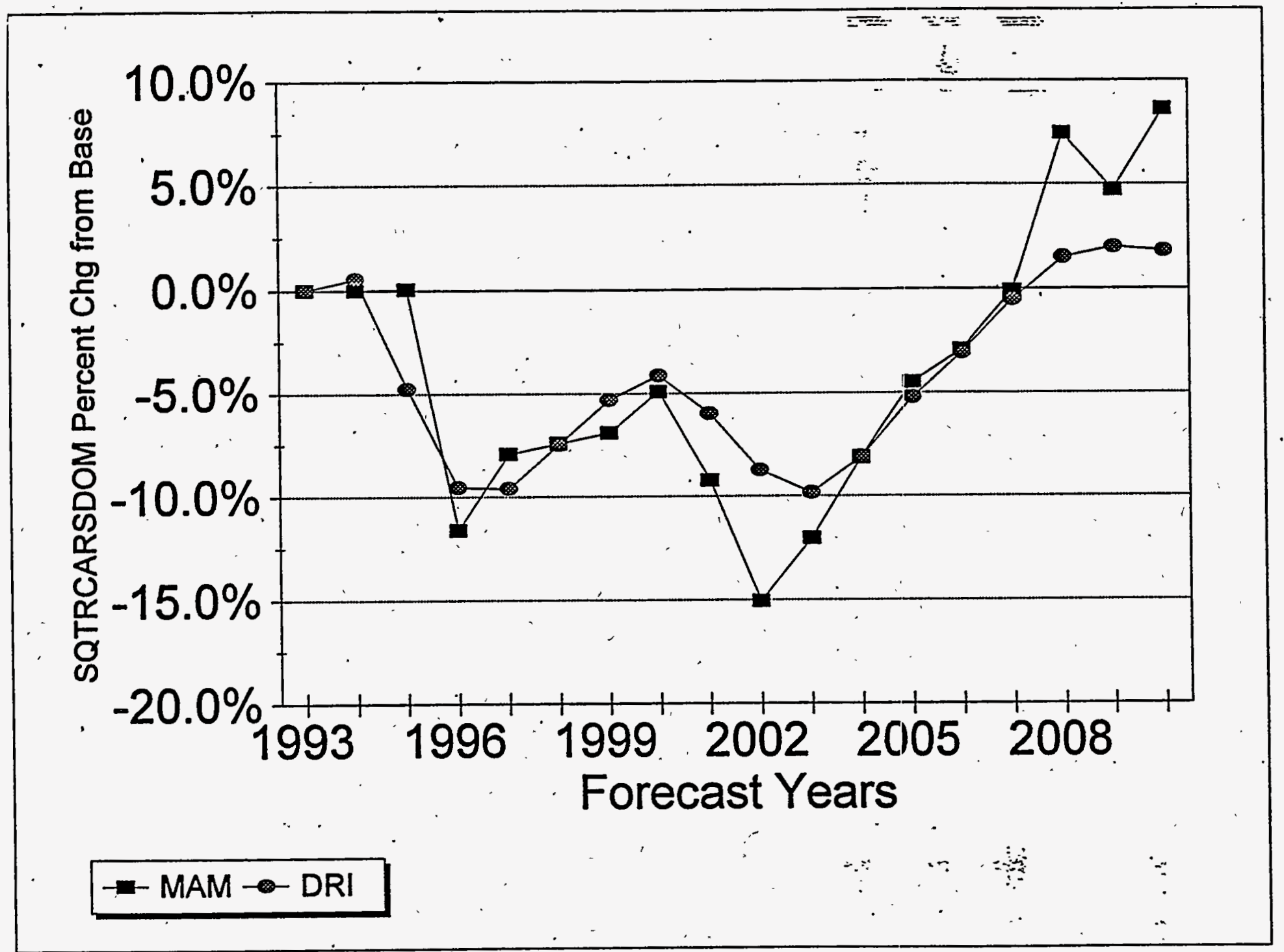


Figure 7. Historical World Oil Price Scenario: Percent Change in Consumer Price Index

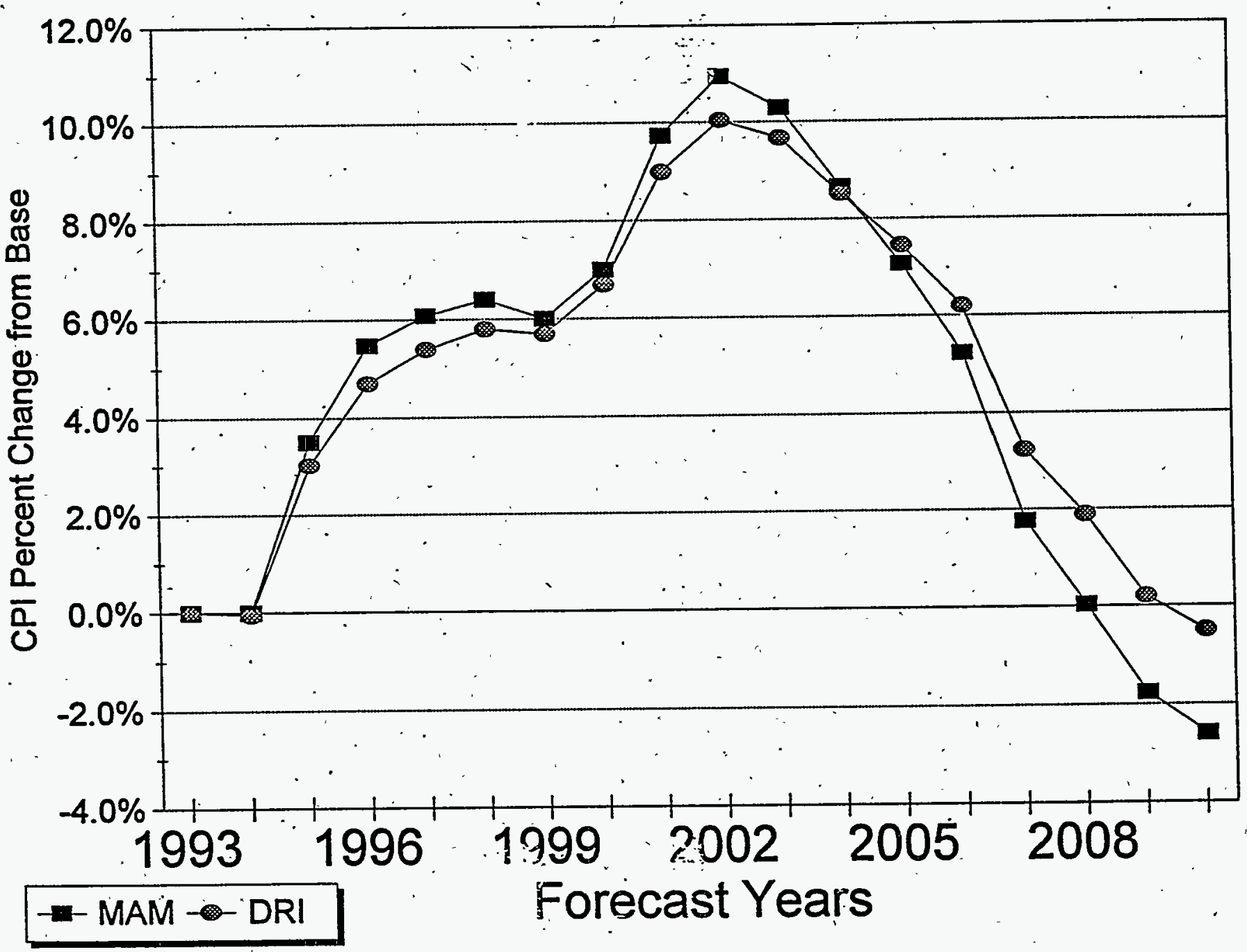


Figure 8. Historical World Oil Price Scenario: Absolute Change in Utility Bond Rate

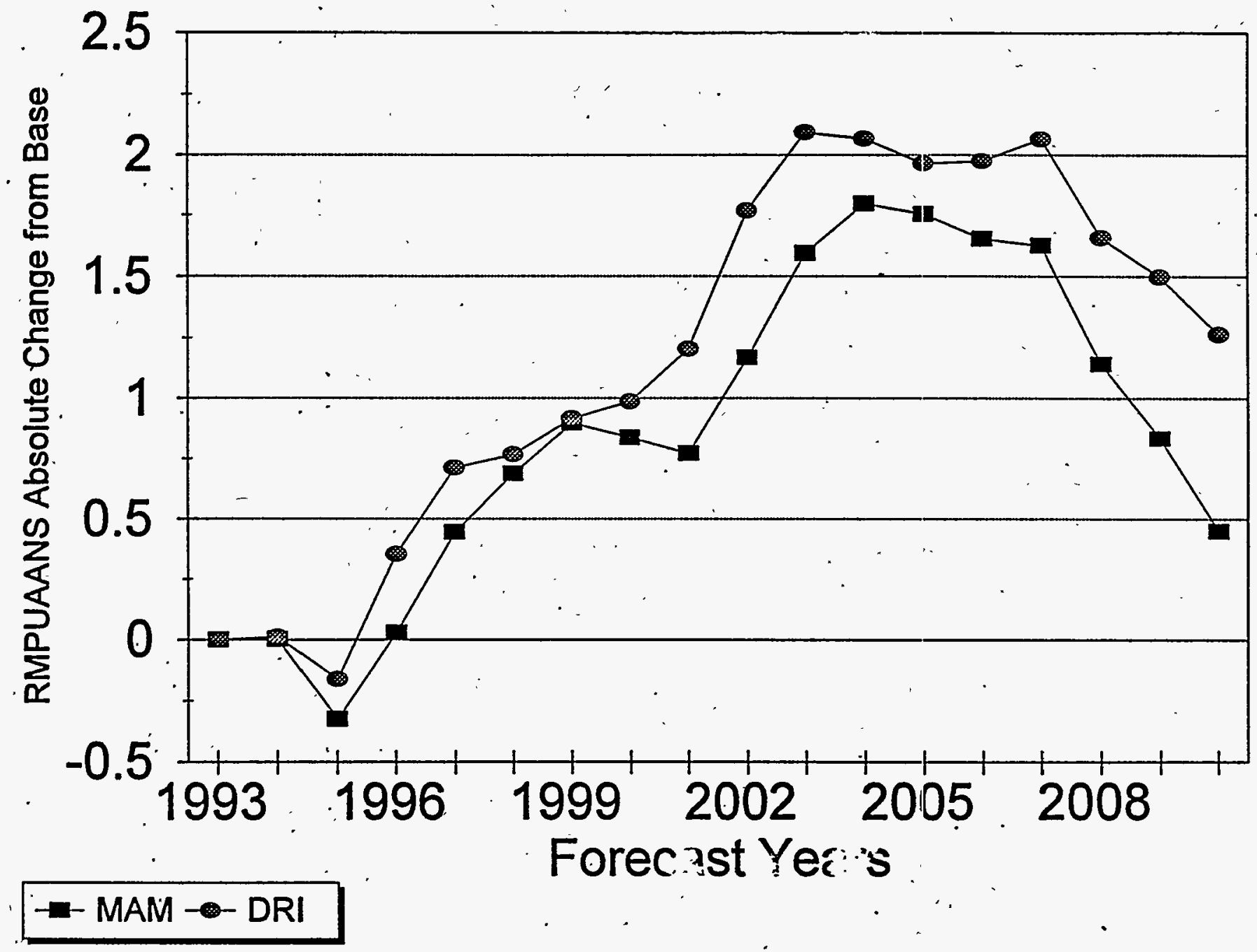


Figure 9. Historical World Oil Price Scenario: Absolute Change in Unemployment Rate

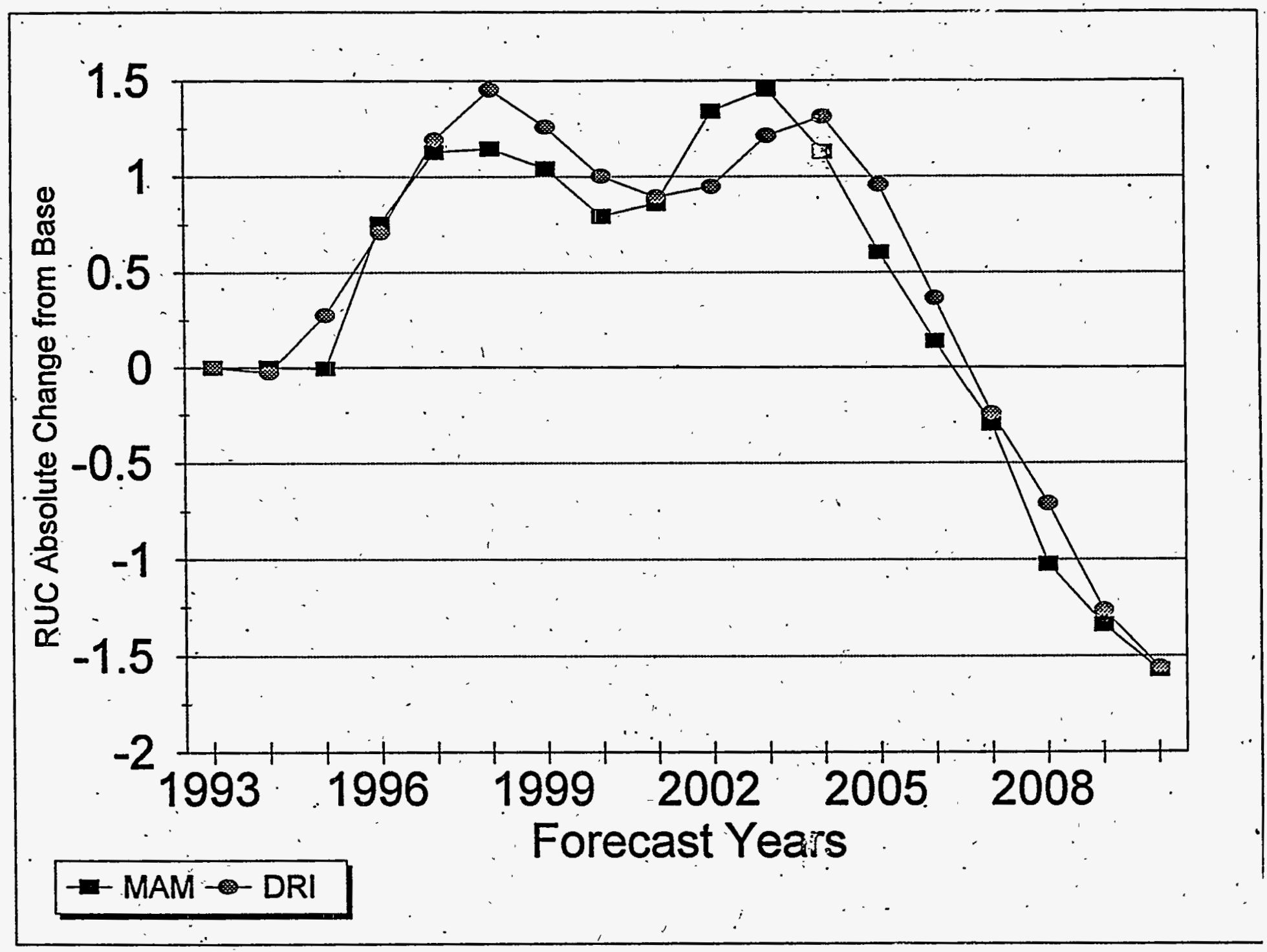




\subsection{AEO94 High World Oil Price Scenario}

As described in Table 1, the AEO94 High World Oil Price scenario is driven by world oil prices that are above the baseline forecast case. Real world oil prices in this scenario range from a low of $\$ 13.96$ per barrel to a high ${ }_{1}$ of $\$ 28.23$ per barrel, and rise steadily throughout the forecast period. The baseline world oil price varies from a low of $\$ 14.61 \mathrm{per}$ barrel to a high of $\$ 23.42$ per barrel, also rising throughout the forecast period. The time series of forecasted wcrld oil prices for both the baseline and the alternate case are provided in Tables A-2 and A-5 of the appendix to this report.

\section{First Set of Comparisons: MAM AEO94 High World Oil Price Scenario vs. MAM Base Scenario}

Figures 10 through 12 illustrate the changes from the baseline in the relevant MAM output variables, related to the changes in world oil price. Figures 10 through 12 illustrate that changes in the output variables are consistent with the macroeconomic theories discussed earlier in this report. GDP rises less quickly than under the baseline scenario, as oil prices increase steadily above reference case values. In quantitative terms, WPI05 is increased by $4.5 \%$ in 2010 , and GDP is $0.41 \%$ lower than in the reference case. In all forecast years, changes in personal income track closely to changes in GDP as expected. 
Figure 10. MAM Base Compared to MAM AEO94 High World Oil Price

- Scenario

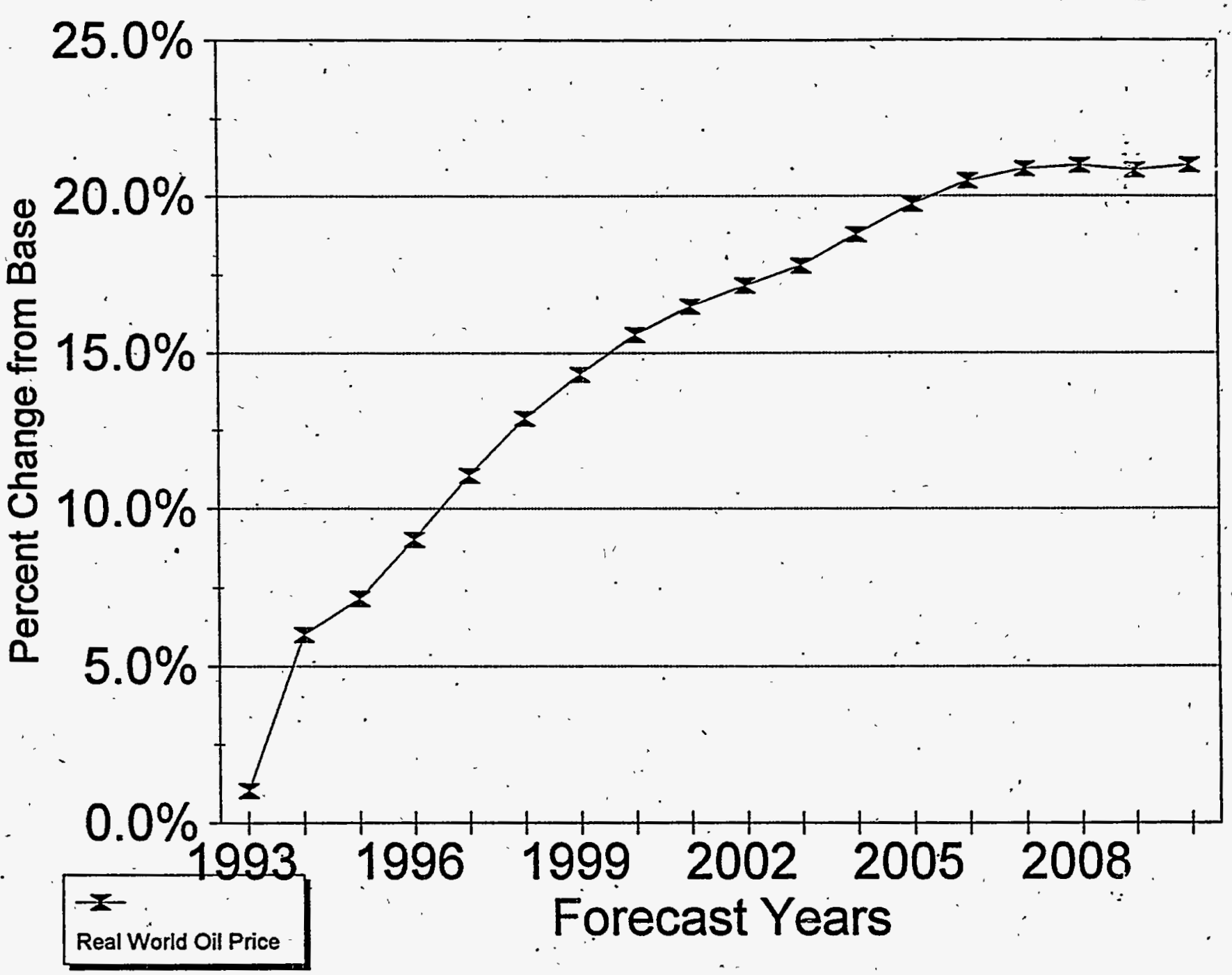


Figure 11. MAM Base Compared to MAM AEO94 High World Oil Price Scenario

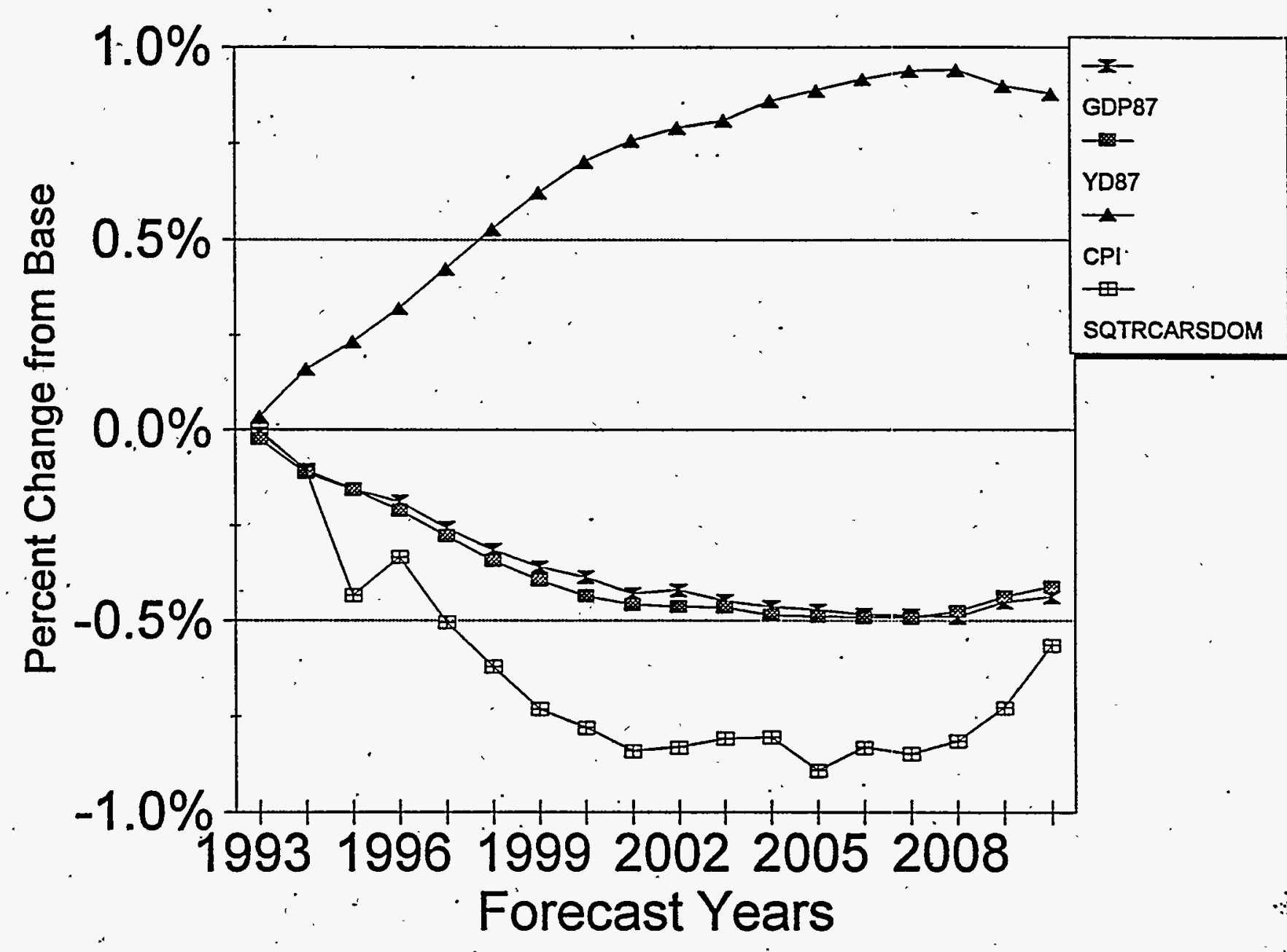


The changes in CPI, utility bond interest rate, and unemployment rate also correspond to the changes that are to be expected based on macroeconomic theory. As the reference case WPI05 increases.over the forecast, the CPI is slightly higher than the reference case CPI values. The utility bond interest rate rises over the period of 1993-1998 in both the baseline and the alternative scenarios, and falls slightly for most years beyond 1998 in the forecast. As is the case with the CPI, the utility bond rate is slightly higher under the high world oil price scenario, compared to the baseline values.

The unemployment rate is slightly higher under the high world oil price scenario, compared to the base case. This result is due to the upward pressure that is exerted on inflation rates within periods of high oil prices such as those sustained throughout this alternative case. 
Figure 12. MAM Base Compared to MAM AEO94 High World Oil Price Scenario

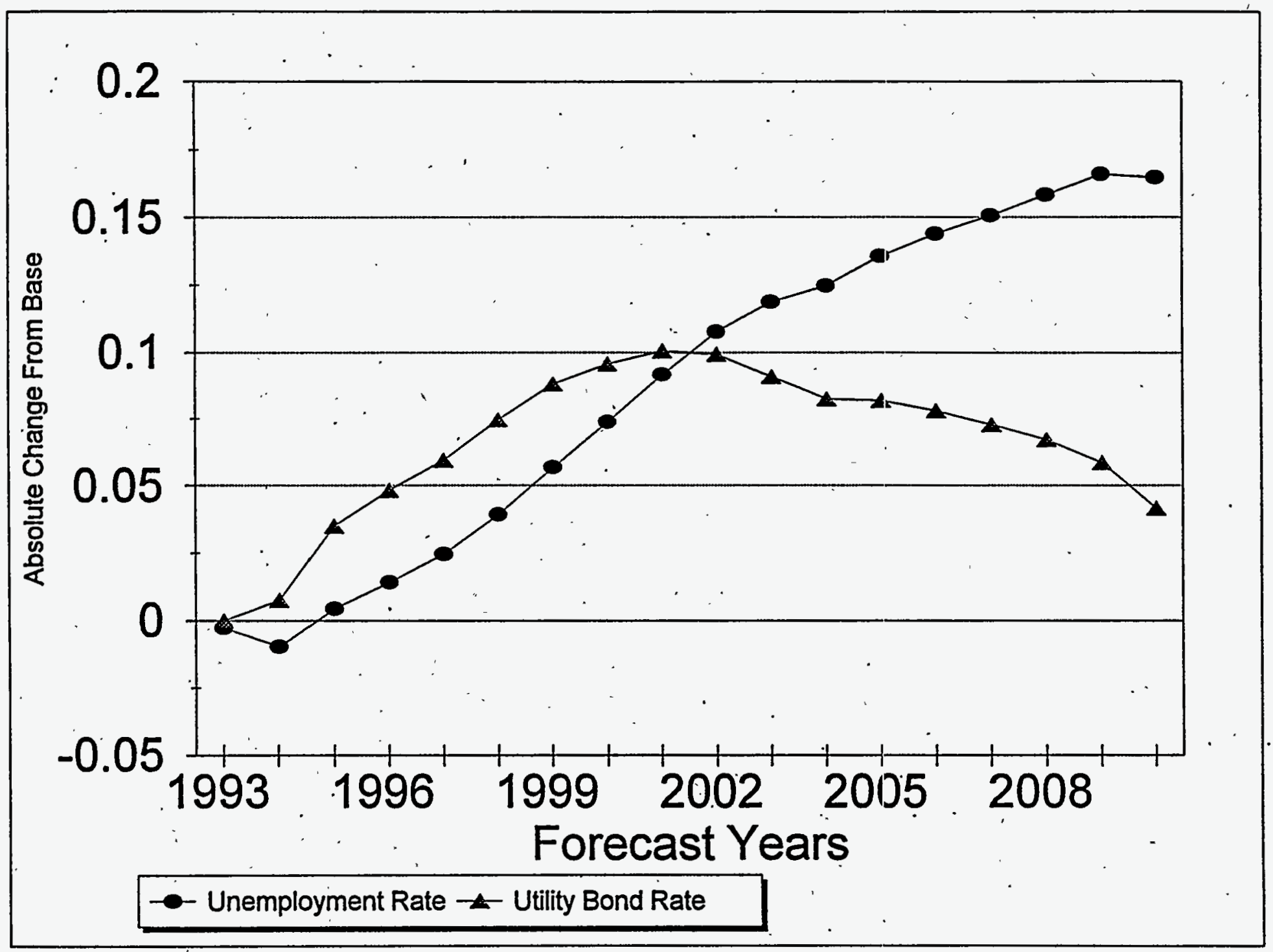


Second Set of Comparisons: MAM AEO94 High World Oil Price Scenario vs. DRI AEO94 High, World Oil Price Scenario

Under the high world oil price scenario, the key outputs of the NEMS MAM differ by $1.61 \%$ or less from the outputs of the full DRI model. This range is similar to the differences between MAM and DRI in the reference case. In summary, MAM produces results that closely mirror DRI full model results under the AEO94 High World Oil Price scenario. Figures 13 through 18 compare the MAM scenario results to the DRI scenario results for the key output variables listed in Table 2 of this report. 
Figure 13. AEO94 High World Oil Price Scenario: Percent Change in Constant \$1987 Gross Domestic Product

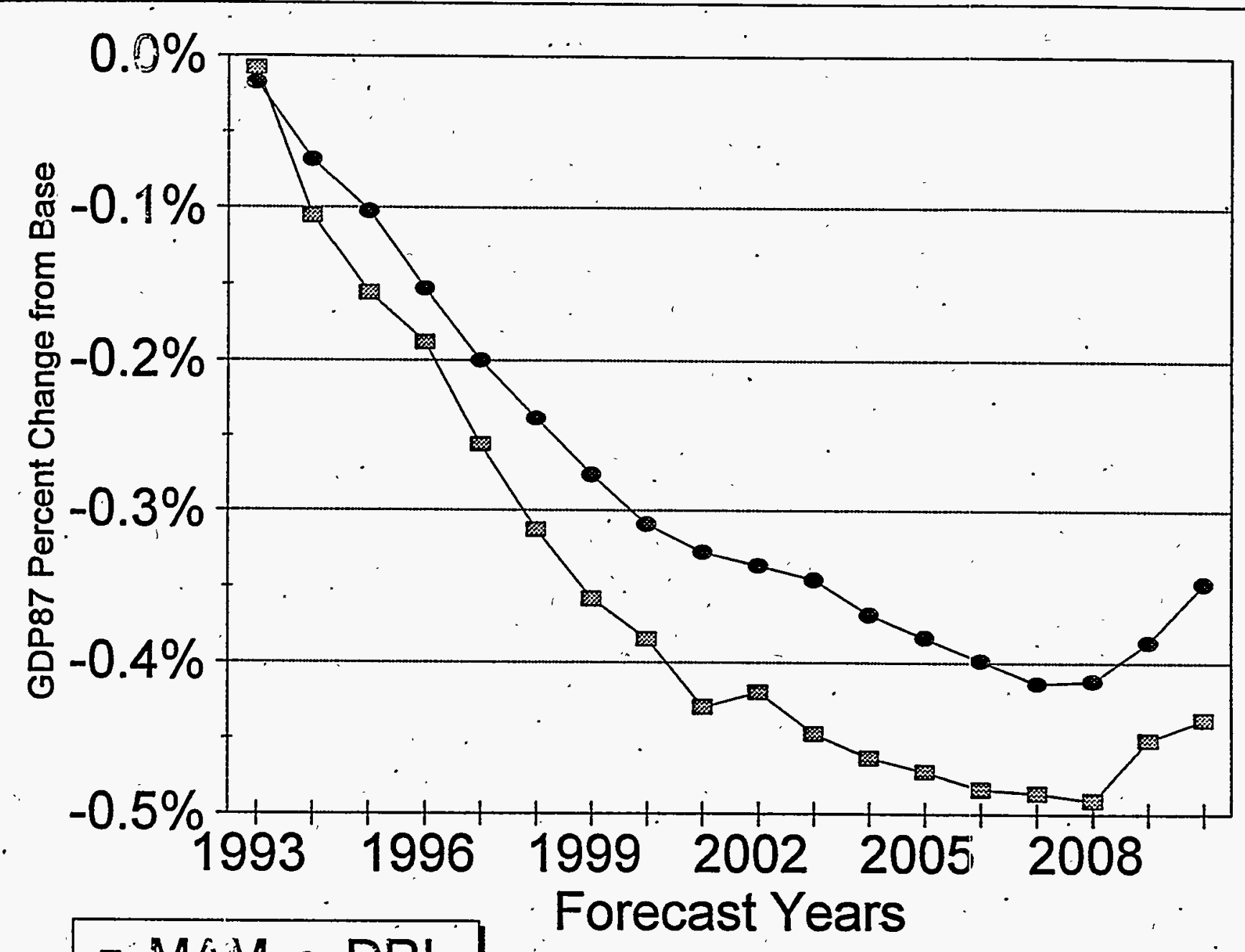

$-\mathrm{MAM} \rightarrow \mathrm{DRI}$ 
Figure 14. AEO94 High World Oil Price Scenario: Percent Change in Constant $\$ 1987$ Disposable Income

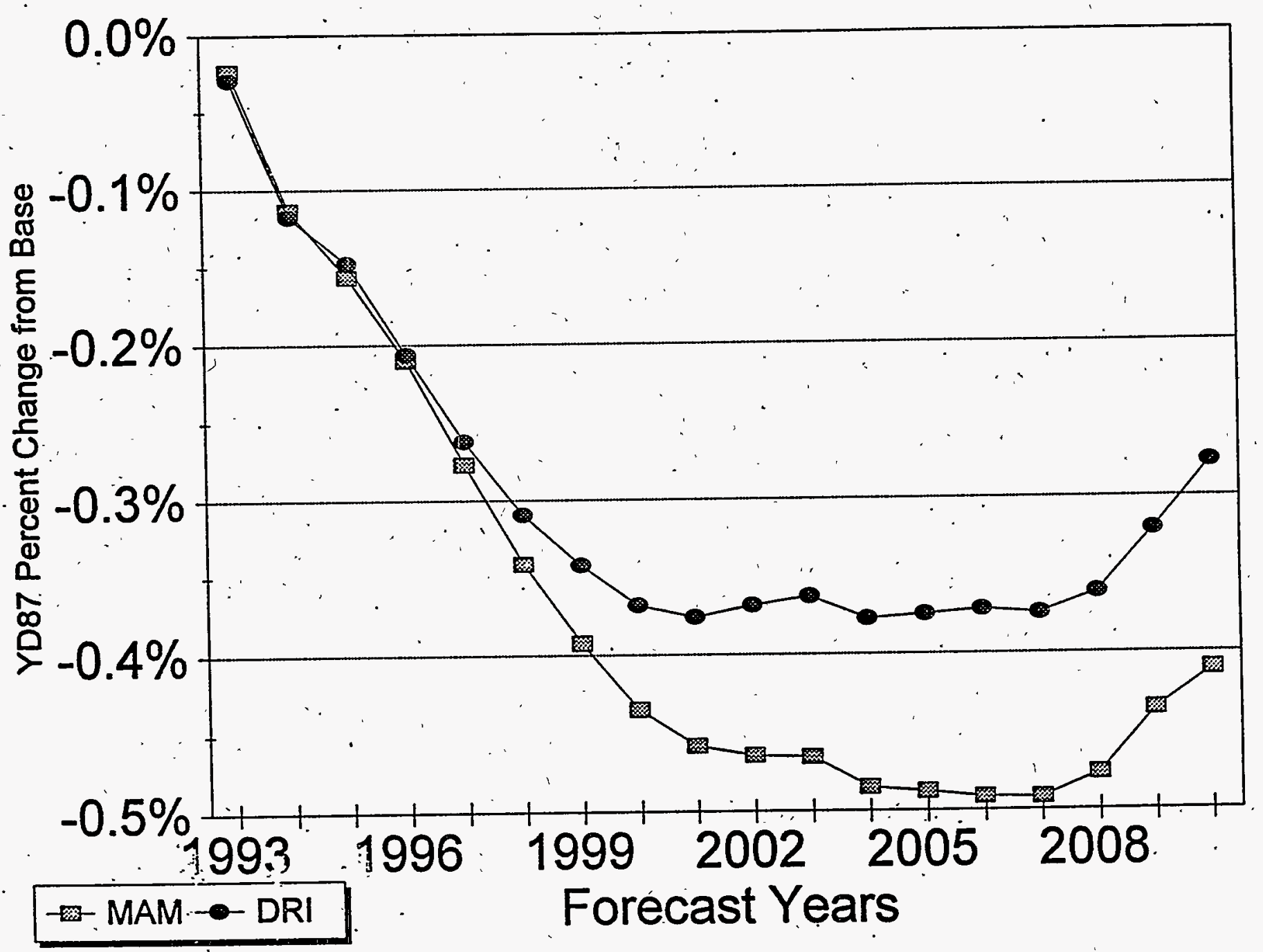


Figure 15. AEO94 High World Oil Price Scenario: Percent Change in Unit Sales of Domestic Automobiles

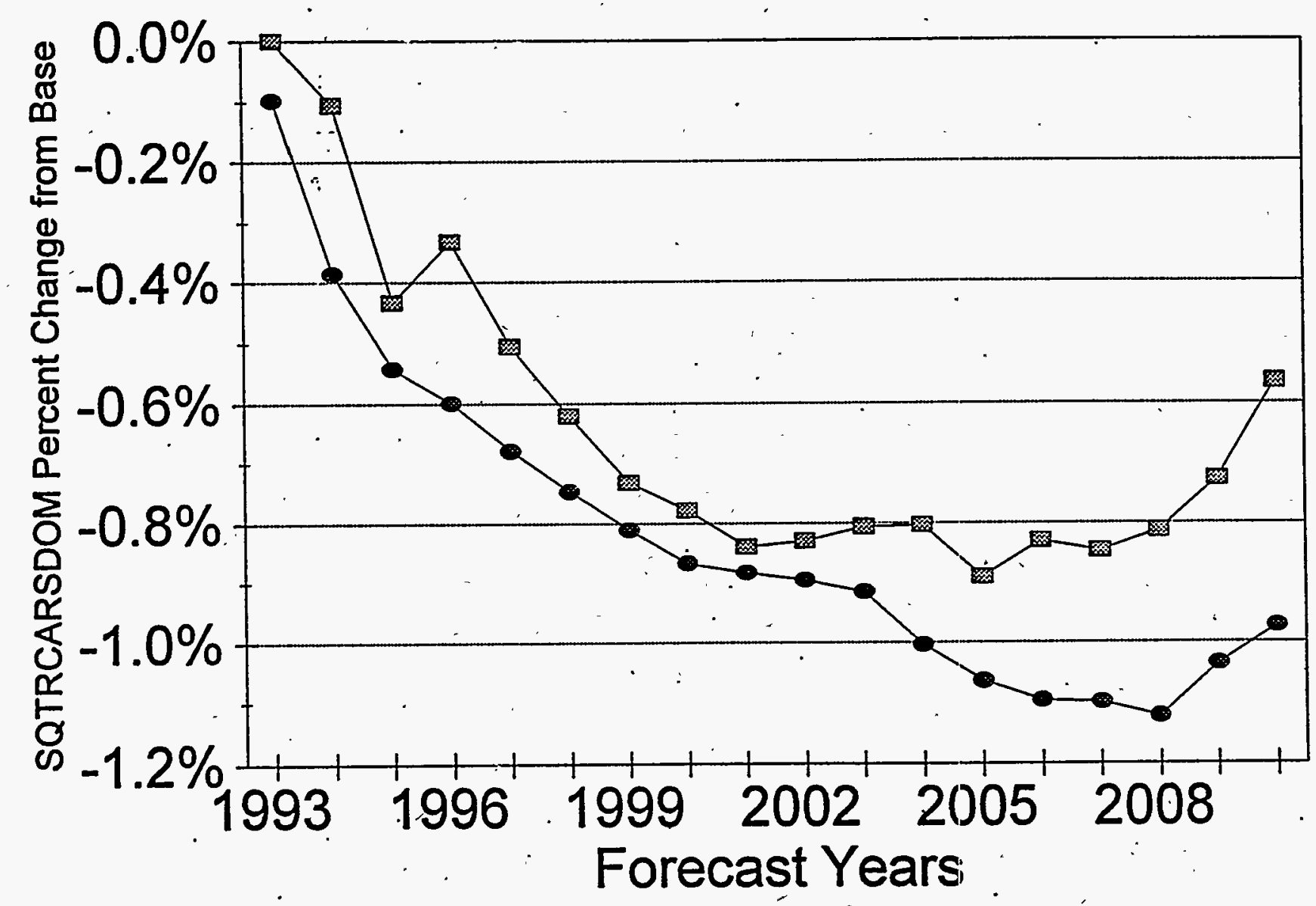

$-\mathrm{MAM} \rightarrow \mathrm{DRI}$ 
Figure 16. AEO94 High World Oil Price Scenario: Percent Change in Consumer Price Index

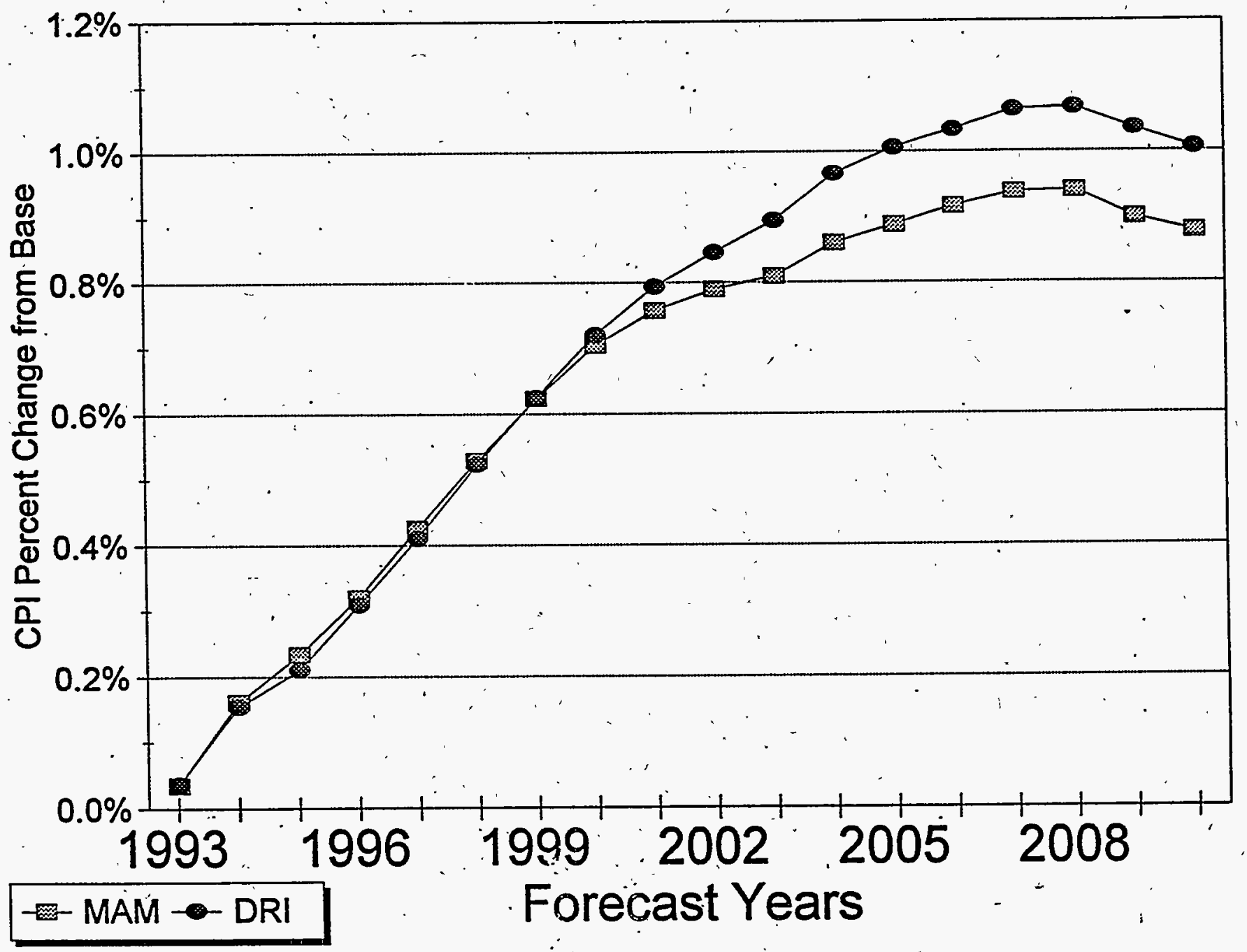


Figure 18. AEO94 High World Oil Price Ścenario: Absolute Change in Unemployment Rate

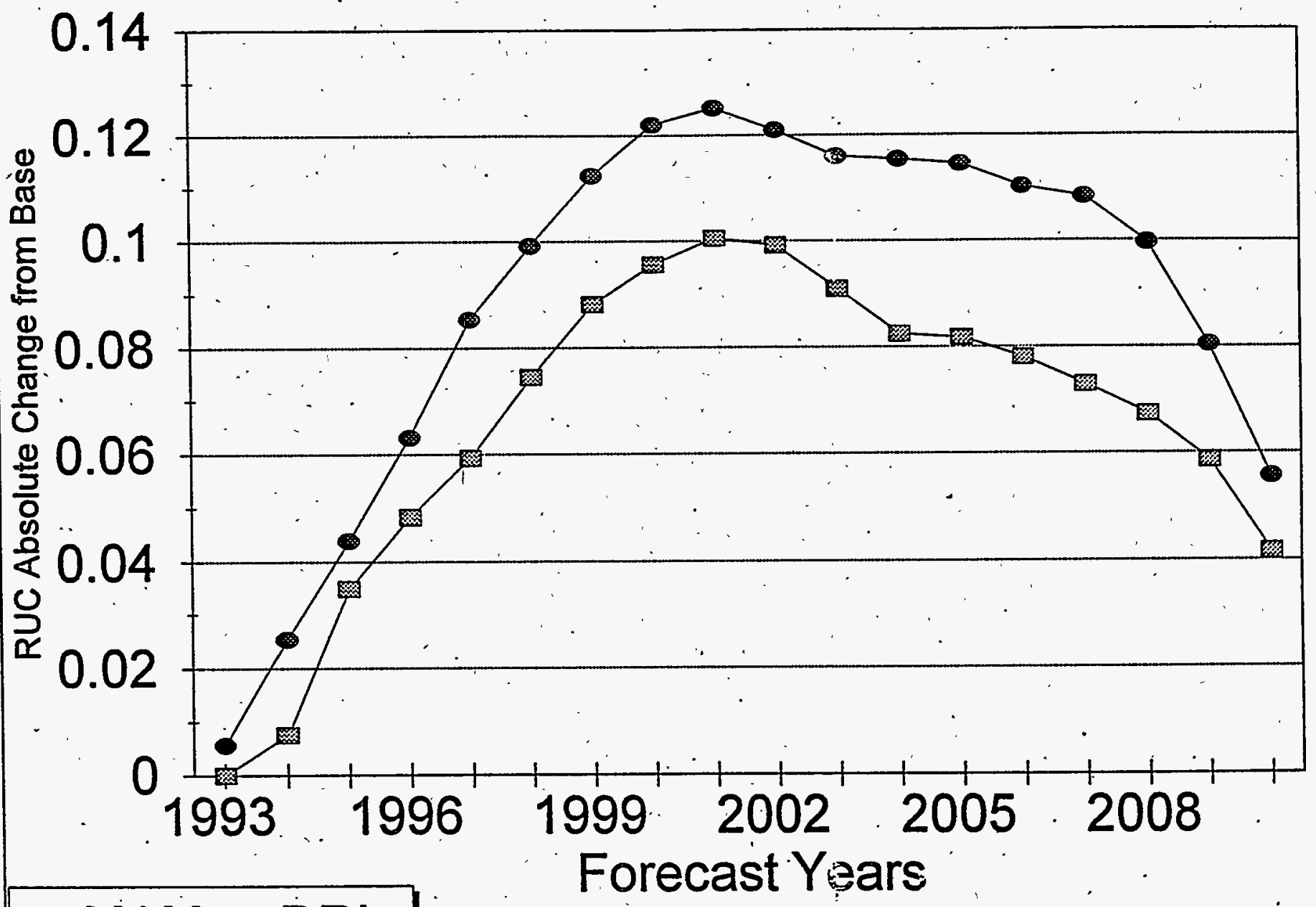

$-\mathrm{mAM}-\mathrm{D}-\mathrm{DRI}$ 


\subsection{AEO94 Low World Oil Price Scenario .}

As described in Table 1, the AEO94 Low World Oil Price scenario is driven by world oil prices that are below the baseline forecast case. Forecasted world oil prices fluctuate nonmonotonically in this scenario, ranging from $\$ 12.22$ per barrel to $\$ 16.68$ per barrel. As stated previously, the baseline real world oil price varies from a low of $\$ 14.61$ per barrel to a high of $\$ 23.42$ per barrel, rising steadily throughout the forecast period. The time series of forecasted world oil prices for both the baseline and the alternate case are provided in Tables A-2 and A-7 . of the appendix to this report.

\section{First Set of Comparisons: MAM AEO94 Low World Oil Price Scenario vs. MAM Base Scenario}

Figures 19 through 21 illustrate the changes from the baseline in the relevant MAM output variables, related to the changes in world oil price. Figures 19 through 21. illustrate that changes in the output variables are consistent with the macroeconomic theories discussed earlier in this report. GDP rises more quickly than under the baseline scenario, under sustained periods of oil prices lower than the reference case values. In quantitative terms, WPI05 under the AEO94 Low World Oil Price scenario is $22.7 \%$ lower than the reference forecast in 2010 , and GDP is $0.47 \%$ higher than in the reference case. In all forecast years, changes in personal income track closely to changes in GDP as expected. 
Figure 19. MAM Base Compared to MAM AEO94 Low World Oil Price Scenario

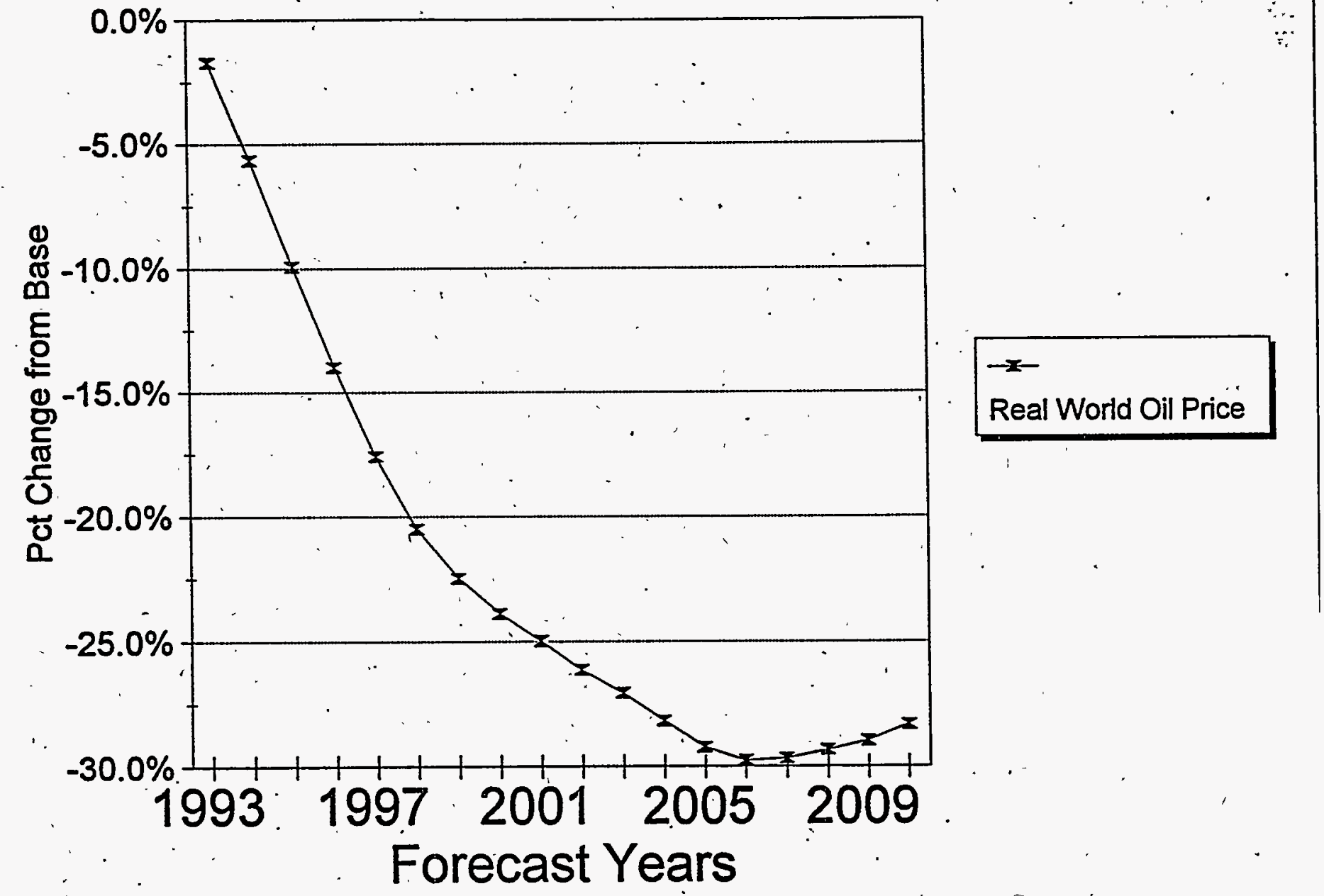


Figure 20. MAM Base Compared to MAM AEO94 Low World Oil Price Scenario

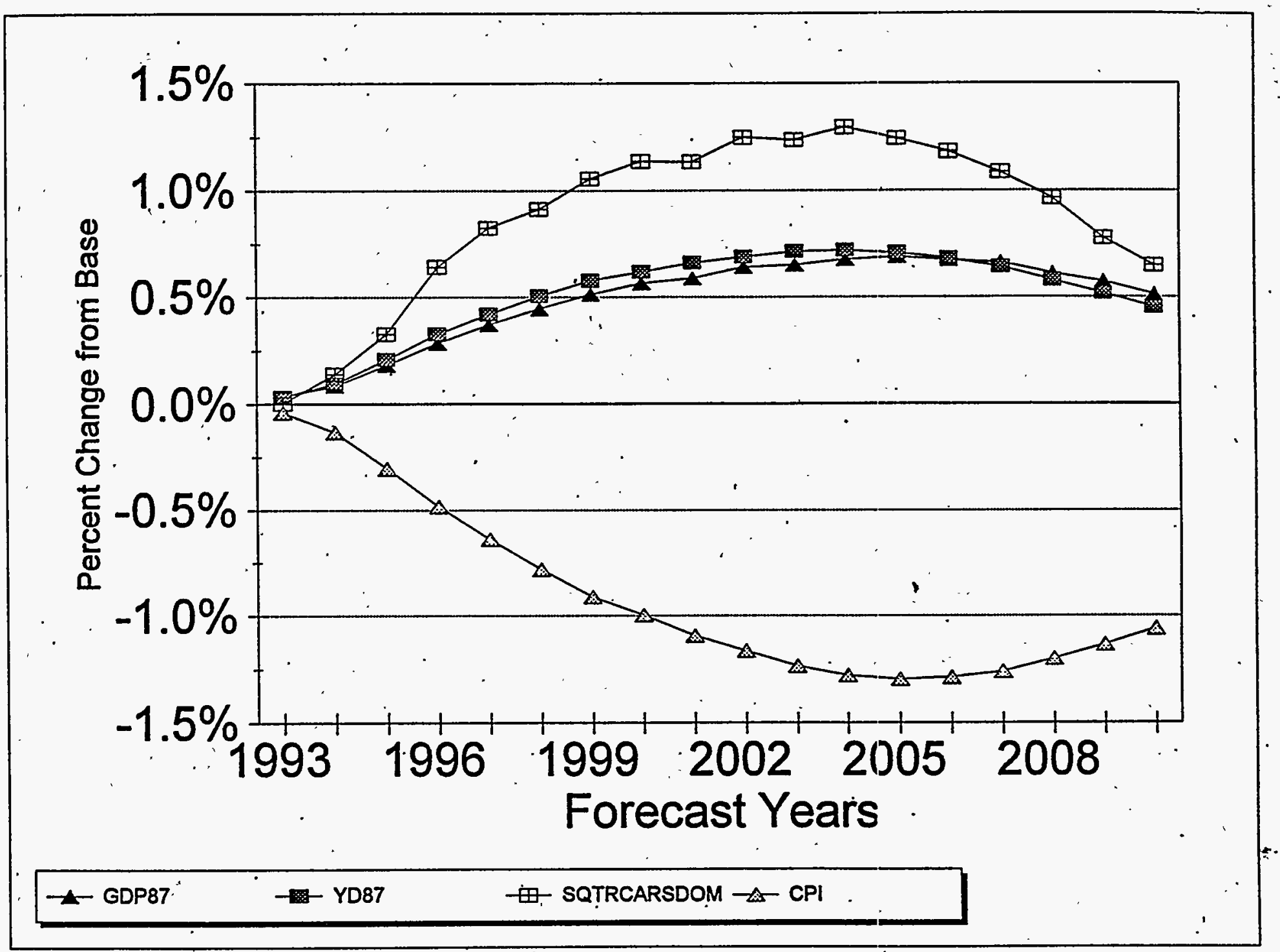


As WPI05 increases more slowly under the Low World Oil Price scenario compared to the baseline, the CPI is consistently lower than the reference case CPI values. The utility bond interest rate rises over the period of 1993-1998 in both the baseline and the alternative scenarios, and falls slightly for most years beyond 1998 in the forecast. As is the case with the CPI, the utility bond rate is notably lower under the low oil price scenario compared to the baseline values.

The unemployment rate is lower under the low world oil price scenario, compared to the base case. This result is due to the lack of pressure on inflation rates within periods of low oil prices such as those sustained throughout this alternative case. 
Figure 21. MAM Base Compared to MAM AEO94 Low World Oil Price Scenario

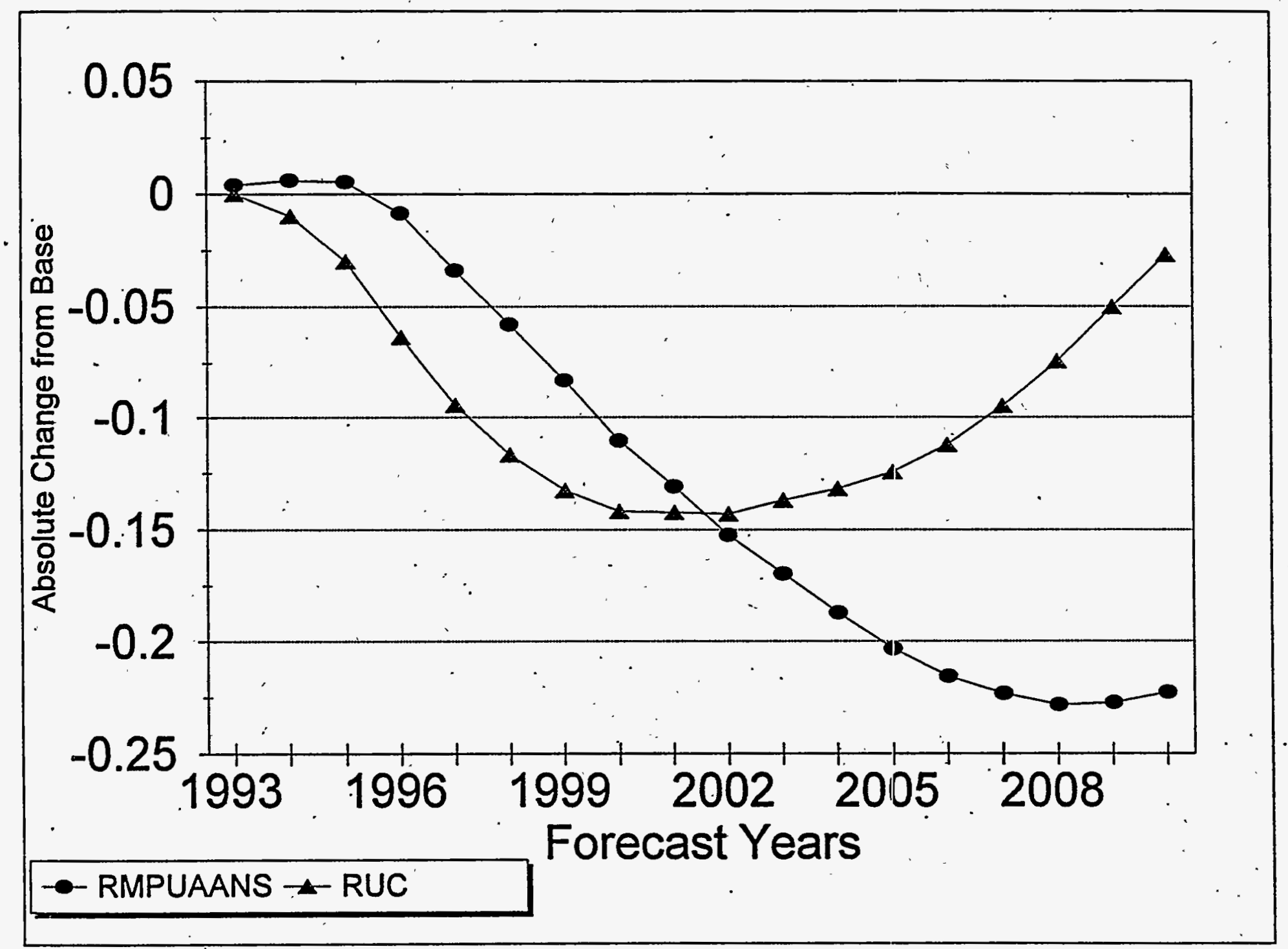


Second Set of Comparisons: MAM AEO94 Low World Oil Price Scenario vs. DRI AEO94 Low World Oil Price Scenario

Under the-low world oil price scenario, the key outputs of the NEMS MAM differ by $2.15 \%$ or less from the outputs of the full DRI model. This range is similar to the differences between MAM and DRI in the reference case and the alternative cases presented to this point. In summary, MAM produces results that closely mirror DRI full model results under the AEO94 Low World Oil Price scenário. Figures 22 through 27 compare the MAM scenario results to the DRI scenario results for the key output variables listed in Table 2 of this report. 


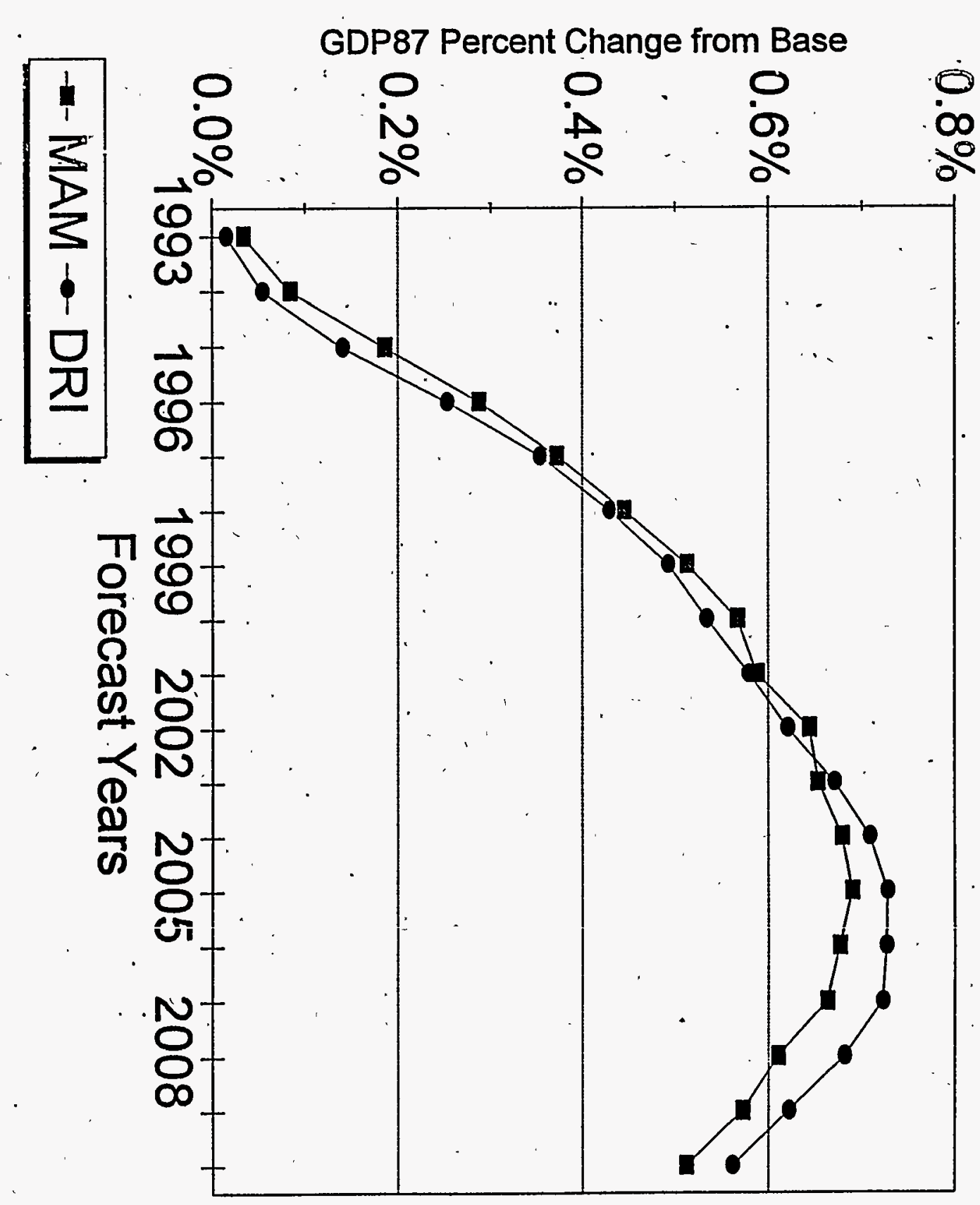

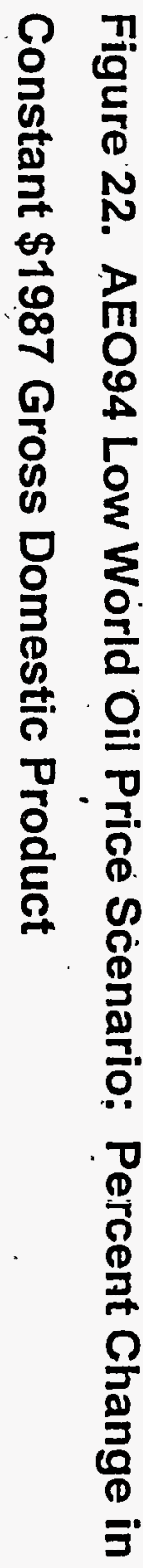




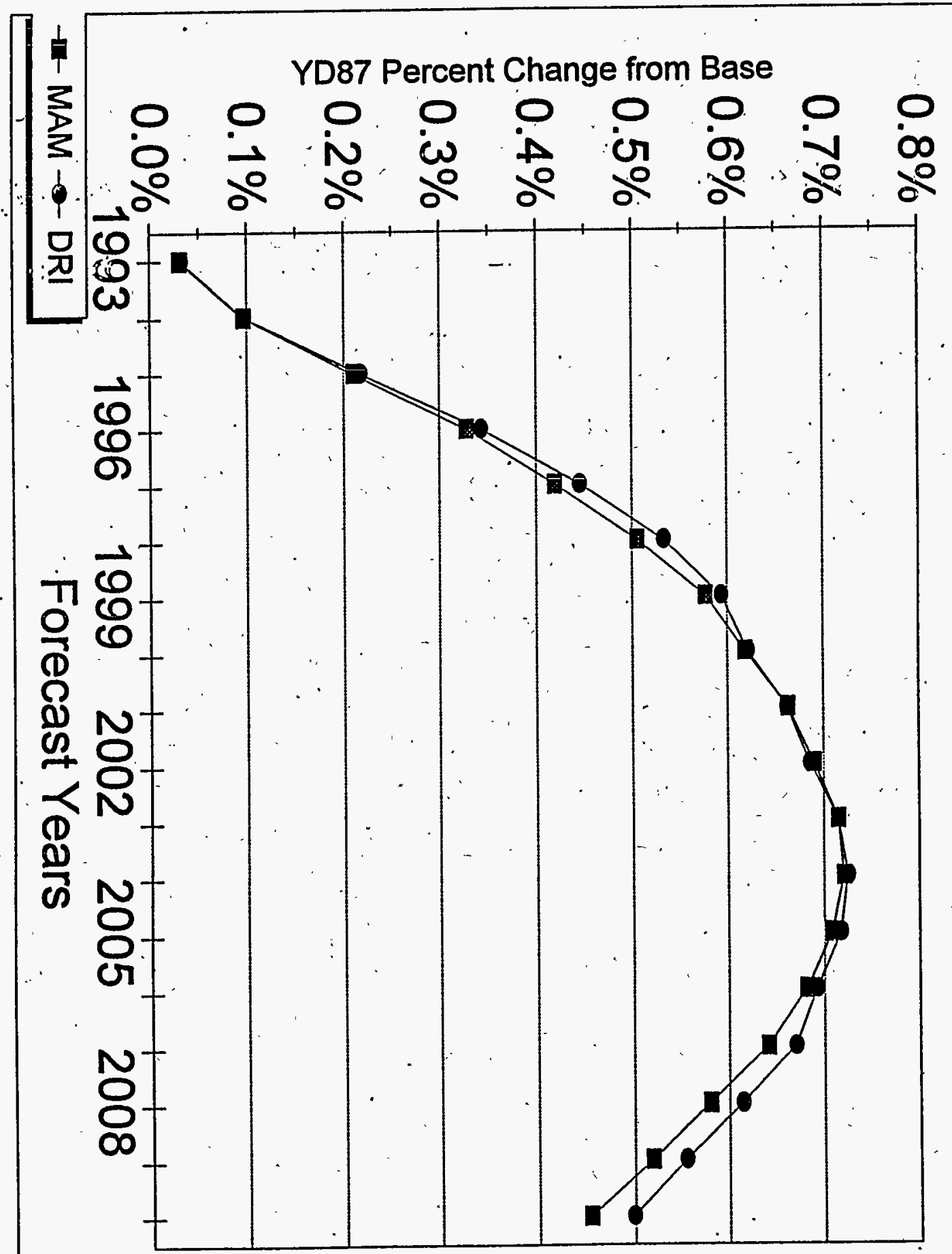

尺

స

\&

임

잉

뭉

ㅇํㅇ

崩

응

ล

응

C 
Figure 24. AEO94 Low World Oil Price Scenario: Percent Change in Unit Sales of Domestic Automobiles.

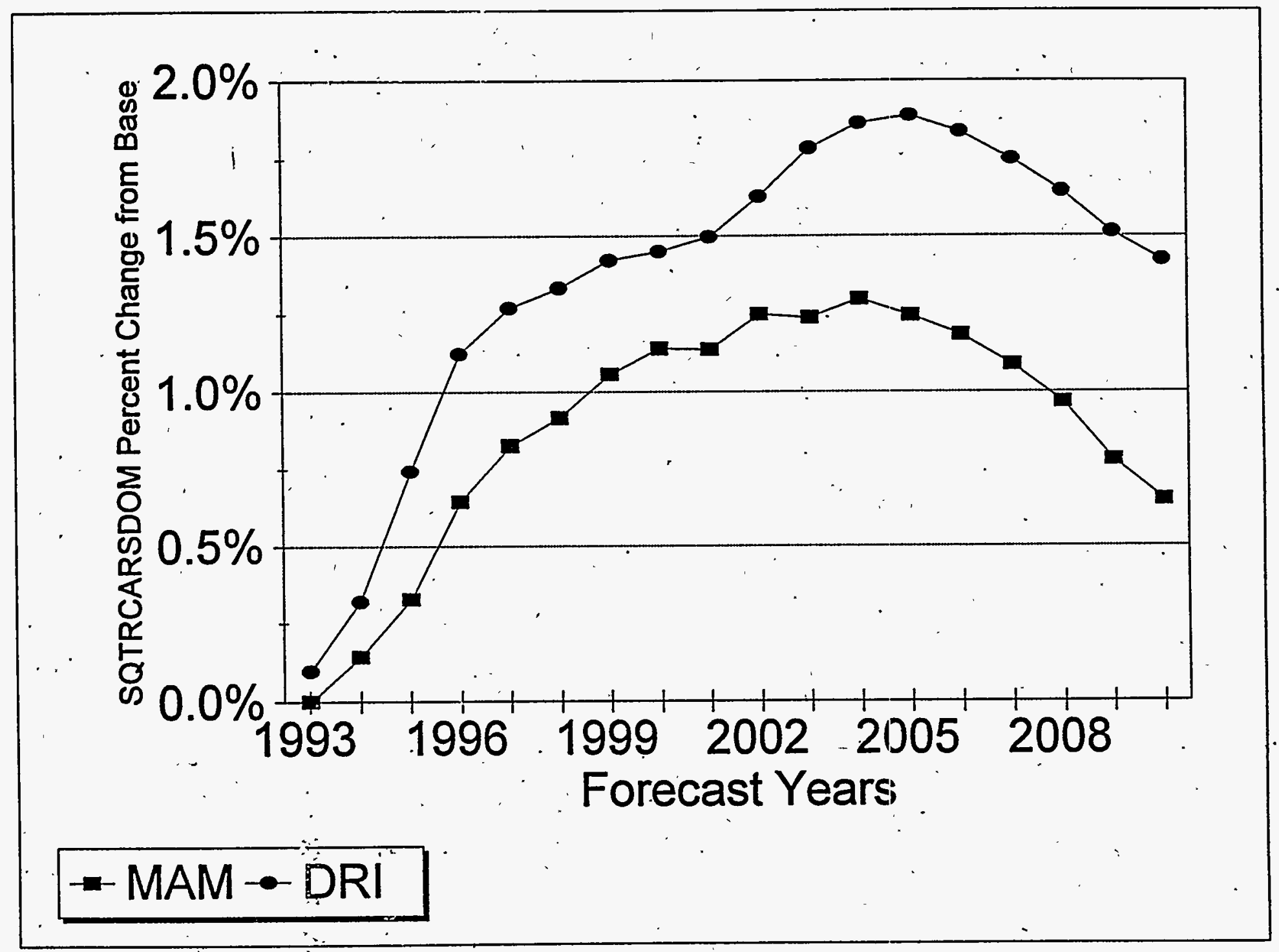


Figure 25. AEO94 Low World Oil Price Scenario: Percent Change in . Consumer Price Index

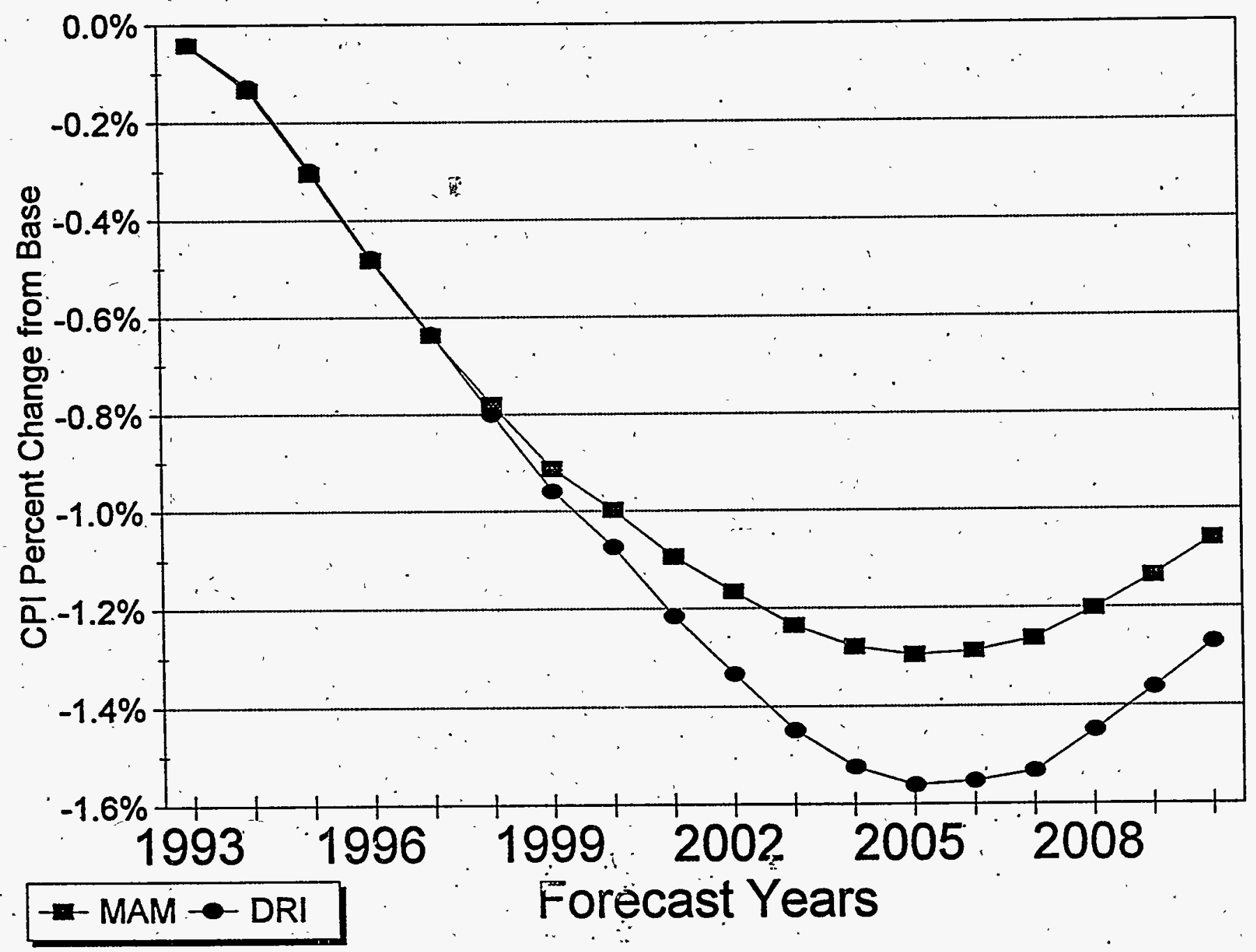


Figure 26. AEO94 Low World Oil Price Scenario: Absolute Change in Utility Bond Rate

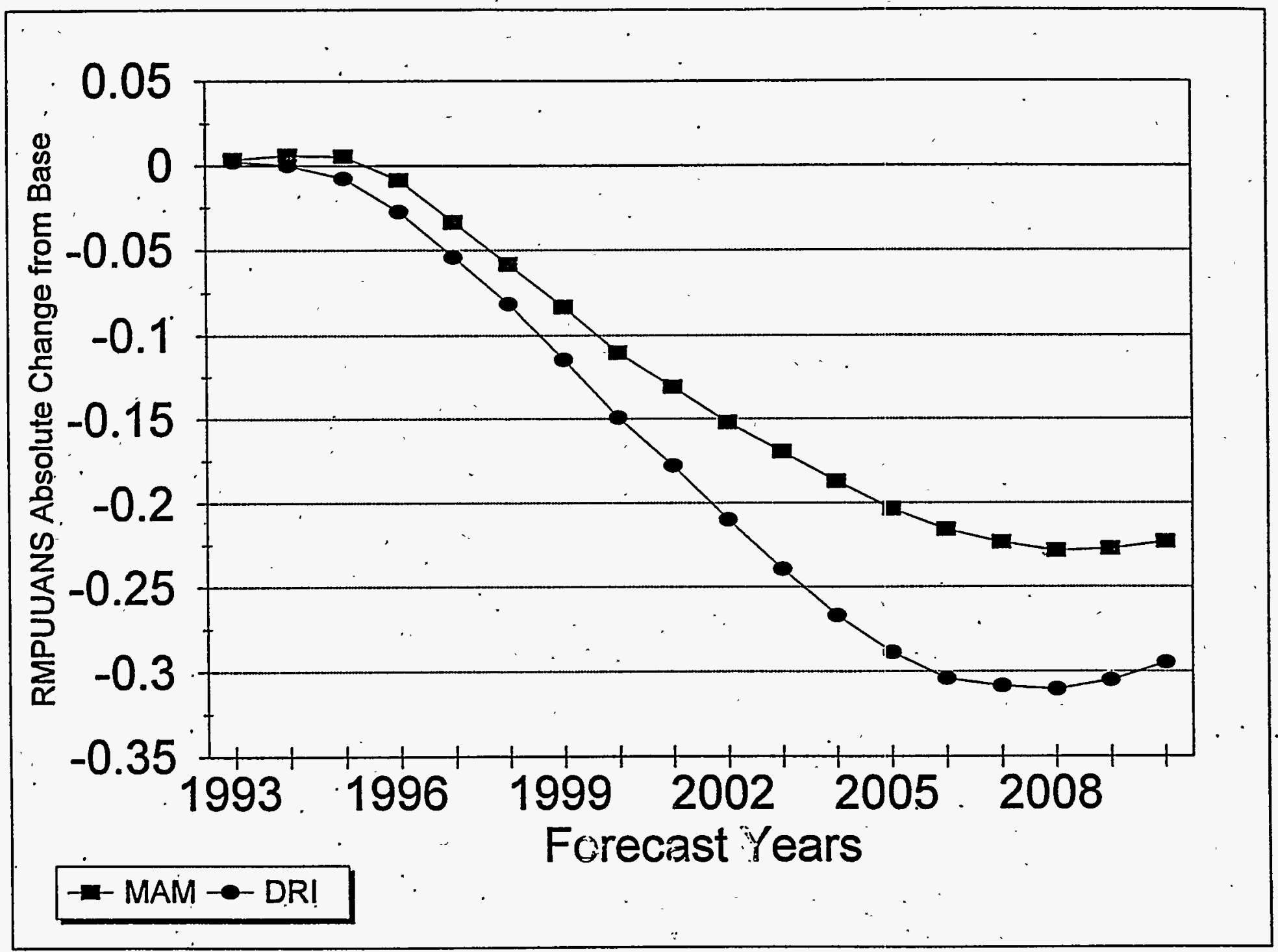


Figure 27. AEO94 Low World Oil Price Scenario: Absolute Change in Unemployment Rate

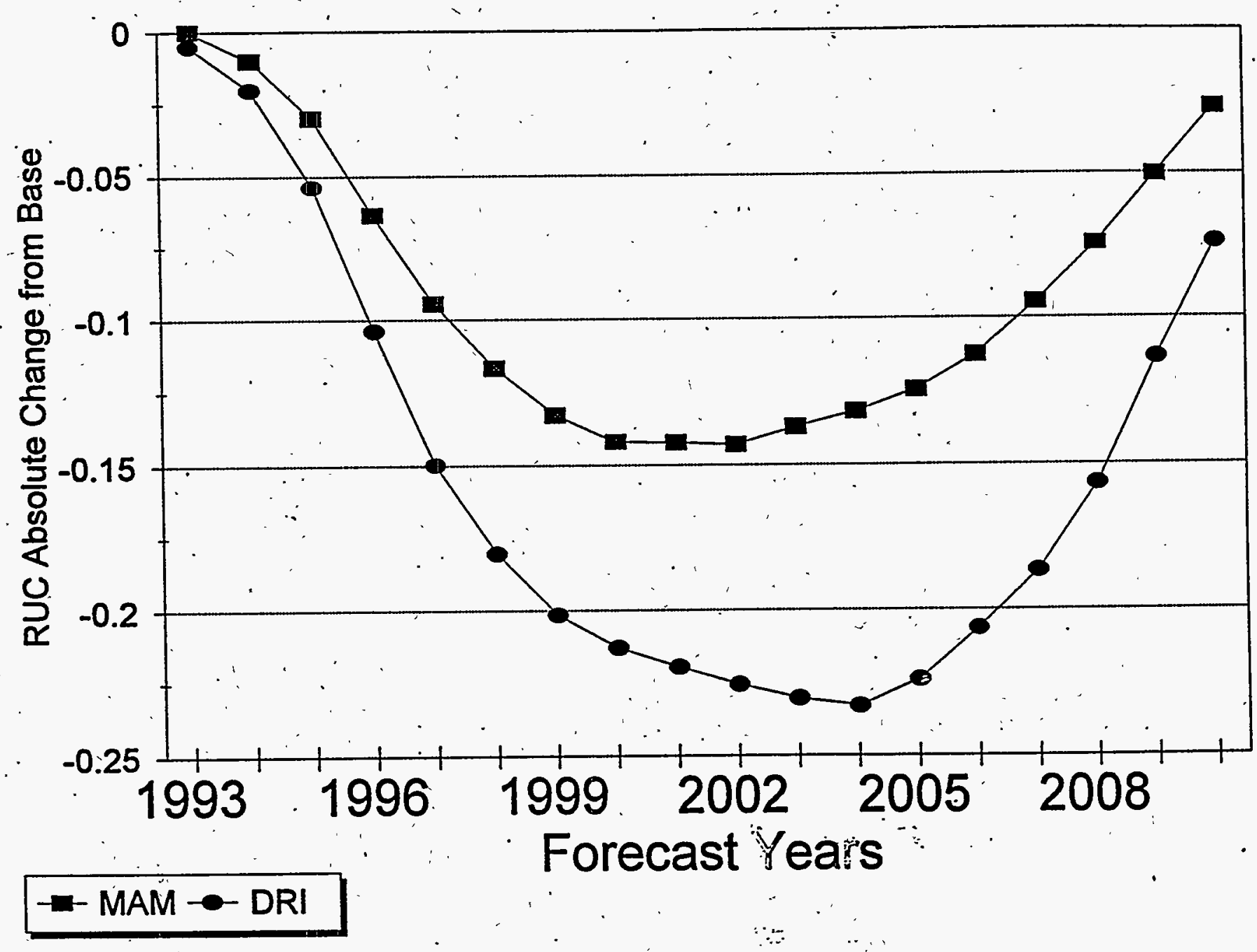




\subsection{Immediate Increase World Oil Price Scenario}

As described in Table 1, the Immediate Increase World Oil Price scenario utilizes a world oil price series that is adjusted upwards by $20 \%$ over the baseline value for all forecast years. This scenario measures the performance of MAM within a specified bound of price variability compared to the base case. Real world oil prices in this scenario range from a low of $\$ 17.54$ per barrel to a high of $\$ 28.11$ per barrel, and rise steadily within these bounds throughout the forecast. As stated previously, the baseline world oil price varies from a low of $\$ 14.61$ per barrel to a high of $\$ 23.42$ per barrel, also rising steadily throughout the forecast period. The time series of forecasted world oil prices for both the baseline and the alternate case are provided in Tables A-2 and A-9 of the appendix to this report.

\section{First Set of Comparisons: MAM Immediate Increase World Oil Price Scenario vs.} MAM Base Scenario

Figures 28 through 30 illustrate the changes from the baseline in the relevant MAM output variables; related to the changes in world oil price. Figures 28 through 30 illustrate that changes in the output variables are consistent with the macroeconomic theories discussed earlier in this report. As in the AEO94 High World Oil Price scenario, GDP rises more slowly under the higher world oil prices than under the baseline scenario. In quantitative terms, the $20 \%$ difference between the alternative and base case world oil prices under this scenario results in a 2010 value for GDP that is $0.28 \%$ lower than the reference case value. In all forecast years, changes in personal income track closely to changes in GDP as expected. Figures A-1 and A-2 in the Appendix to this report illustrates the annual estimates of elasticity with respest to real world oil price for the GDP and personal income variables under this scenario. 
Figure 28. MAM Base Compared to MAM Immediate Increase World Oil Price Scenario

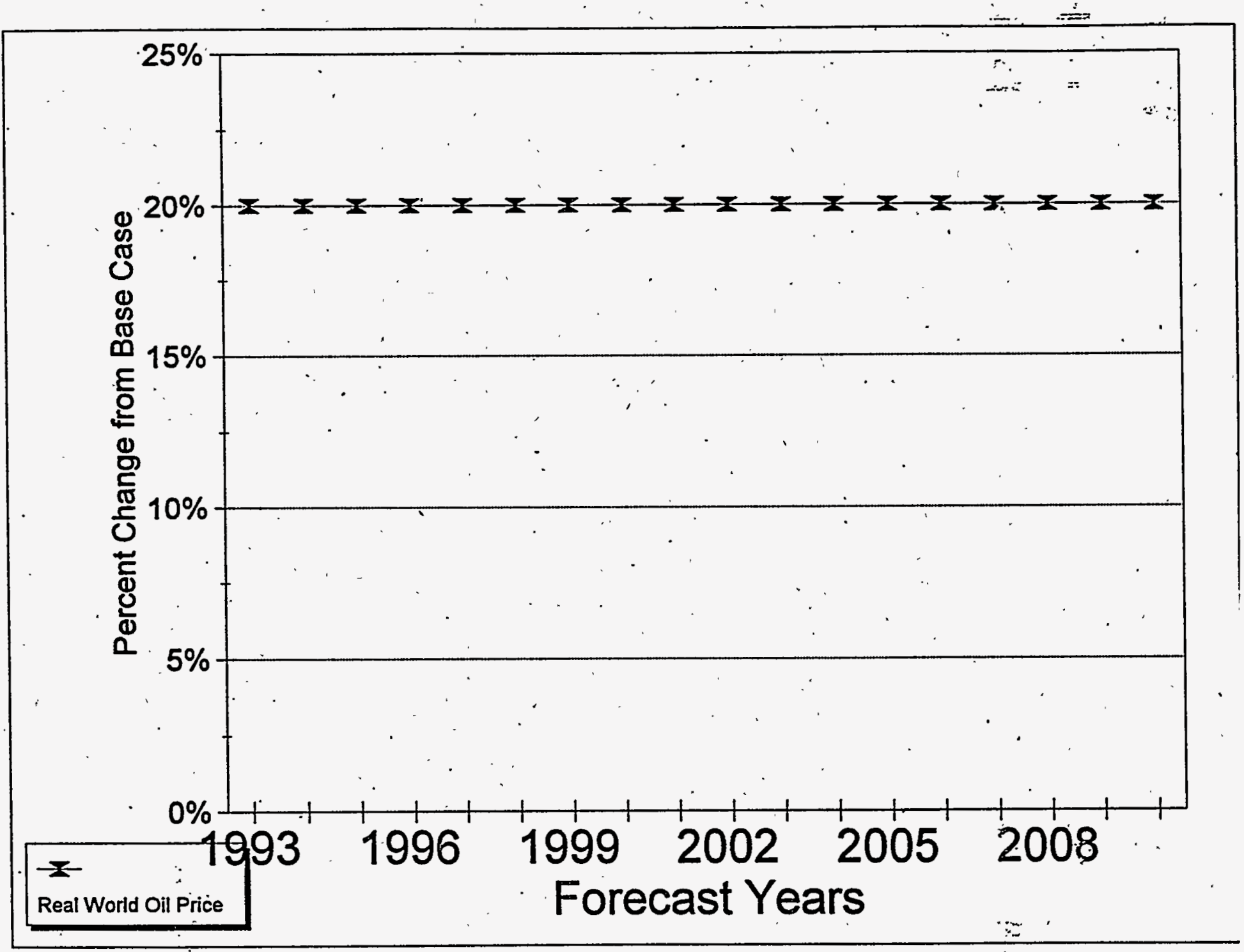


Figure 29. MAM Base Compared to MAM Immediate Increase World Oil Price Scenario

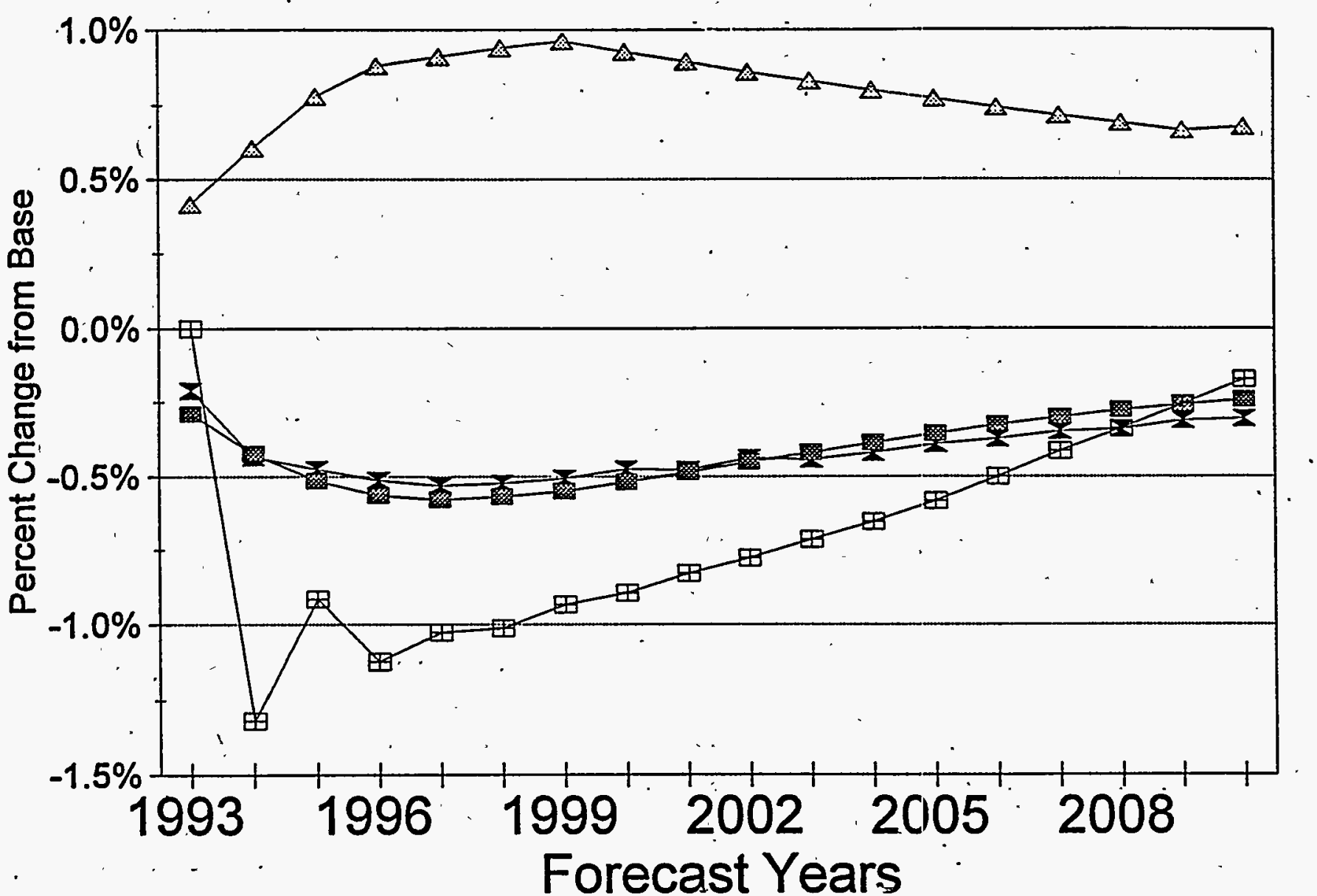


As the real world oil price increases more quickly under the Immediate Increase World Oil Price scenario compared to the baseline, the CPI is consistently above the reference case CPI values. The utility bond interest rate rises over the period of 1993-1998 in both the baseline and the alternative scenarios, and falls slightly for most years beyond 1998 in the forecast. As is the case with the CPI, the utility bond rate is higher under the immediate increase scenario compared to the baseline values.

As is the case with the AEO94 High World Oil Price scenario, unemployment rates are . consistently higher under the Immediate Increase World Oil Price scenario, compared to the base case. This result is again partly explained by the upward pressure exerted upon inflation rates within periods of high oil prices such as those sustained throughout this alternative case. 
Figure 30. MAM Base Compared to MAM Immediate Increase World Oil Price Scenario

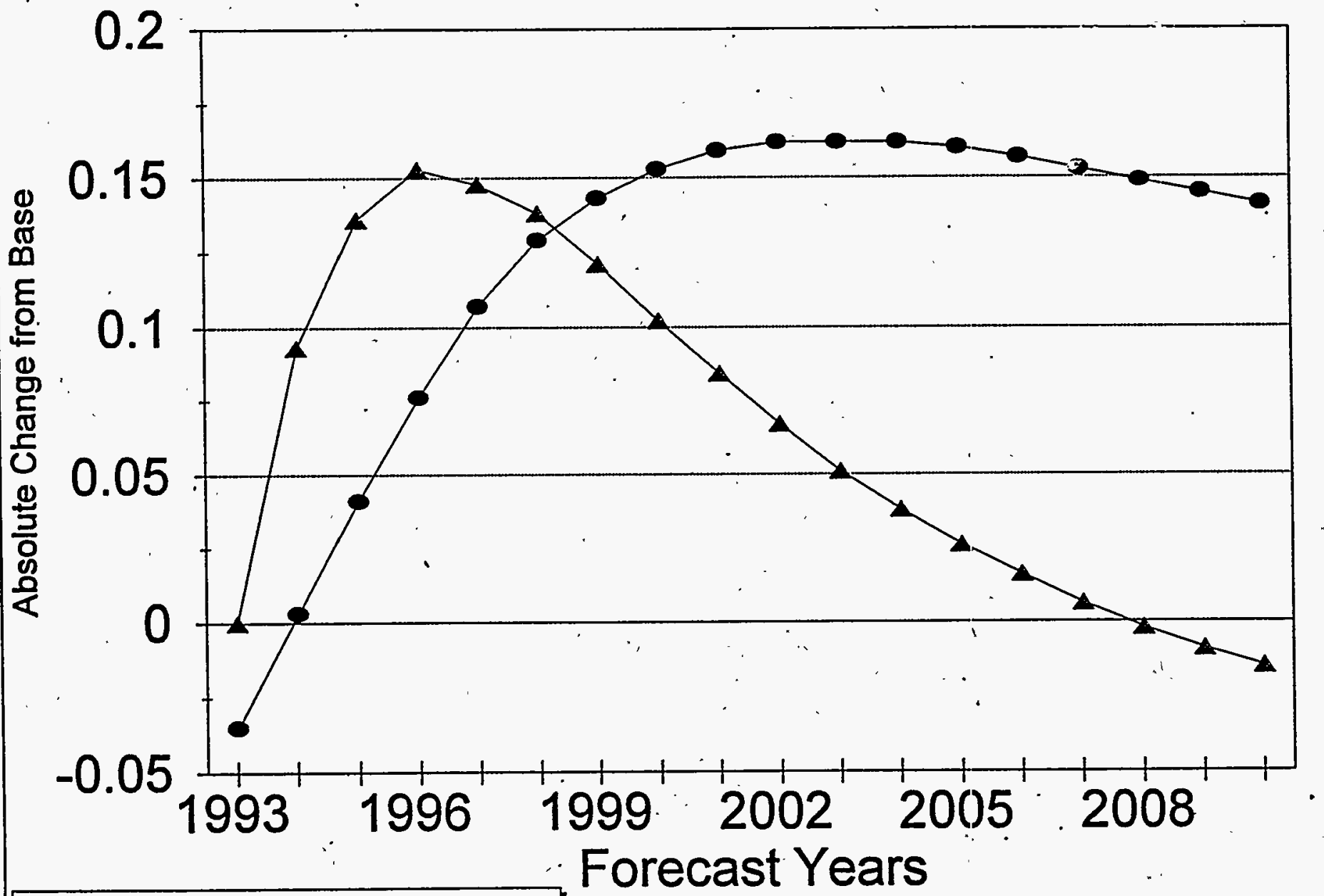

$\rightarrow$ RMPUAANS $\rightarrow$ RUC 
Second Set of Comparisons: MAM Immediate Increase World Oil Price Scenario vs. DRI Immediate Increase World OiI Price Scenario

Under the increased oil price scenario, the key outputs of the NEMS MAM differ by $0.83 \%$ or less from the outputs of the full DRI model. This range is well within the maximum percent differences between MAM and DRI in all cases presented to this point. In summary, MAM produces results that closely mirror DRI full model results under the Immediate Increase World Oil Price scenario. Figures 31 through 36 compare the MAM scenario results to the DRI scenario results for the key output variables listed in Table 2 of this report. 
Figure 31. Immediate Increase World Oil Price Scenario: Percent Change in Constant $\$ 1987$ Gross Domestic Product

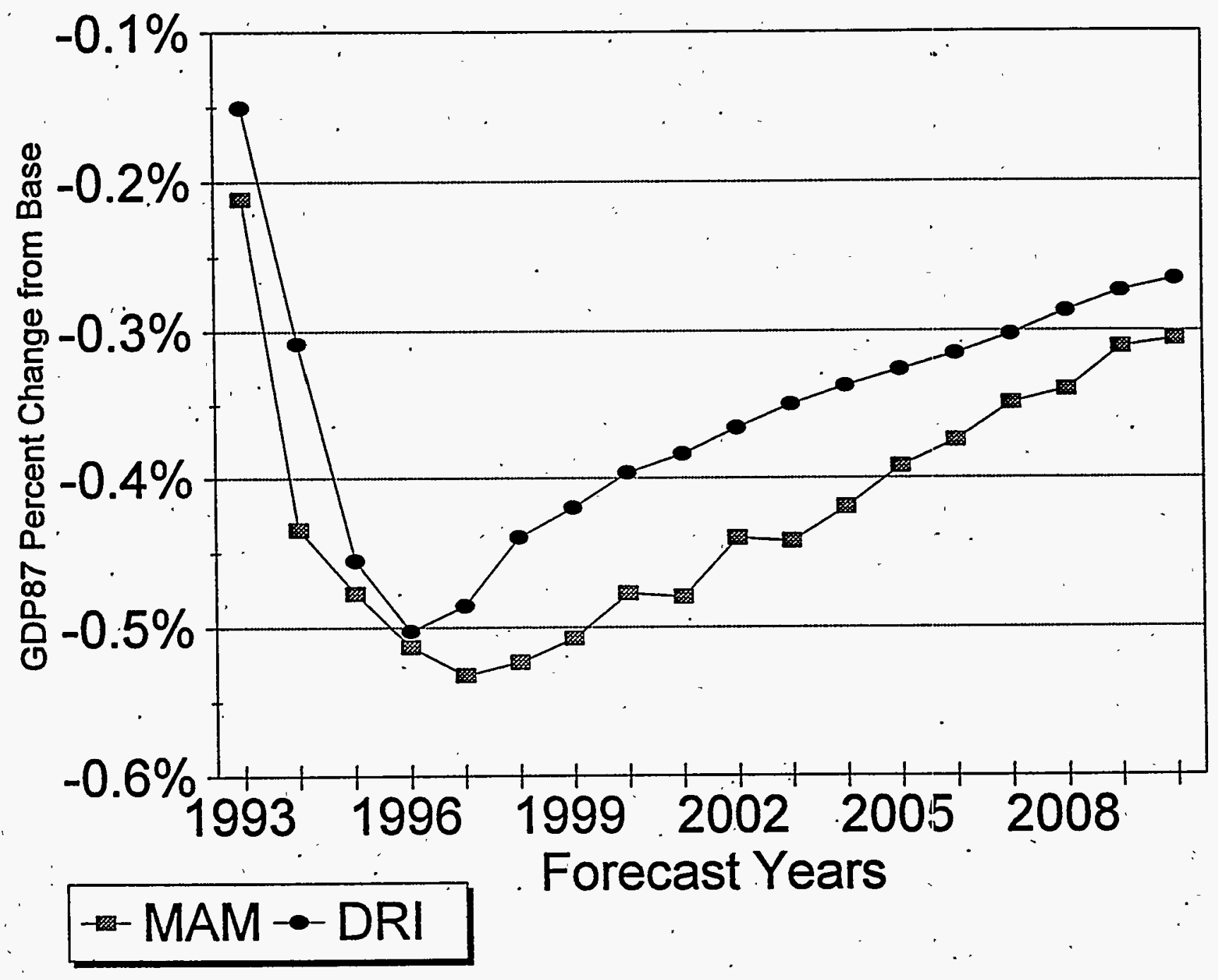


Figure 32. Immediate Increase World Oil.Price Scenario: Percent Change in Constant \$1987 Disposable Income

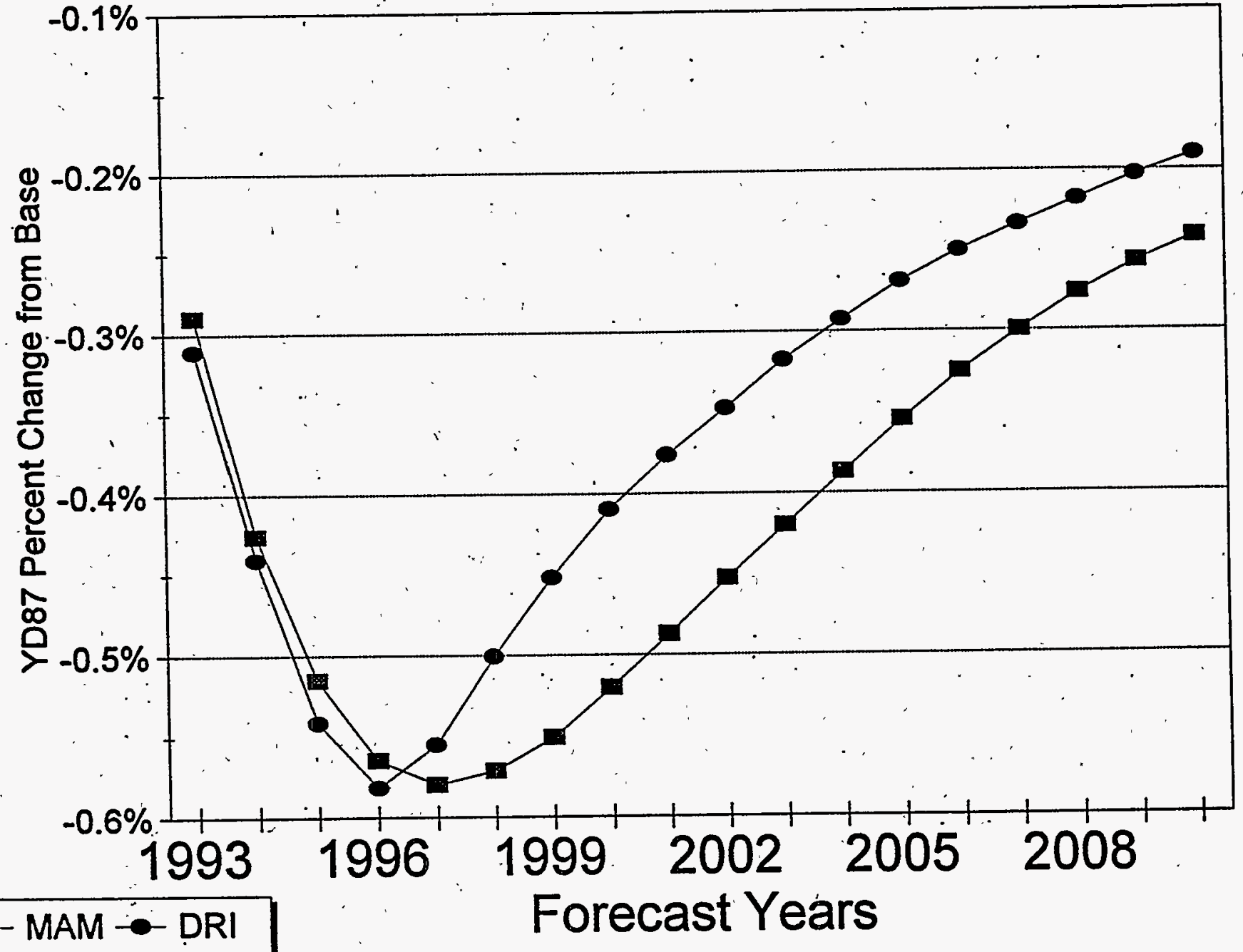


Figure 33. Immediate Increase World Oil Price Scenario: Percent $\therefore$ Change in Unit Sales of Domestic Automobiles

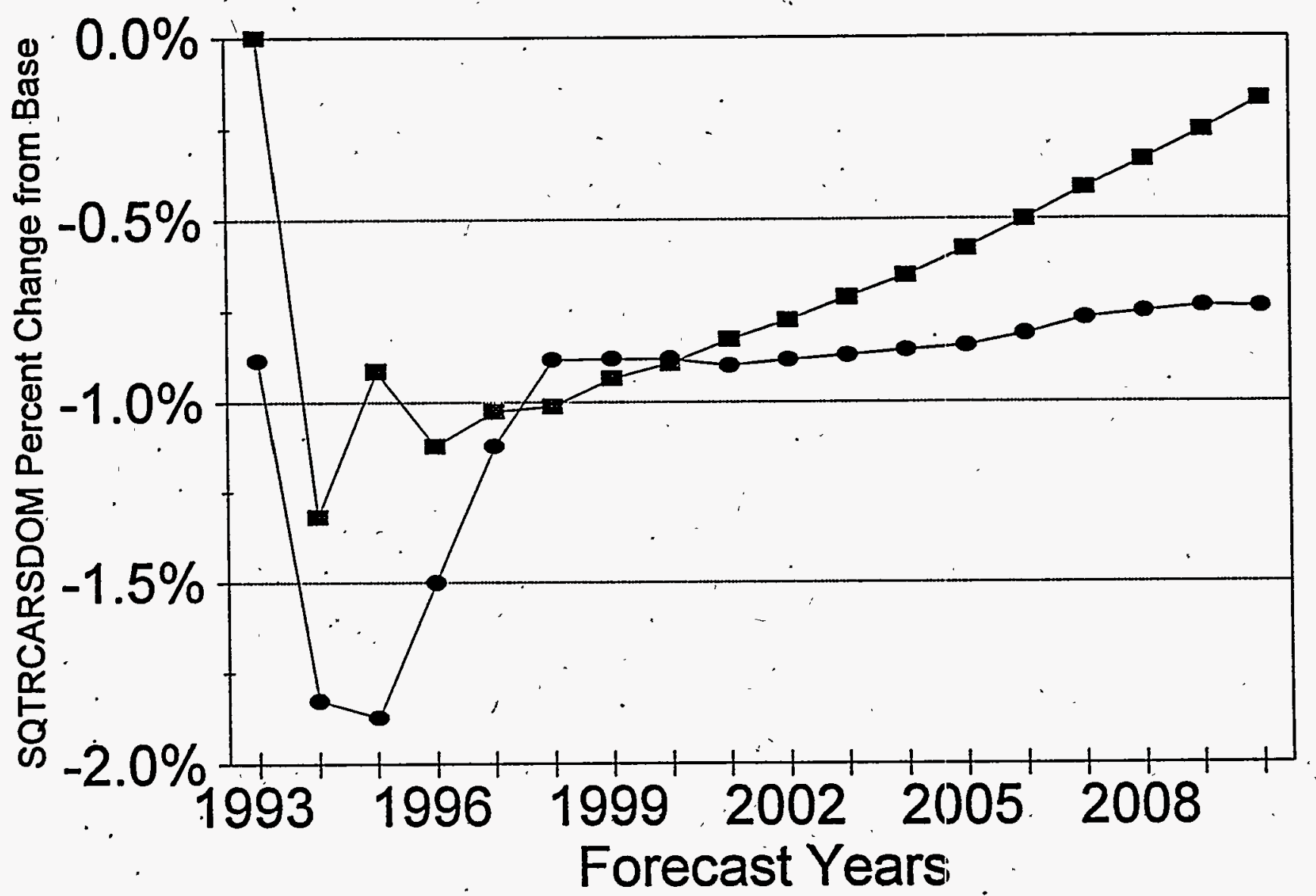


Figure 34. Immediate Increase World Oil Price Scenario: Percent . Change in Consumer Price Index

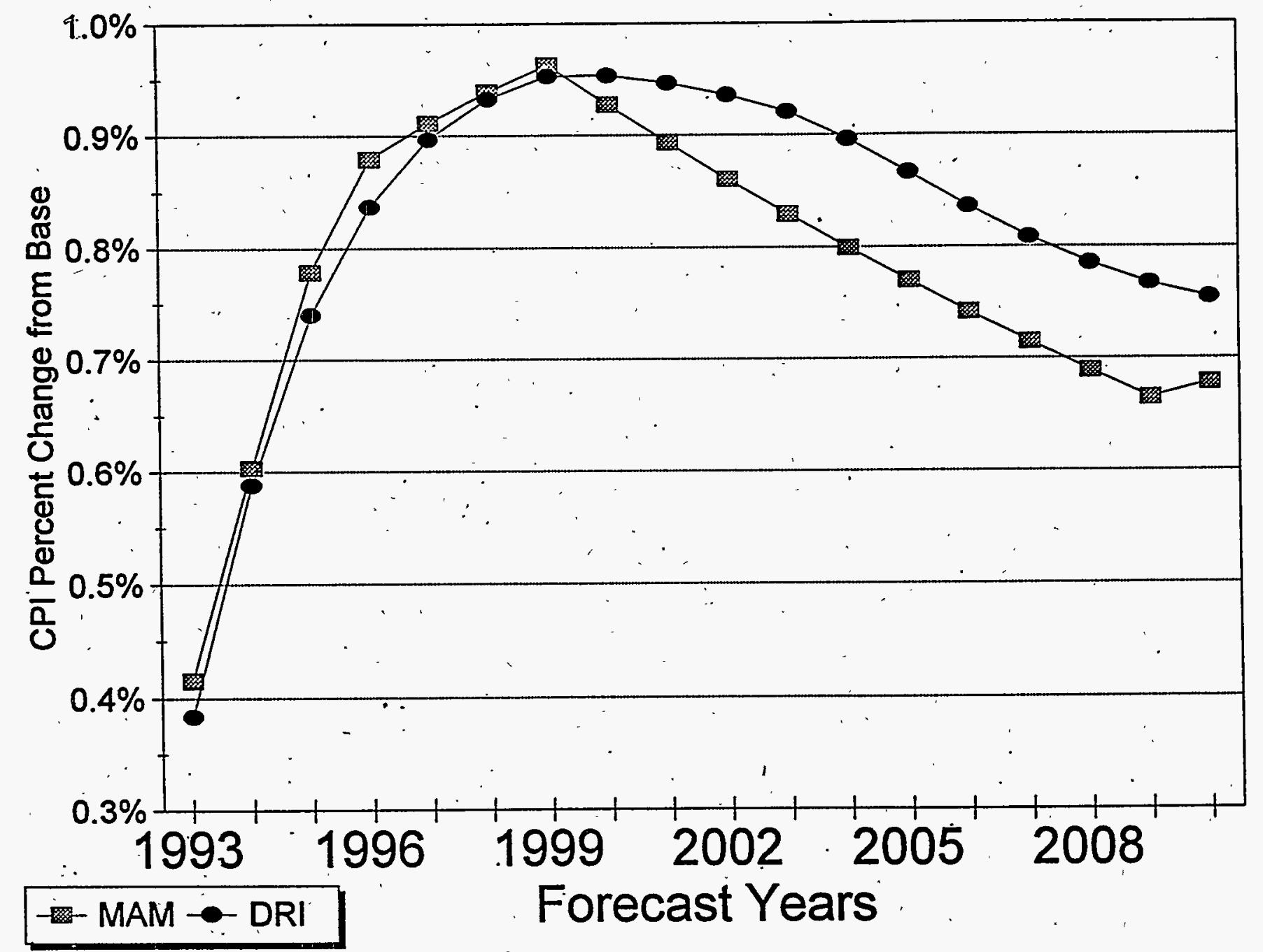


Figure 35. Immediate Increase World Oil Price Scenario: Absolute . Change in Utility Bond Rate

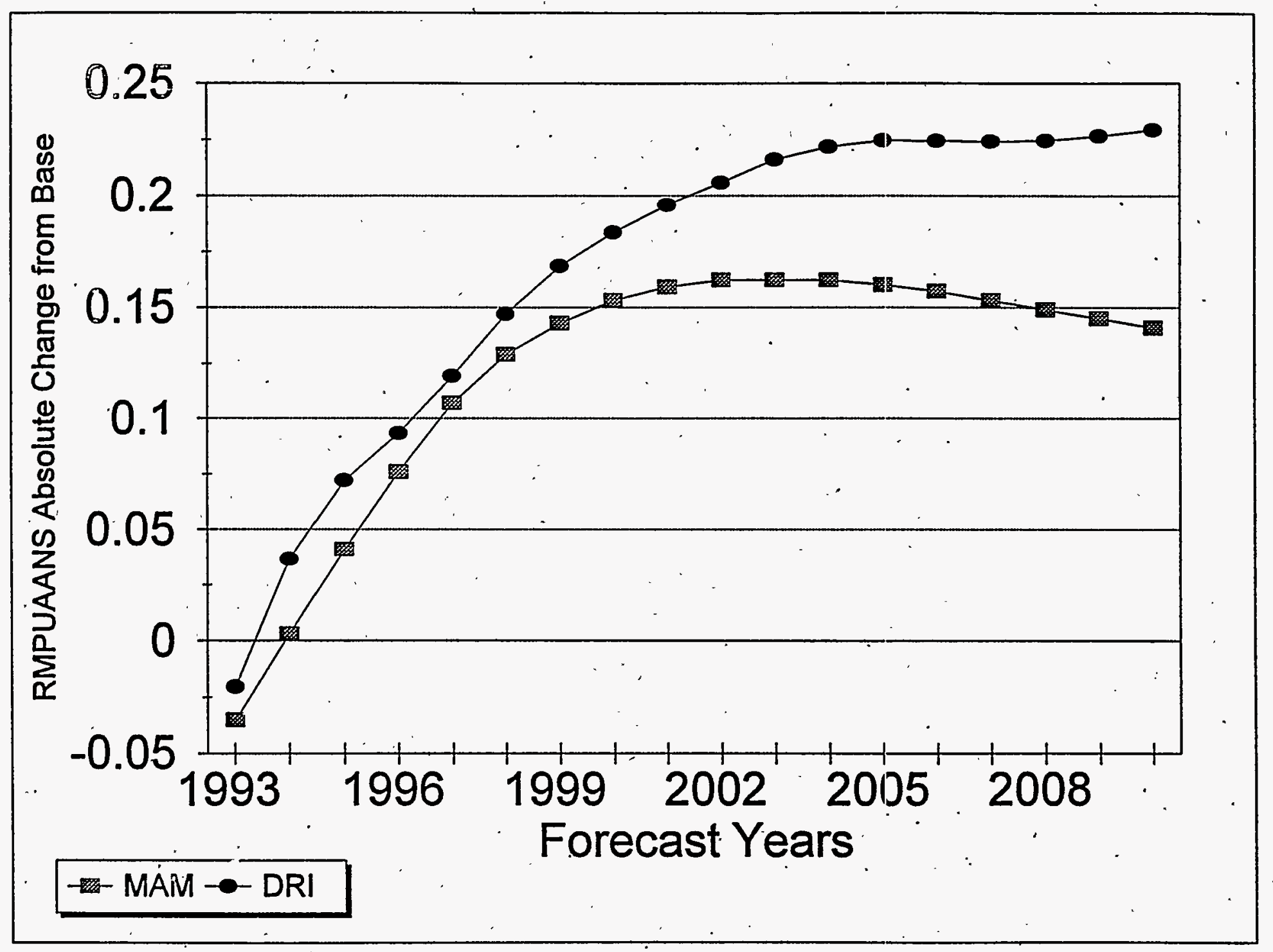




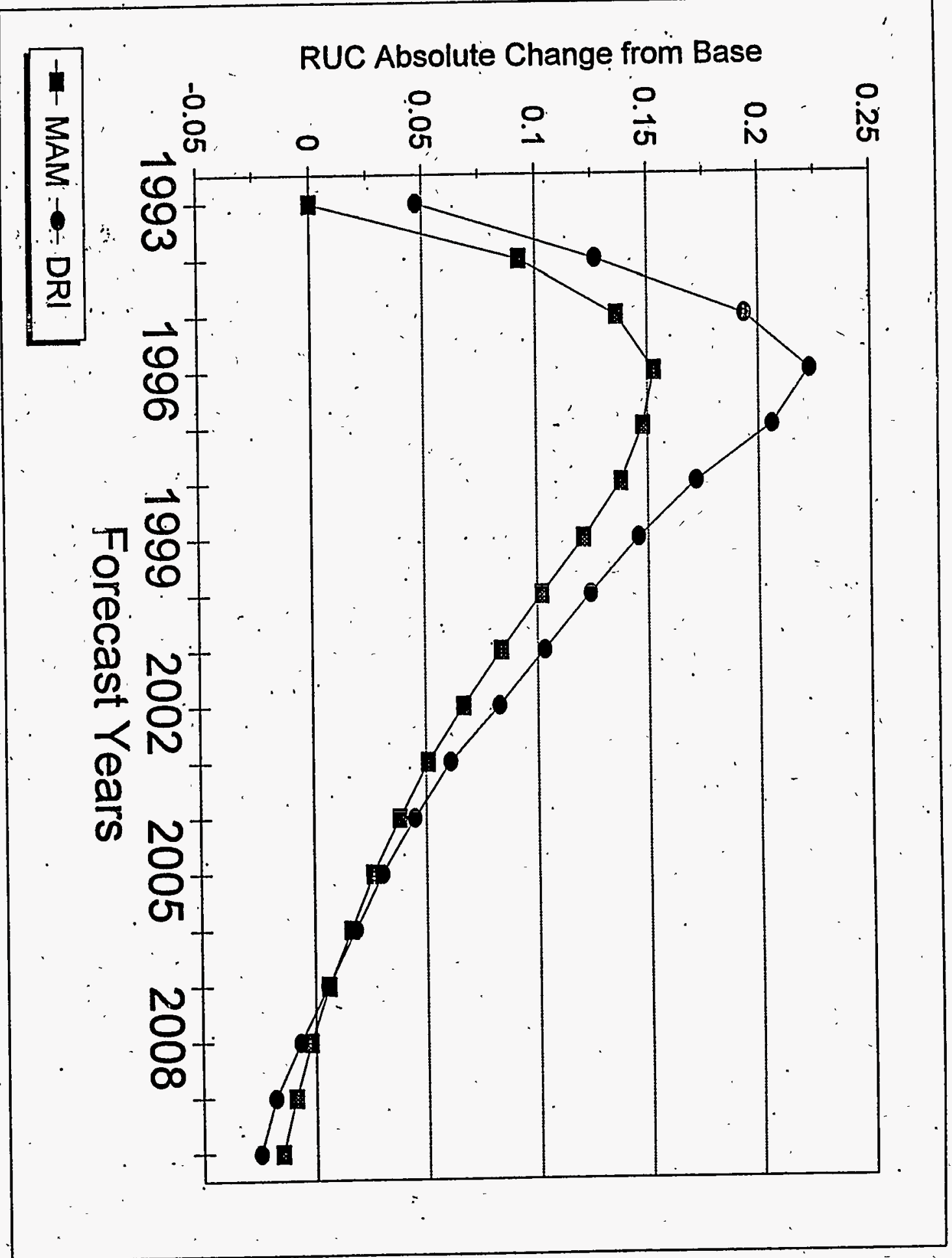

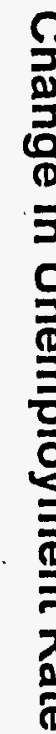

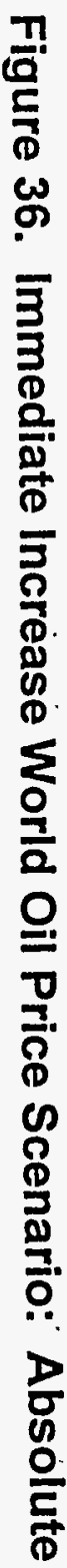




\subsection{Ramped'Decline World Oil Price Scenario}

As described in Table 1, the Ramped Decline World Oil Price scenario utilizes a world oil price series that is $\mathrm{x} \%$ below the corresponding baseline value for real world oil price in year $\mathrm{x}$ of the forecast period. This scenario evaluates the responsiveness of the MAM under a user-specified path of increasing divergence from base case real world oil price projections. Real world oil prices in this scenario range from a low of $\$ 14.36$ per barrel to a high of $\$ 19.21$ per barrel, and fluctuate within these bounds, experiencing periods of rising prices and periods of falling prices over the forecast horizon. As stated previously, the baseline real world oil price varies from a low of $\$ 14.61$ per barrel to a high of $\$ 23.42$ per barrel, and rises steadily throughout the forecast period. The time series of forecasted world oil prices for both the baseline and the alternate case are provided in Tables A-2 and A-11 of the appendix to this report.

\section{First Set of Comparisons: MAM Ramped Decline World Oil Frice Scenario vs.} MAM Base Scenario

Figures 37 through 39 illustrate the changes from the baseline in the relevant MAM output variables, related to the changes in real world oil price. Figures 37 through 39 illustrate that changes in the output variables are consistent with the macroeconomic theories discussed earlier in this report. As in the AEO94 Low World Oil Price scenario, GDP rises more quickly under the lower world oil prices than under the baseline scenario. In quantitative terms, the $18 \%$ difference between the alternative and base case world oil prices under this scenario results in a 2010 value for GDP that is $0.36 \%$ higher than the reference case value. In all forecast years, changes in personal income track closely to changes in GDP as expected. 
Figure 37. MAM Base Compared to MAM Ramped Decline World Oil Price Scenario

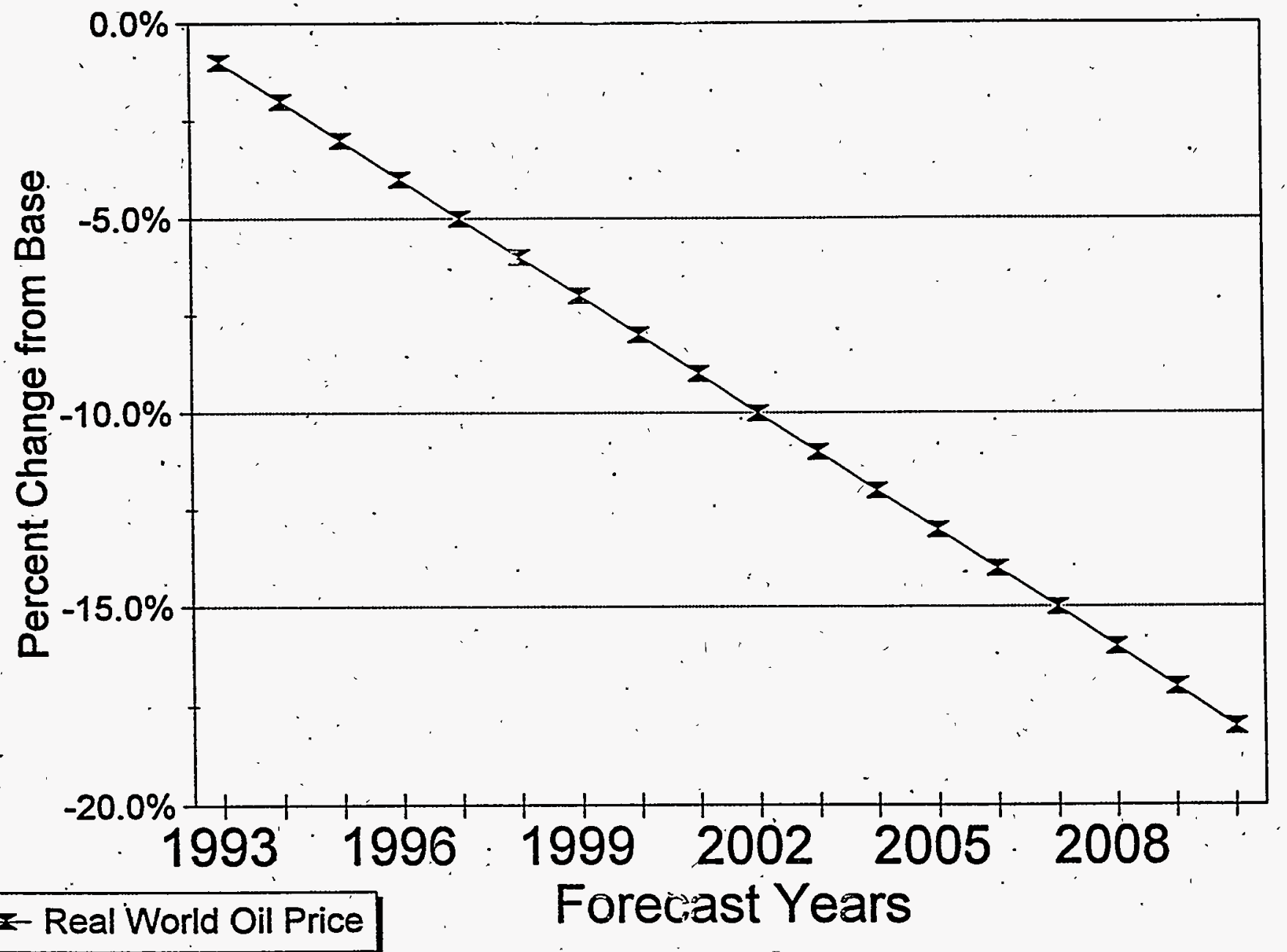


Figure 38. MAM Base Compared to MAM Ramped Decline World Öil Price Scenario

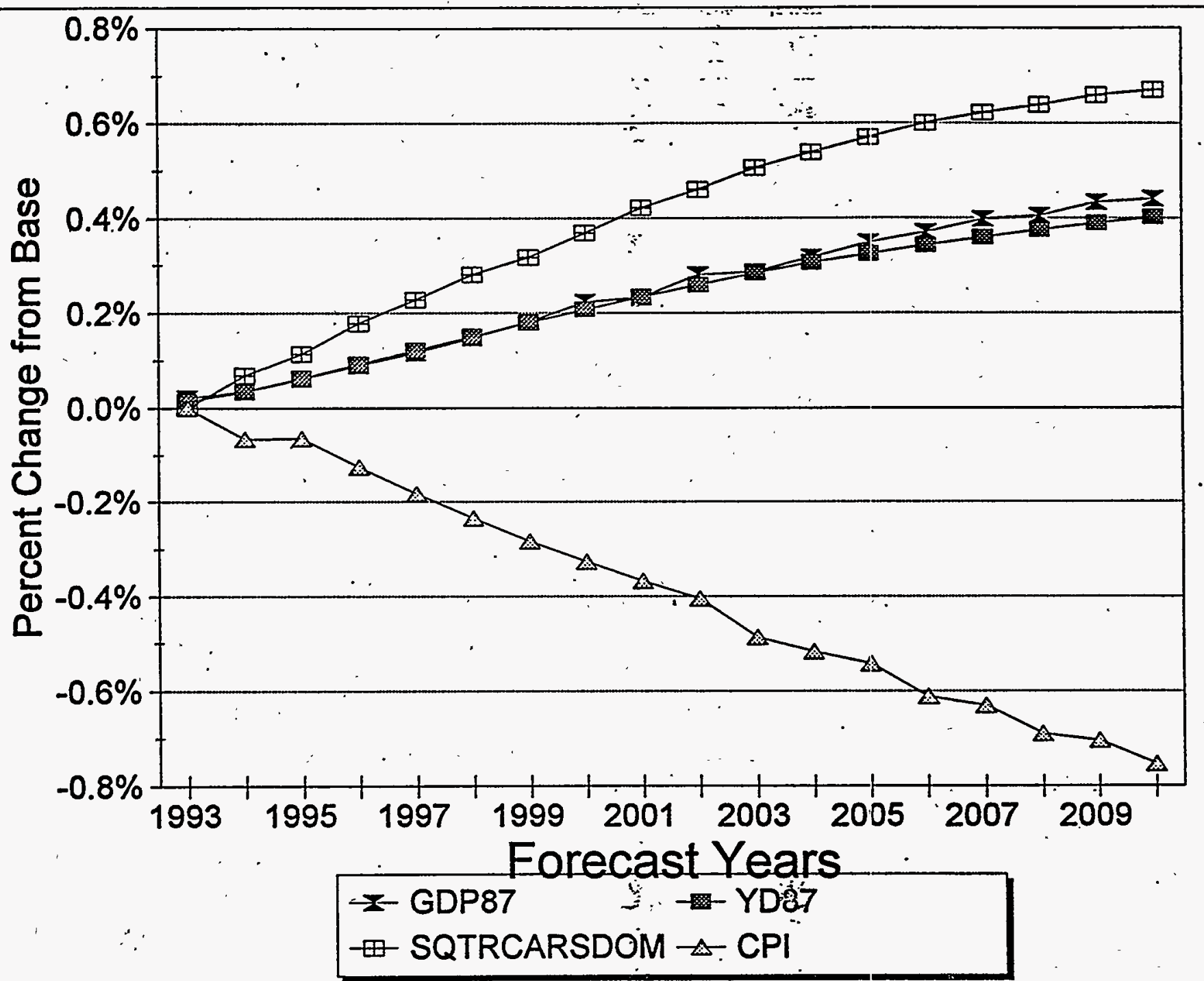


As the real world oil price increases more slowly under the Ramped Decline World Oil Price scenario compared to the baseline, the CPI is generally slightly below the reference case CPI values. The utility bond interest rate rises over the period of 1993-1998 in both the baseline and the alternative scenarios, and falls slightly for most years beyond 1998 in the forecast. As is the case with the CPI, the utility bond rate is lower under the ramped decline scenario compared to the baseline values.

As is the case with the AEO94 Low World Oil Price scenario, unemployment rates are consistently lower under the Ramped Decline World Oil Price scenario, compared to the base case. This result is again partly explained by the lack of pressure on inflation rates within periods of low oil prices such as those sustained throughout this alternative case. 
Figure 39. MAM Base Compared to MAM Ramped Decline World Oil

- Price Scenario

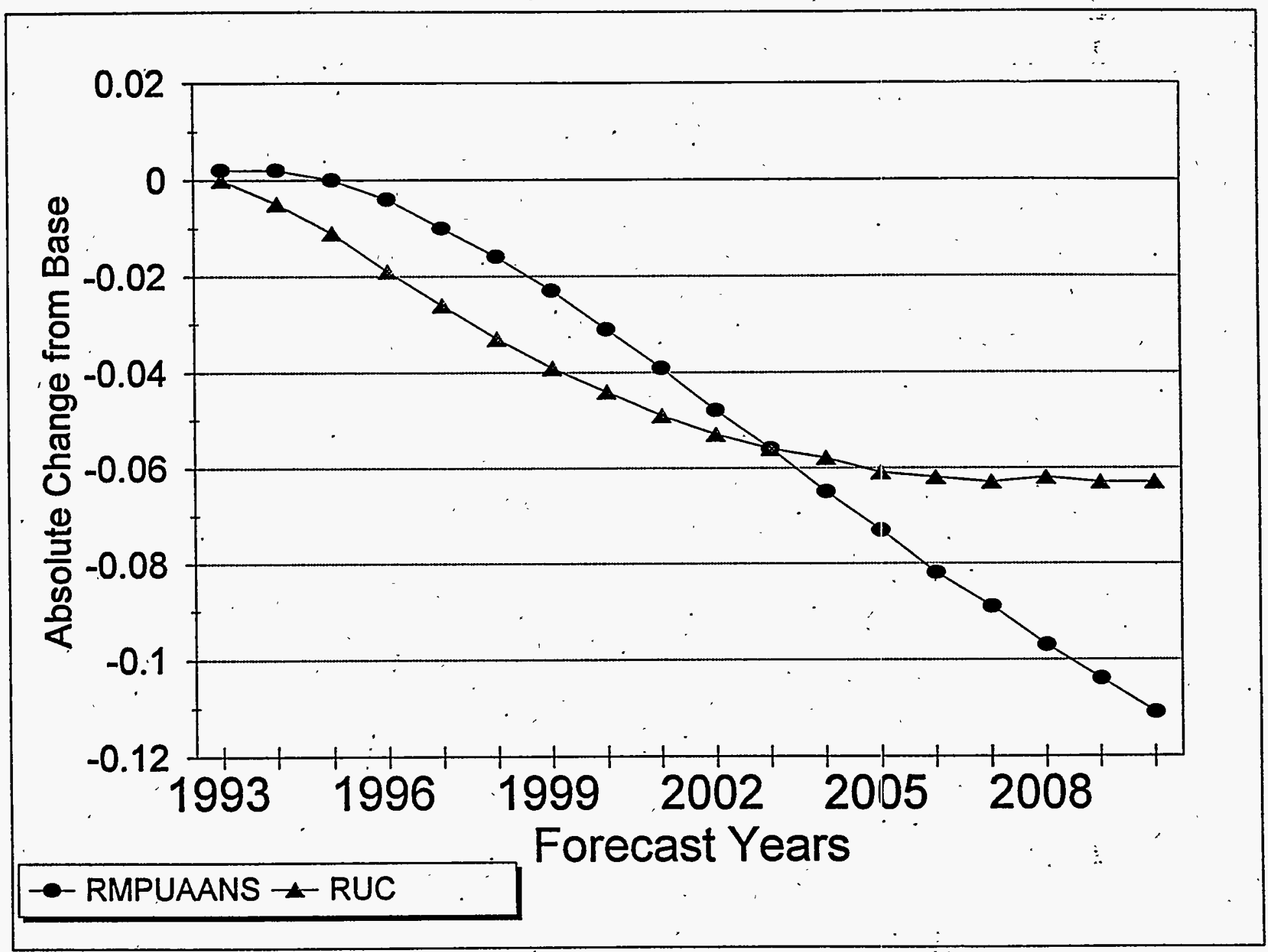


Second Set of Comparisons: MAM Ramped Decline World Oil Price Scenario.vs. DRI Ramped Decline World Oil Price Scenario

Under the ramped decline scenario, the key outputs of the NEMS MAM differ by $1.84 \%$ or less from the outputs of the full DRI model. This range is comparable to the percent differences between MAM and DRI in all cases presented to this point. In summary, MAM produces results that closely mirror DRI full model results under the Ramped Decline World Oil Price scenario. Figures 40 through 45 compare the MAM scenario results to the DRI scenario results for the key output variables listed in Table 2 of this report. 
Figure 40. Ramped Decline World Oil Price Scenario: Percent Change in Constant $\$ 1987$ Gross Domestic Product

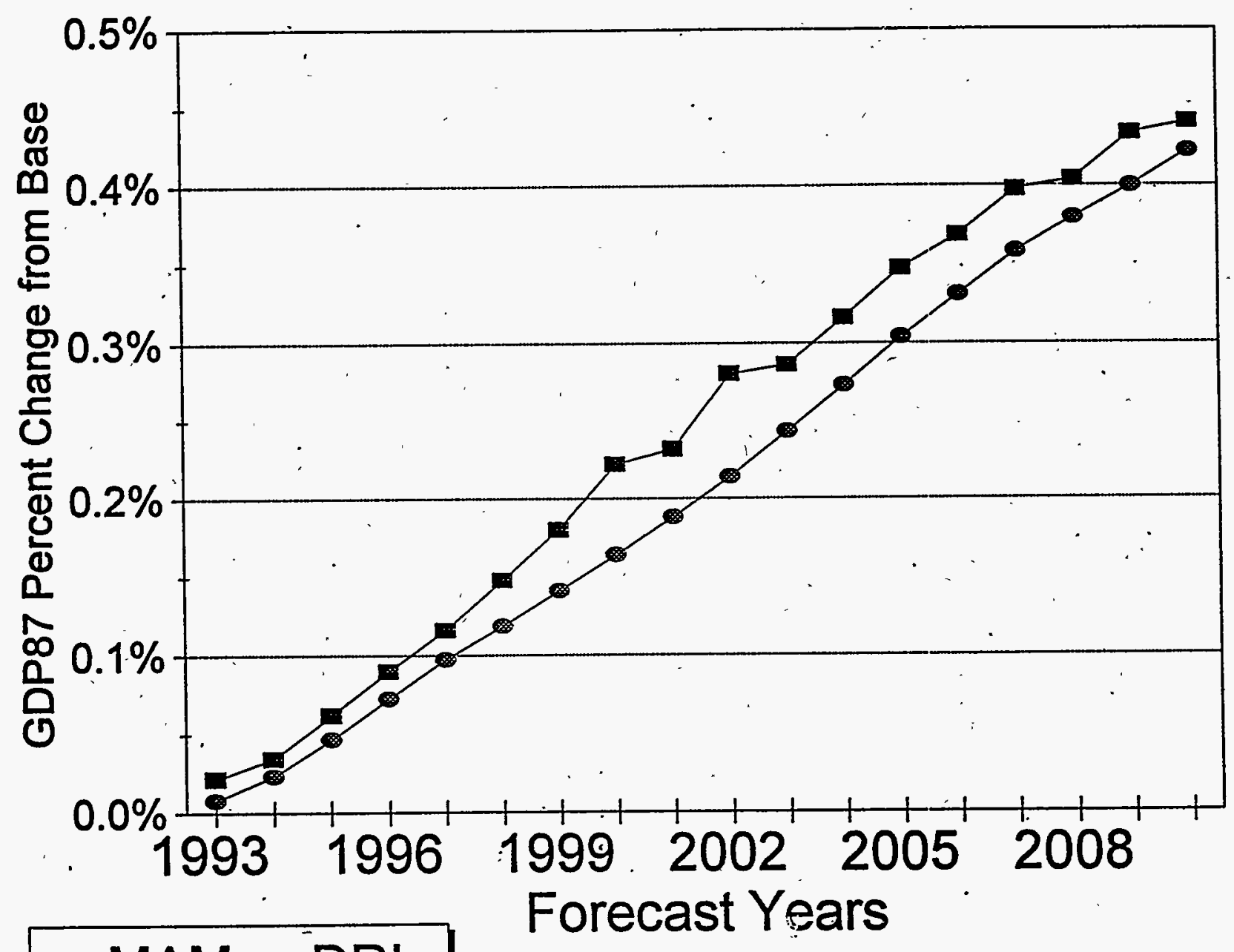


Figure 41. Ramped Decline World Oil Price Scenario: Percent Change in Constant \$1987 Disposable Income

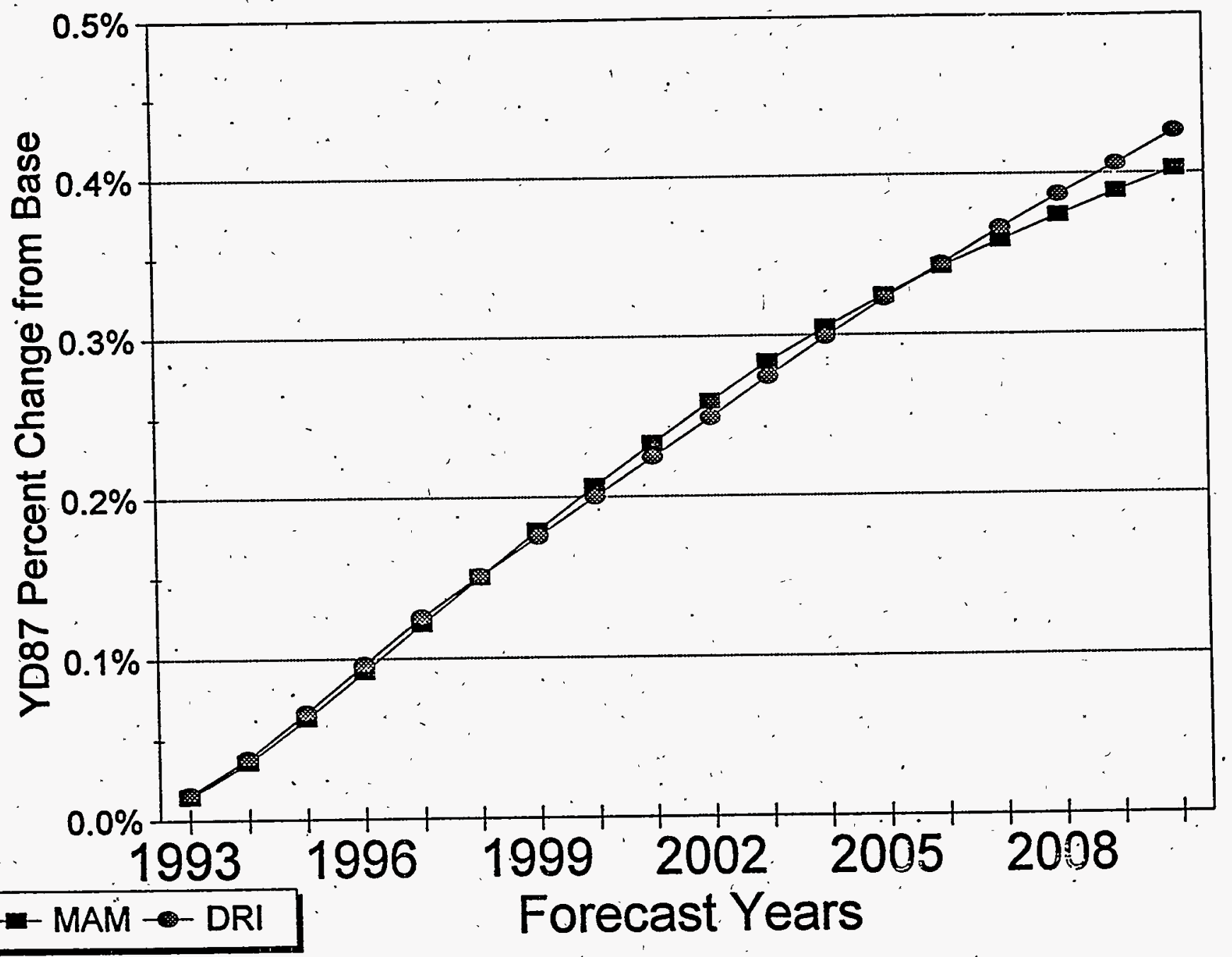


Figure 42. Ramped Decline World Oil Price Scenario: Percent Change in Unit Sales of Domestic Automobiles

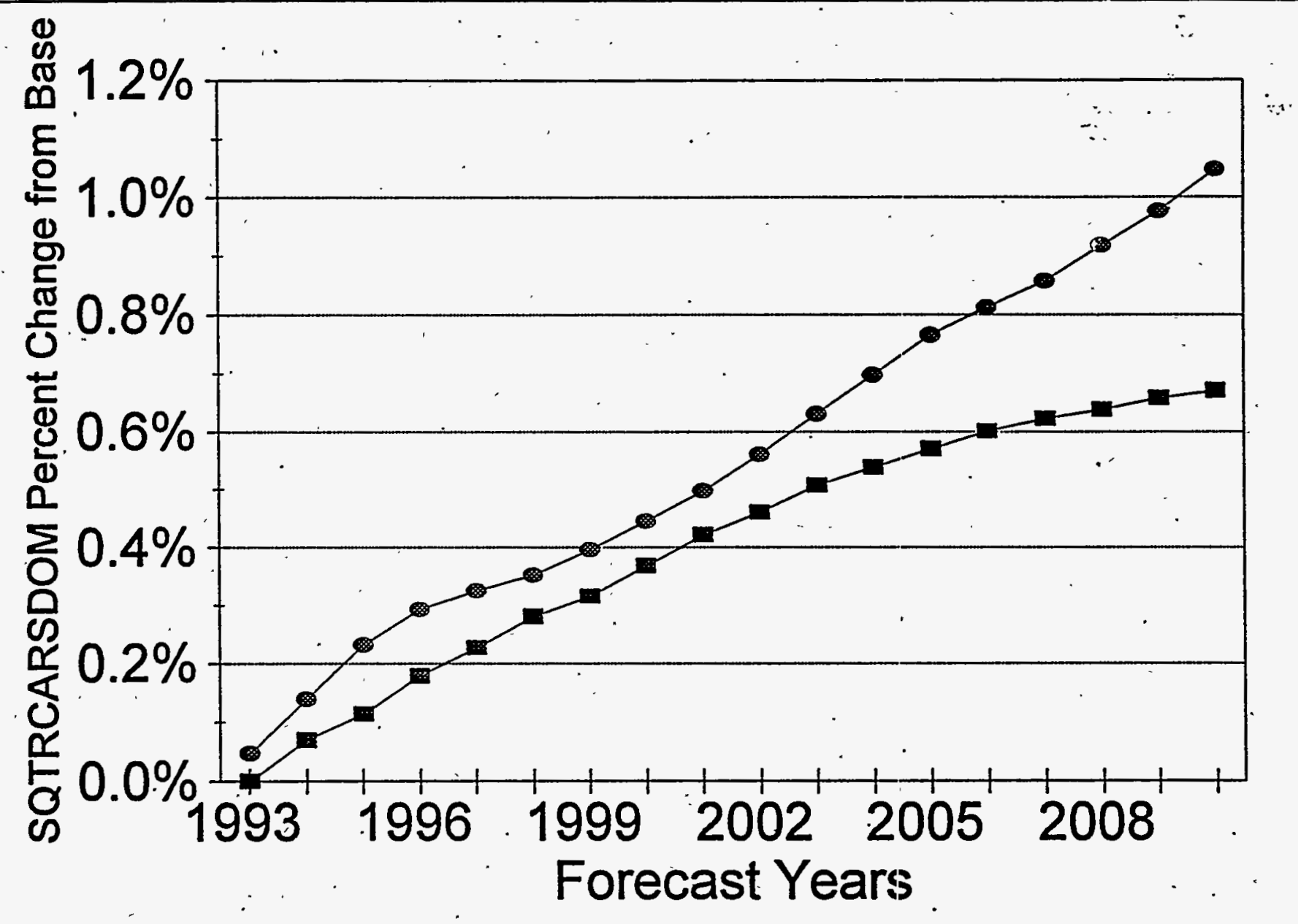

MAM - - DRI 
Figure 43. Ramped Decline World Oil Price Scenario: Percent Change in Consumer Price Index

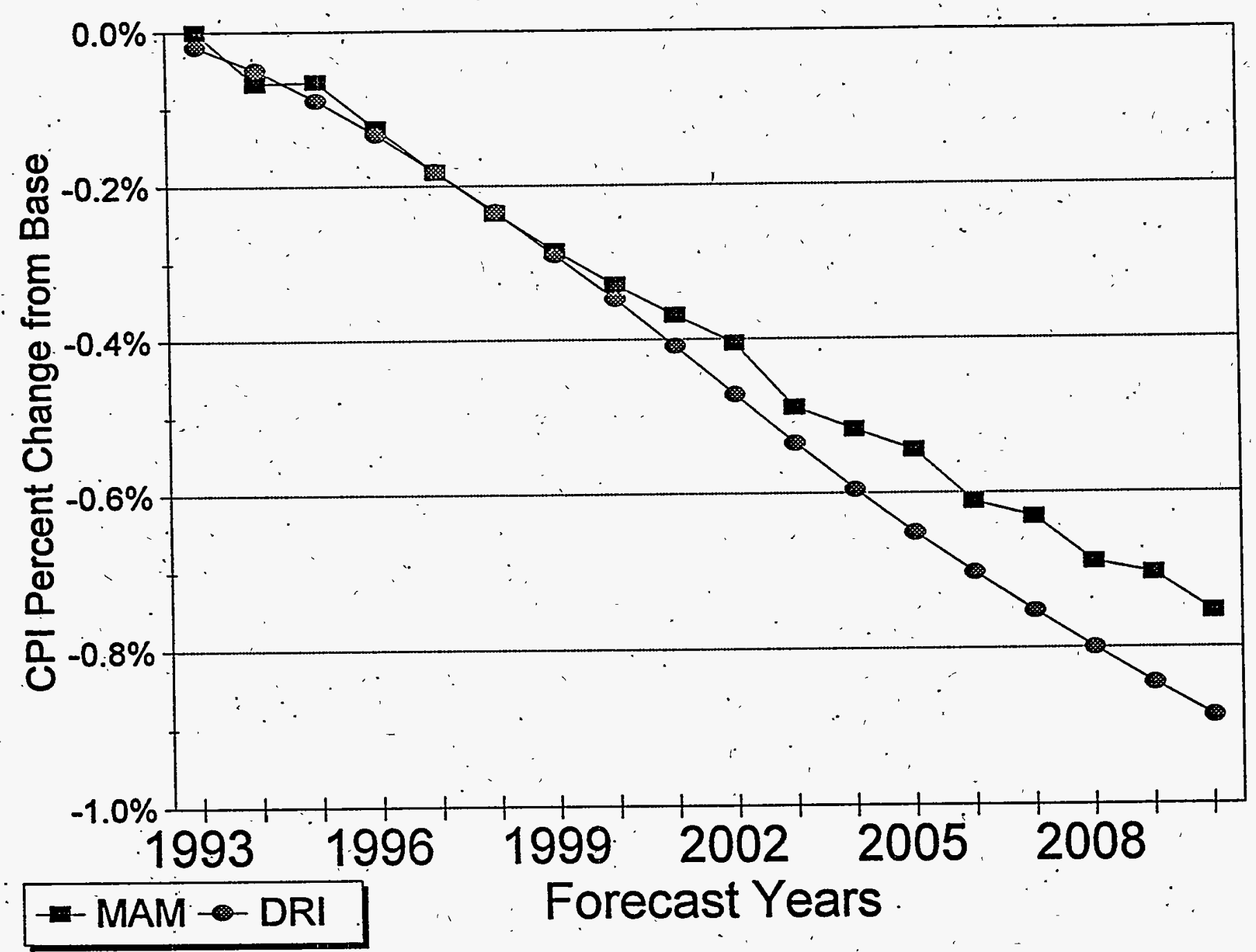


Figure 44. Ramped Decline World Oil Price Scenario: Absolute Change in Utility Bond Rate

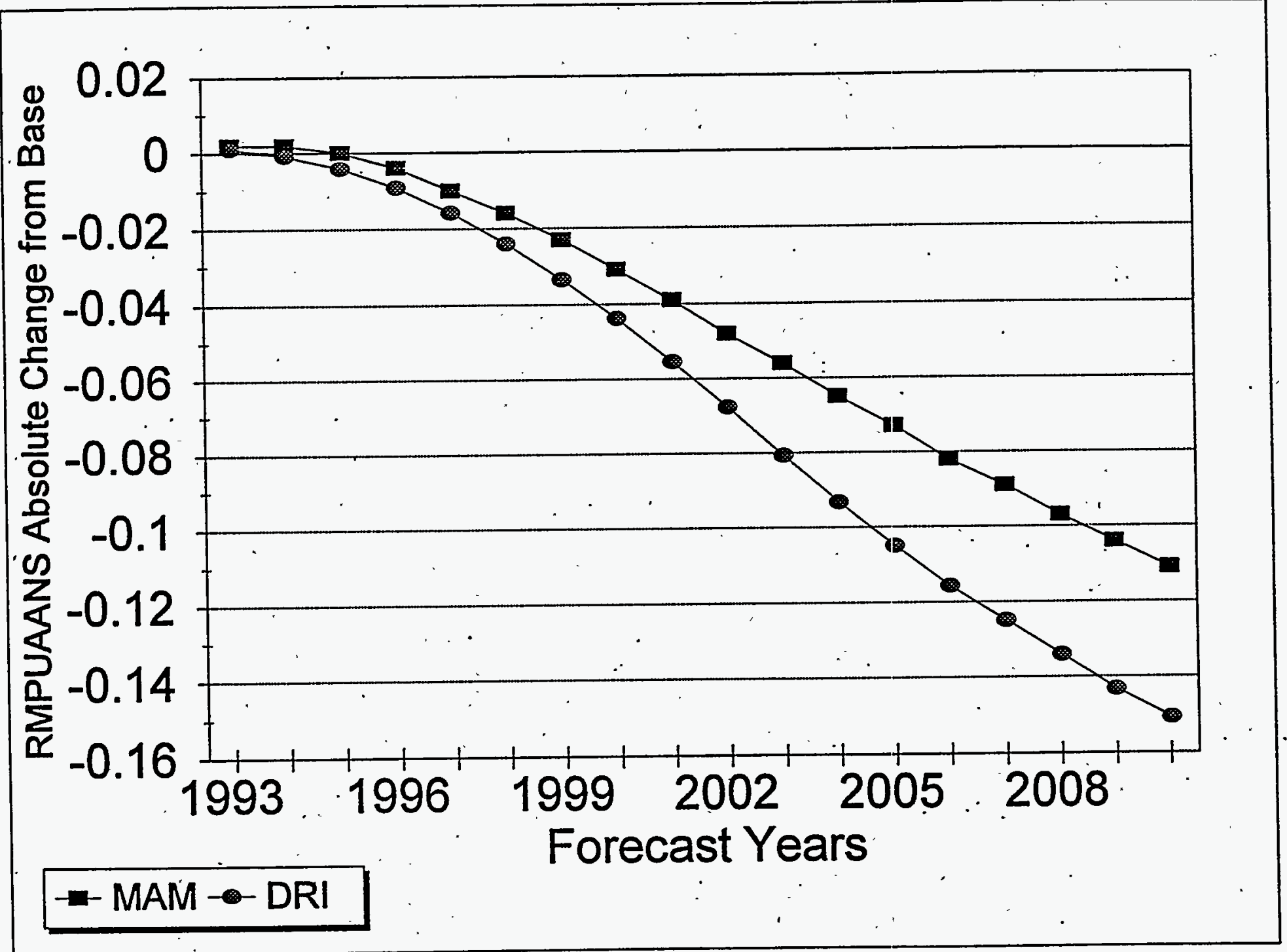


Figure 45. Ramped Decline World Oil Price Scenario: Absolute Change in Unemployment Rate

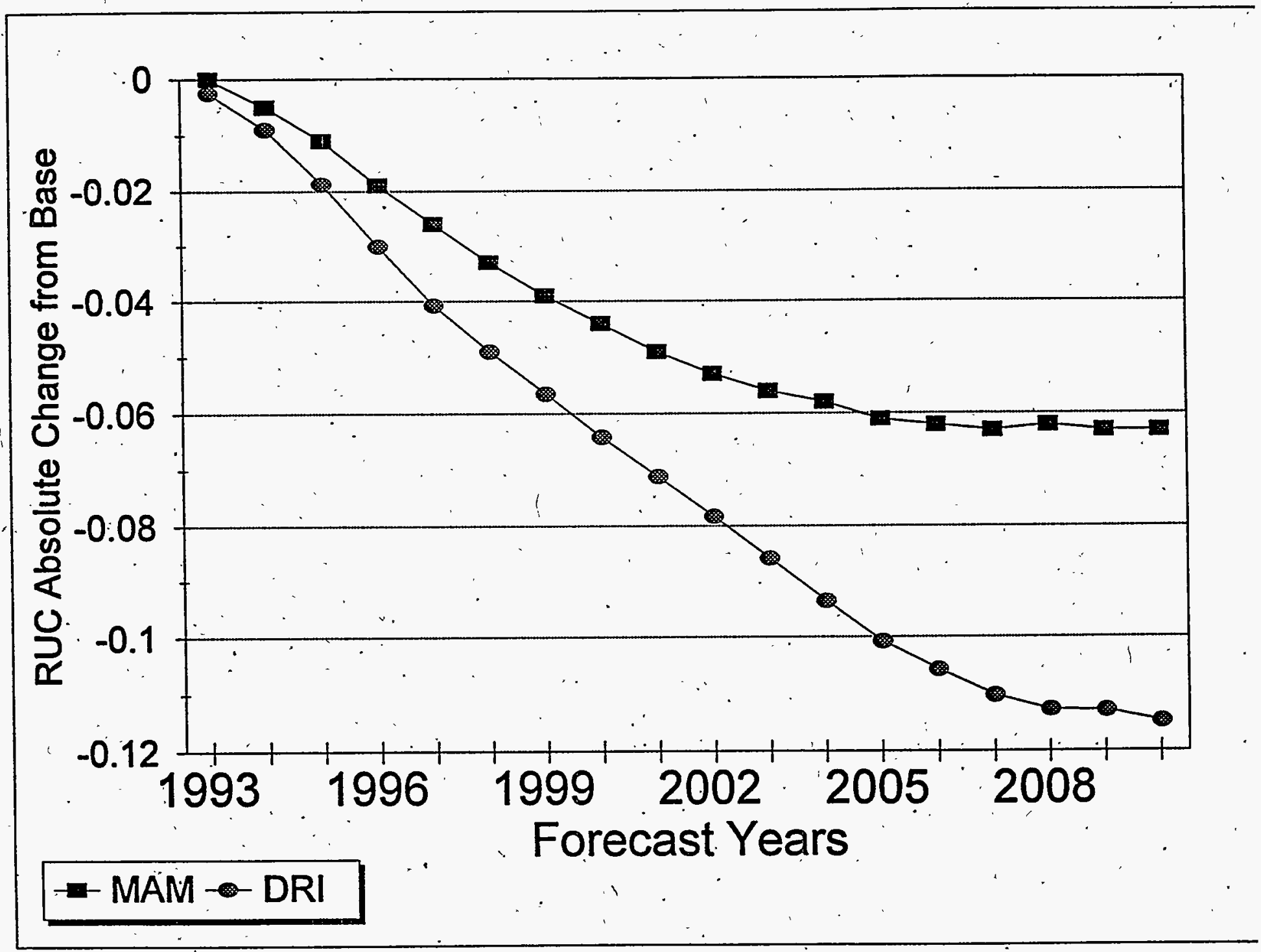


Appendix 


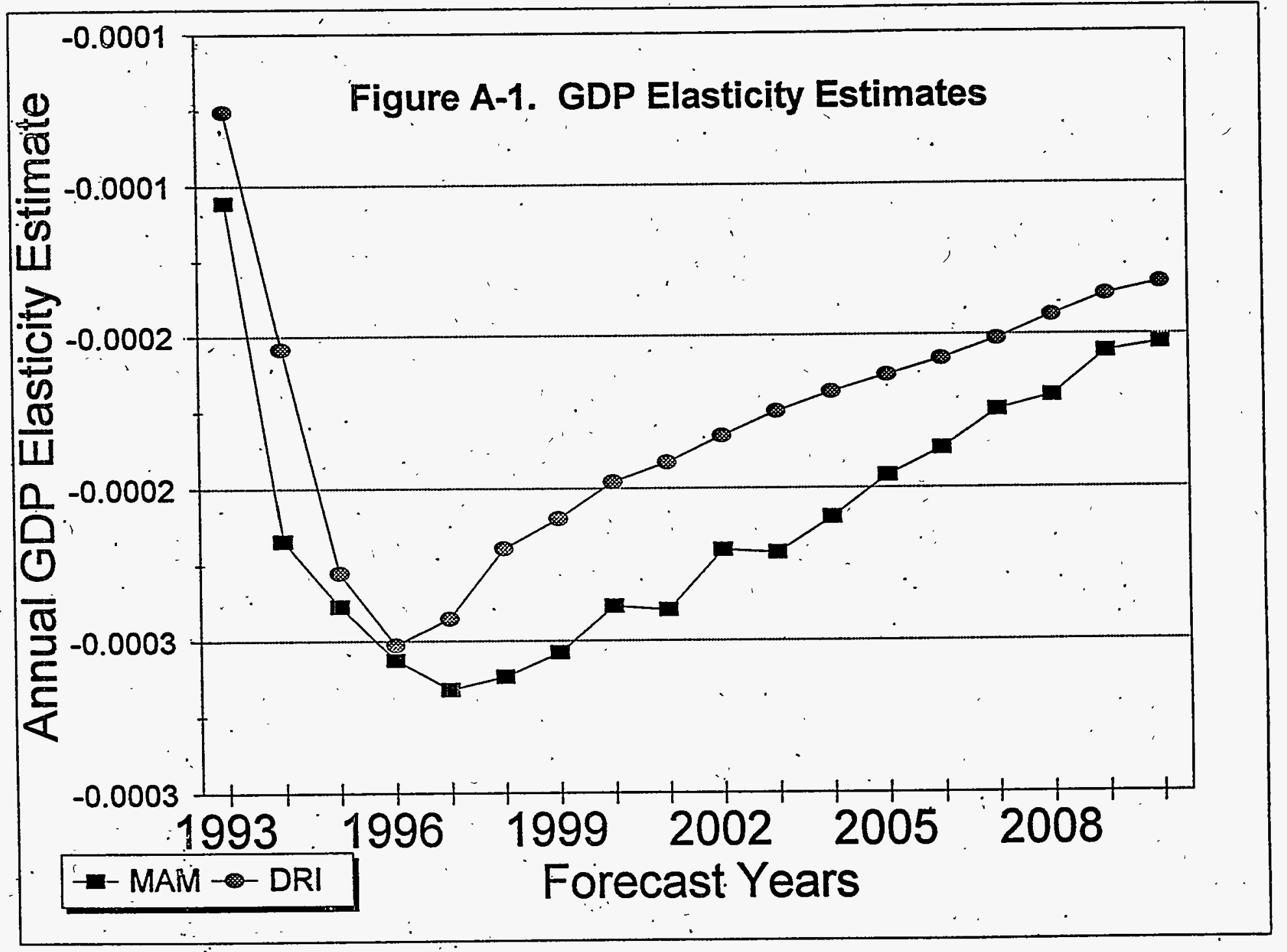




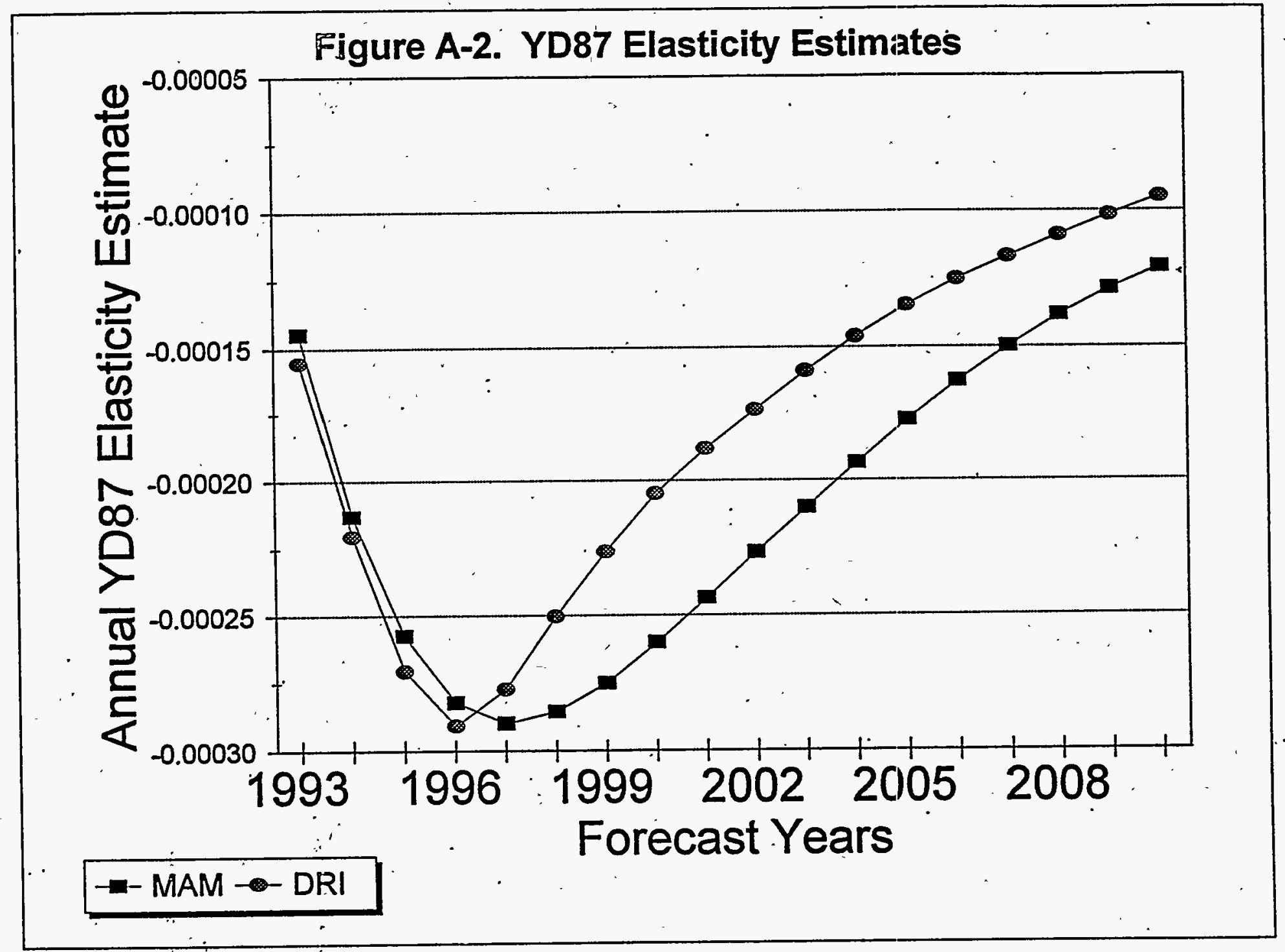




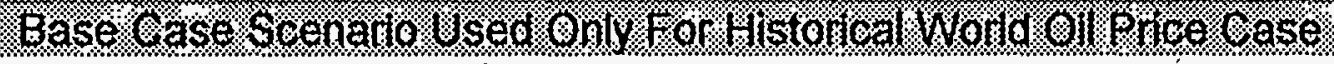


\% \%

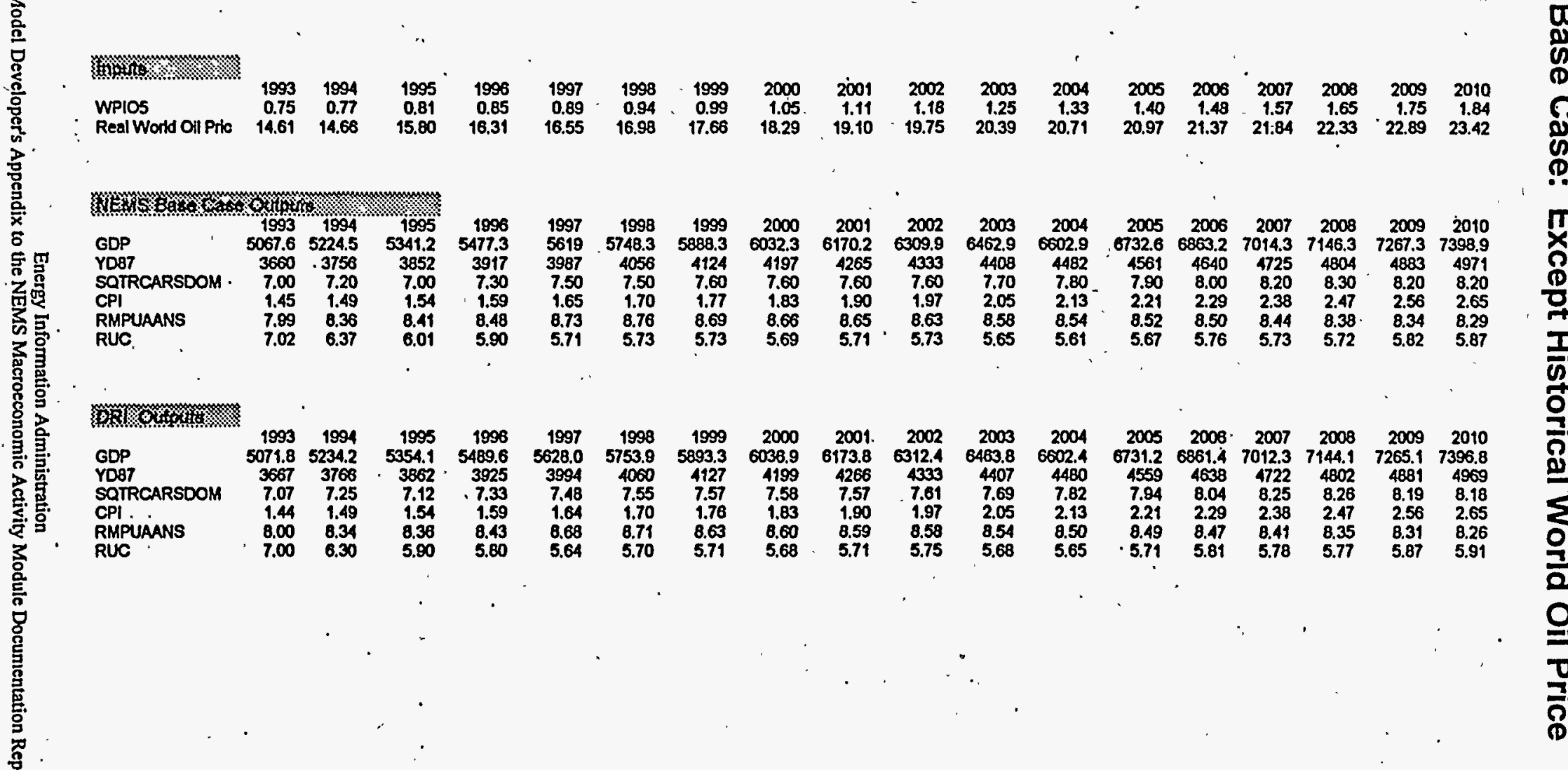




\section{Mistorical World OI Price Pait Scenario}

\begin{tabular}{|c|c|c|c|c|c|c|c|c|c|c|c|c|c|c|c|c|c|c|}
\hline $\mathrm{RH}$ & & & & & & & & & & & & & & & & & & \\
\hline $\begin{array}{l}\text { WPTOS } \\
\text { Real World Oil Price }\end{array}$ & $\begin{array}{r}1993 \\
0.76 \\
13.82\end{array}$ & $\begin{array}{r}1994 \\
0.77 \\
13.79\end{array}$ & $\begin{array}{r}1895 \\
1.47 \\
38.82\end{array}$ & $\begin{array}{r}1896 \\
1.63 \\
.39 .49\end{array}$ & $\begin{array}{r}1997 \\
1.64 \\
36.31\end{array}$ & $\begin{array}{r}1998 \\
1.75 \\
38.48\end{array}$ & $\begin{array}{r}1999 \\
1.78 \\
33.93\end{array}$ & $\begin{array}{r}2000 \\
2.22 \\
45.81\end{array}$ & $\begin{array}{r}2001 \\
3.09 \\
68.34\end{array}$ & $\begin{array}{r}2002 \\
3.38 \\
65.92\end{array}$ & $\begin{array}{r}2003 \\
3.21 \\
56.21\end{array}$ & $\begin{array}{r}2004 \\
.2 .99 \\
47.19\end{array}$ & $\begin{array}{r}2005 \\
2.92 \\
14.43\end{array}$ & $\begin{array}{r}2006 \\
2.78 \\
40.09\end{array}$ & $\begin{array}{l}2007 \\
1.96 \\
20.72\end{array}$ & $\begin{array}{r}2008 \\
2.07 \\
25.29\end{array}$ & $\begin{array}{r}2009 \\
1.85 \\
19.74\end{array}$ & $\begin{array}{r}2010 \\
1.98 \\
23.31\end{array}$ \\
\hline
\end{tabular}

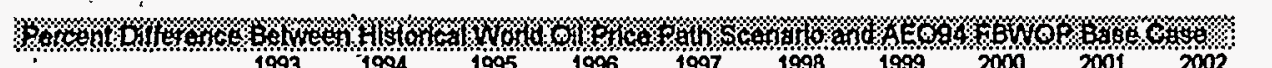

$\begin{array}{lllllllllllllllllll}\cdot & 1993 & 1994 & 1995 & 1996 & 1997 & 1998 & 1999 & 2000 & 2001 & 2002 & 2003 & 2004 & 2005 & 2000 & 2007 & 2003 & 2009 & 2010\end{array}$

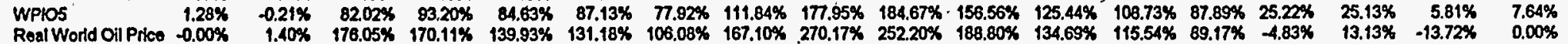

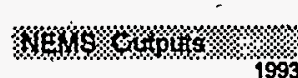

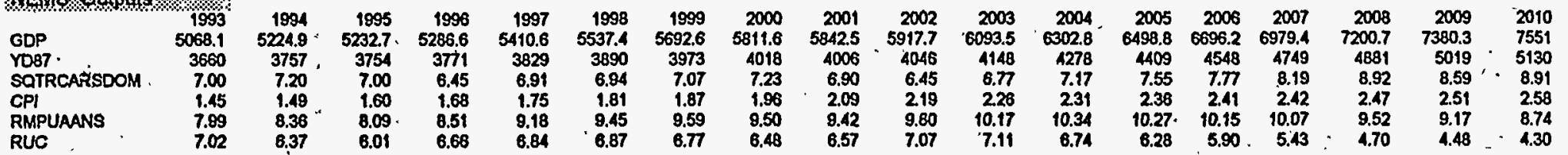

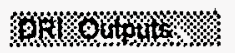

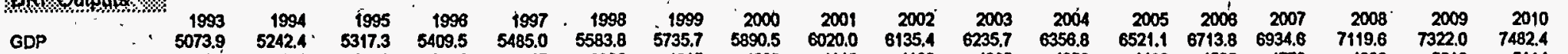

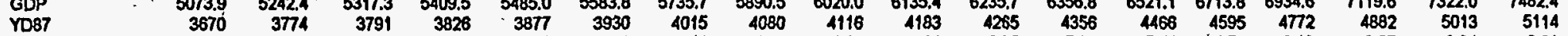

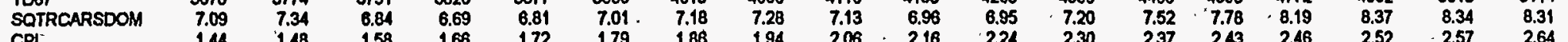

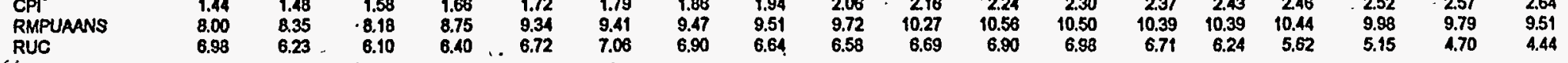

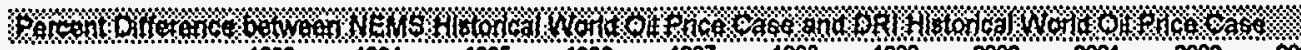

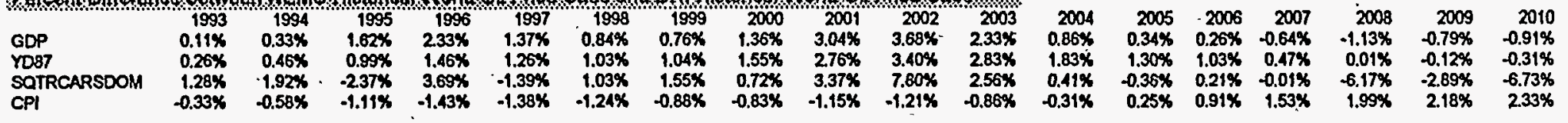


Table A-4. Historical World Oil Price Scenario Supplement

最影

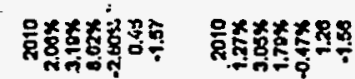

赵部

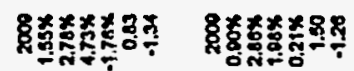

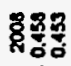

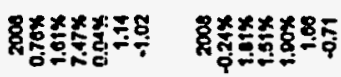

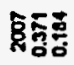

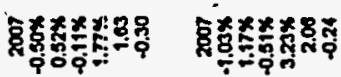

登管

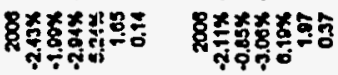

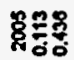

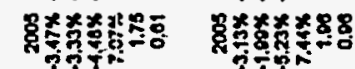

-

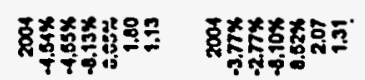

1)

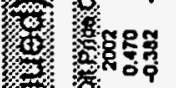

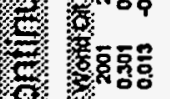

S.

다.

4.

त)

6 . 5 sำ

6.

5 )

-
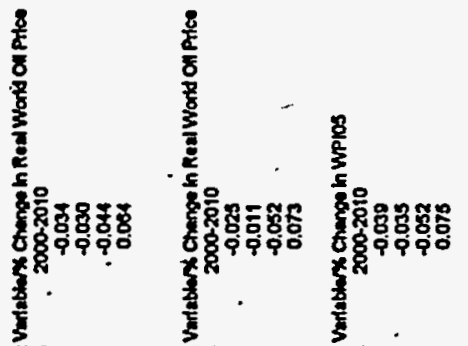

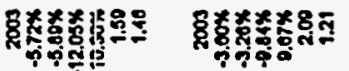

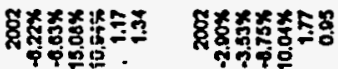

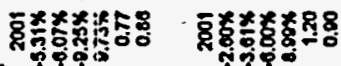

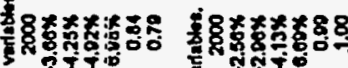

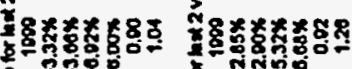

गुक

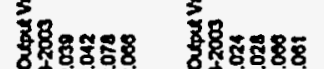

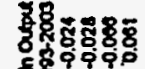

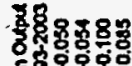

58

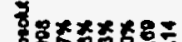

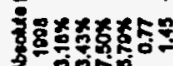

辈

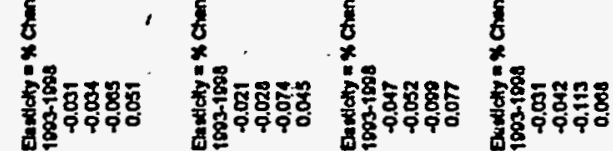

年

족

$8 x \times x \times 58$

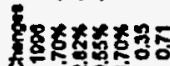

ลำ

.

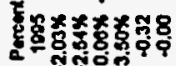

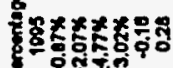

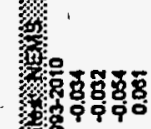

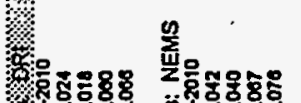

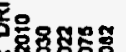

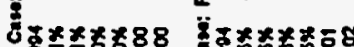

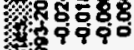

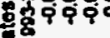

क우웅

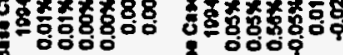

$58 \times \times \times 88$

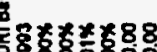

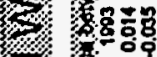

楼

權

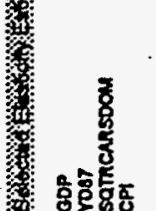

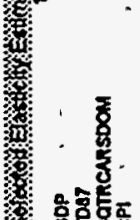

(

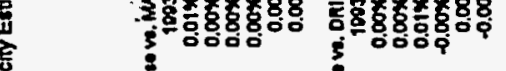

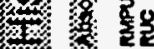

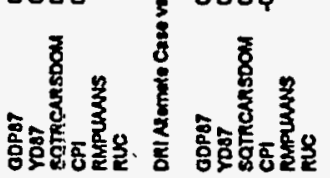


$\begin{array}{lllllllllllllllllll}\text { Inputs } & 1993 & 1994 & 1995 & 1996 & 1997 & 1998 & 1999 & 2000 & 2001 & 2002 & 2003 & 2004 & 2005 & 2006 & 2007 & 2008 & 2009 & 2010\end{array}$

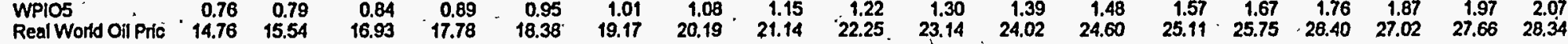

Percent Difference Between AEOQ94 High World Oil Price Path Scenario and Base Case

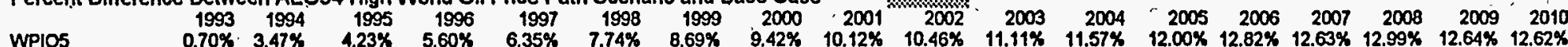

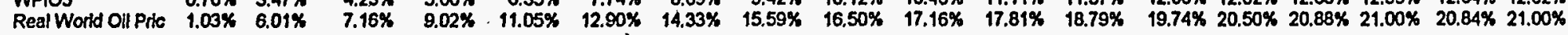

NEMS Outputs

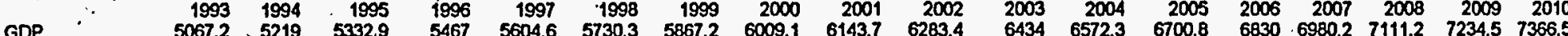

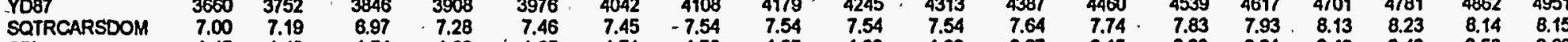

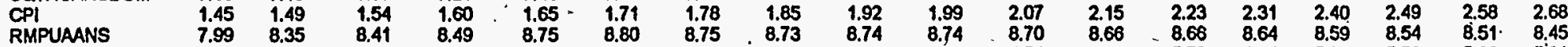

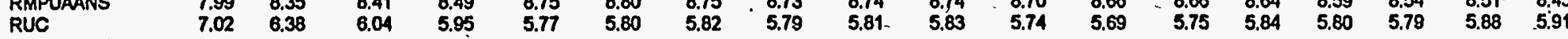

\section{DRI Outputs.}

GDP
YDB7 SOTRCARSDOM RMPUAANS $19931994 \quad 1995$ $\begin{array}{rrrr} & & & \\ 1996 & 1997 & 199 \\ 8.6 & 5481.2 & 5616.8 & 5740.2 \\ 56 & 3917 & 3984 & 404 \\ .08 & 7.28 & 7.43 & 7.50 \\ 54 & 1.59 & 1.65 & 1.71 \\ 38 & 8.46 & 8.72 & 8.77 \\ 5.94 & 5.86 & 5.72 & 5.80\end{array}$ $\begin{array}{rrrr} & & & \\ 1998 & 1999 & 2000 & 2001 \\ 0.2 & 5877.0 & 6018.2 & 6153.6 \\ .50 & 4113 & 4184 & 42 \\ .71 & .7 .51 & 7.51 & 7.50 \\ .77 & 1.77 & 1.84 & 1.91 \\ .80 & \mathbf{8 . 7 1} & 8.71 & 8.72 \\ & 5.82 & 5.80 & 5.83\end{array}$

Percent Difference between NEMYYS ÄEỌ94 Hilgh World ÖII Price Case and DRI AEO94 High World Oll Price Case

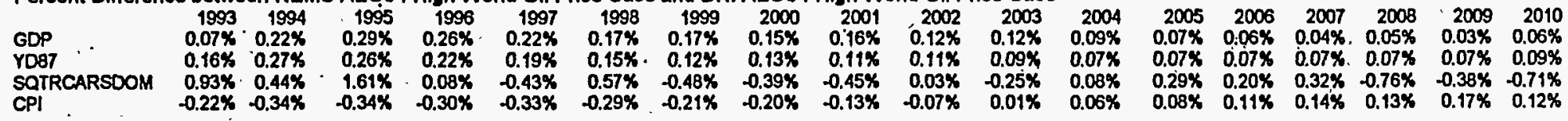




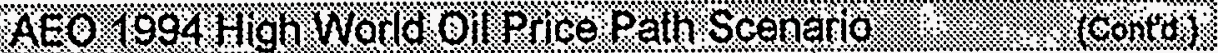

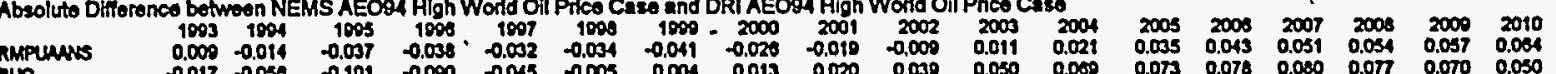

Seloctod Elasticity Estimates: NEMS

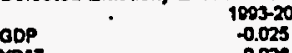

Solthensoom $\quad 0.026$

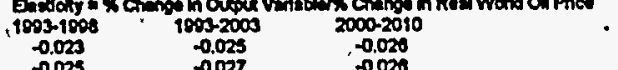

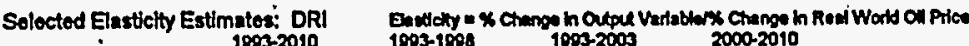

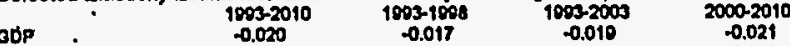

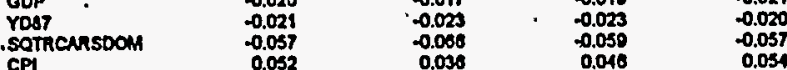

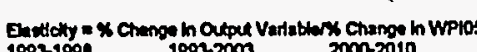

Selected Elasticity Estimatos: NEMS

oDP

$\begin{array}{ll} & 0.028 \\ \text { Yost } & -0.090 \\ \text { SOTRCARsDoni } & -0.007\end{array}$

Soloctod Elasticity Estimates: DRI

$\begin{array}{lllll}\text { YDS7 } & -0.032 & -0.039 & -0.037 & -0.032 \\ \text { SOTICARSDOM } & -0.067 & -0.109 & -0.094 & -0.000 \\ \text { CPI } & 0.070 & 0.000 & 0.073 & 0.083\end{array}$

$1093-2010$
0.001
-0.032

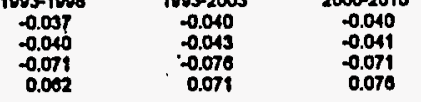

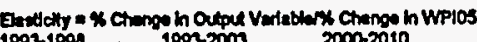

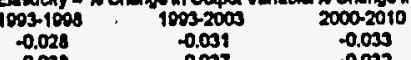

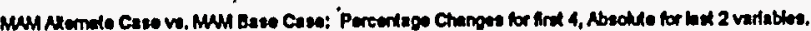

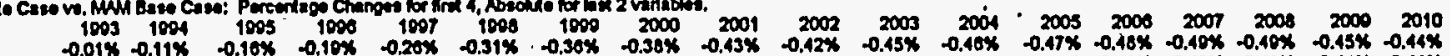

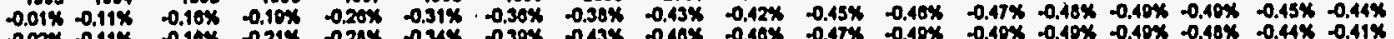

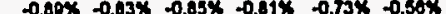

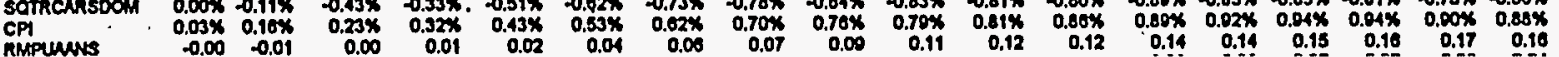

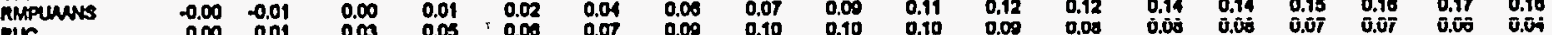

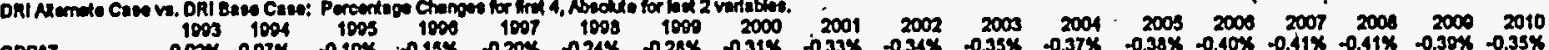

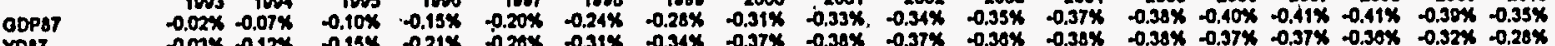

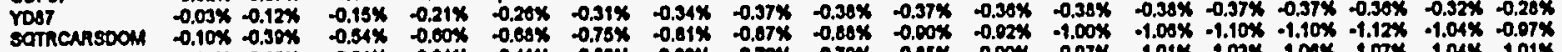

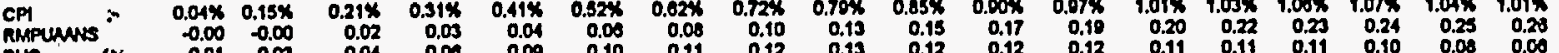




\section{A E0 1994 Low World OII Price Path Scenario}

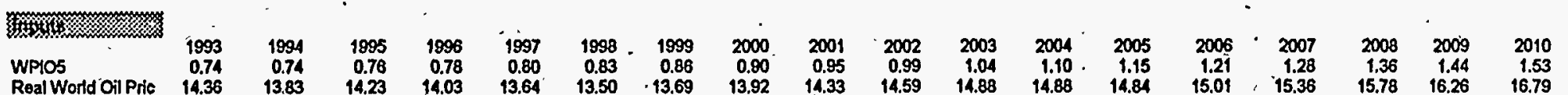

(n)

$\begin{array}{llllllllllllllllll}1994 & 1995 & 1996 & 1997 & 1998 & 1999 & 2000 & 2001 & 2002 & 2003 & 2004 & 2005 & 2006 & 2007 & 2008 & 2009 & 2010 & \end{array}$

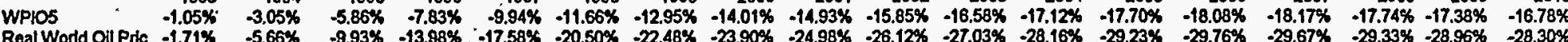

(n)

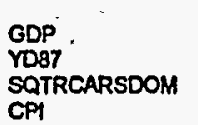

SQTRCARSDOM

RMPUAANS
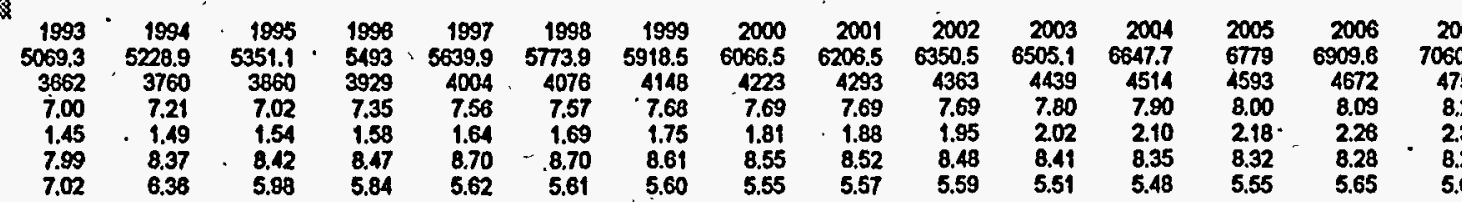

(1)

GDP $\begin{array}{rr}1993 & 1994 \\ 5072.5 & 5237 \\ 3668 & 37 \\ 7.08 & 7.27 \\ 1.44 & 1.48 \\ 8.00 & 8.34 \\ 6.99 & 6.28\end{array}$ CPI RMPAANS $\quad 8.00$

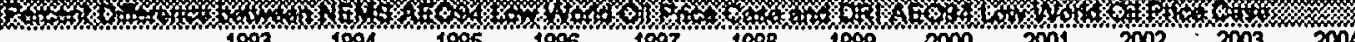

$\begin{array}{llllllllllllllll}2000 & -1000 & 2009 & 2010\end{array}$

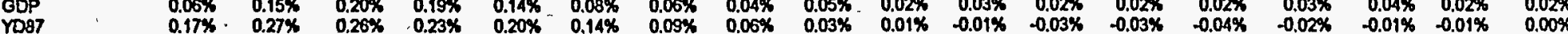

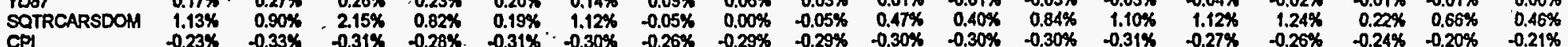


Table A-8. AEO94 Low World Oil Price Scenario Supplement

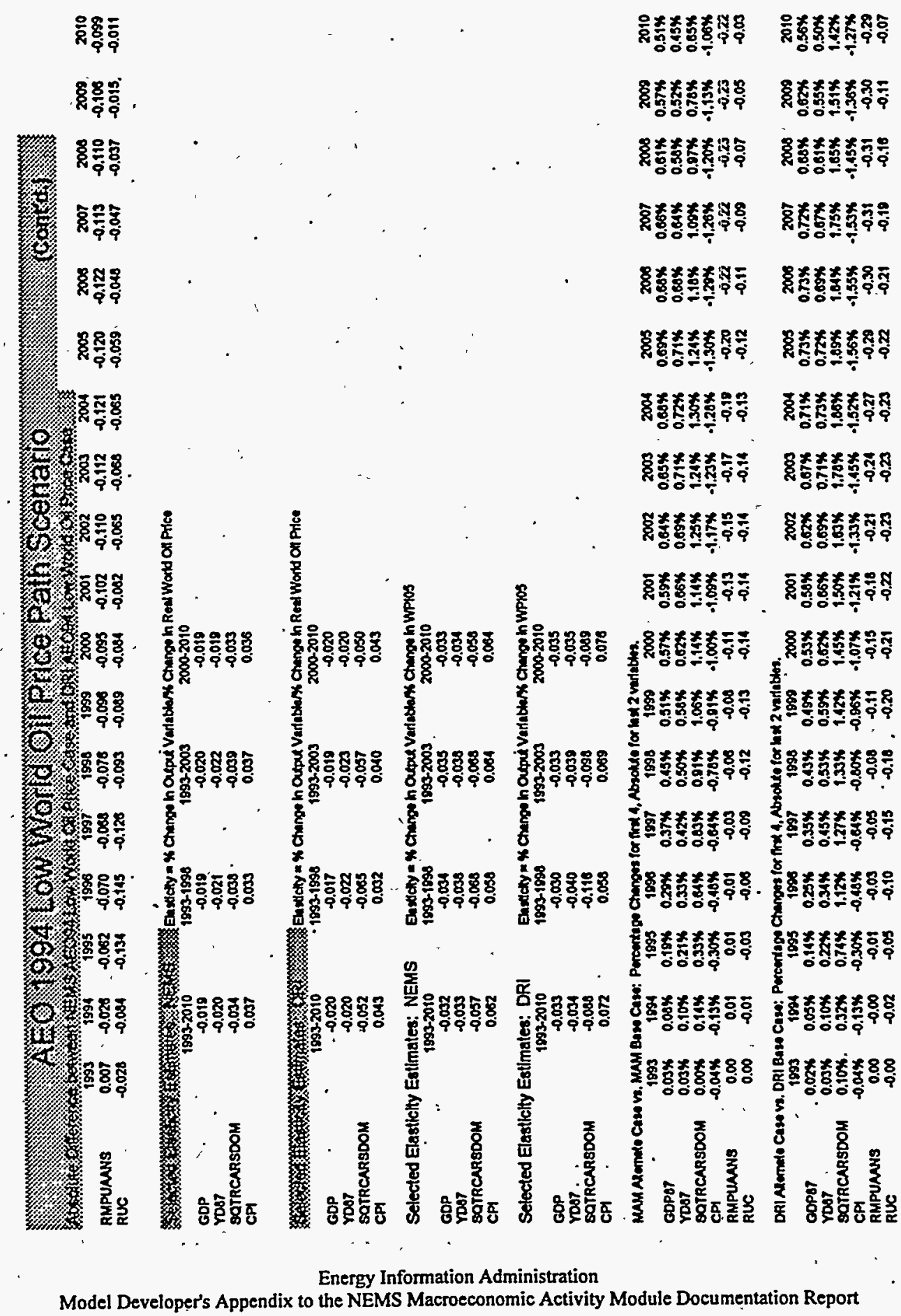




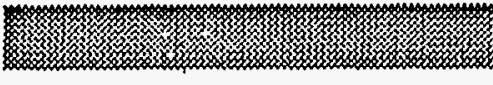

\section{Real Woll OI Price mimediate nerease}

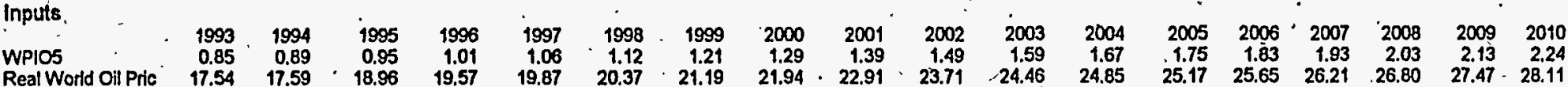

Percent Difference Between Immediate Increase World Oill Price Path Scenario and Base Case

$\begin{array}{llllllllllllllllllllll} & 1993 & 1994 & 1995 & 1996 & 1997 & 1998 & 1999 & 2000 & 2001 & 2002 & 2003 & 2004 & 2005 & 2006 & 2007 & 2008 & 2009 & 2010\end{array}$ $\begin{array}{lllllllllllllllllllllllll}\text { Real World Oil Pric } & 20.00 \% & 20.00 \% & 20.00 \% & 20.00 \% & 20.00 \% & 20.00 \% & 20.00 \% & 20.00 \% & 20.00 \% & 20.00 \% & 20.00 \% & 20.00 \% & 20.00 \% & 20.00 \% & 20.00 \% & 20.00 \% & 20.00 \% & 20.00 \%\end{array}$

NEMS Outputs

GDP

SORRCARSDOM

CPI

RMPUAANS

$19931994 \times 1995 \quad 1996$

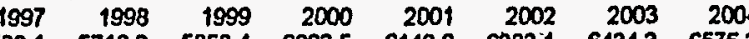

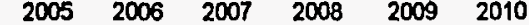
$\begin{array}{rrrrrrrrrrrrr}3650 & 3740 & 3832 & .3894 & 3964 & .4032 & 4102 & 4175 & .4244 & 4313 & 4389 & 4464 \\ 7.00 & 7.11 & 6.94 & 7.22 & 7.42 & 7.42 & 7.53 & 7.53 & 7.54 & 7.54 & 7.65 & 7.75 \\ 1.45 & 1.50 & 1.55 & 1.61 & 1.66 & 1.72 & 1.78 & 1.85 & 1.92 & 1.99 & 2.07 & 2.14 \\ 7.00 & 1.36 & . .45 & 8.56 & 8.84 & .89 & .83 & 8.81 & 8.91 & 8.79 & .74 & 8.70\end{array}$

\begin{tabular}{rrrrrrr}
4 & 4545 & 4625 & 4711 & 4791 & 4870 & 4959 \\
5 & 7.85 & 7.96 & 8.17 & 8.27 & 8.18 & 8.19 \\
\hline & 2.22 & 2.31 & 2.39 & 2.48 & 257 & 2.67
\end{tabular}

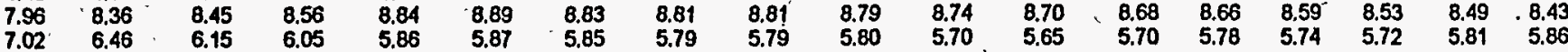

DRI Outputs

GDP

YOBT SOTRCARSDOM

RMPUAANS

RUC

$\begin{array}{rrr}1993 & 1994 & 1995 \\ 5064.1 & 5218.0 & 5329.7 \\ 3655 & 3750 & 38 . \\ 7.01 & 7.12 & 6 . \\ 1.45 & 1.49 & 1.95 \\ 7.98 & 8.38 & 8.43 \\ 7.04 & 6.42 & 6.09\end{array}$

$\begin{array}{rrrrr}1995 & 1996 & 1997 & 1998 \\ 29.7 & 5462.0 & 5600.7 & 5728.6 & 5 \\ 3481 & 3902 & 3972 & 4040 & \\ 6.99 & 7.22 & 7.40 & 7.49 \\ 1.55 & 1.60 & 1.66 & 1.72 \\ 8.43 & 8.52 & 8.80 & 8.85 \\ 6.09 & .6 .02 & 5.84 & .5 .87\end{array}$

\begin{tabular}{rr}
1999 & 2000 \\
\hline 868.5 & 6013.0 \\
4108 & 4182 \\
7.50 & 7.5 \\
1.78 & 1.85 \\
8.79 & 8.79 \\
5.86 & 5.80 \\
\hline
\end{tabular}

\begin{tabular}{rr} 
& \\
\hline $3.0^{\prime}$ & 2001 \\
82 & 450.2 \\
.51 & 7.50 \\
.85 & 1.92 \\
.79 & 8.79 \\
80 & 5.81
\end{tabular}

$\begin{array}{rrr}2002 & 2003 & 2004 \\ 6289.3 & 6441.2 & 6580.1 \\ 4318 & 4393 & 4467 \\ 7.54 & 7.62 & 7.75 \\ 1.99 & 2.07 & 2.15 \\ 8.78 & 8.75 & 8.72 \\ 5.83 & 5.74 & 5.69\end{array}$

Percent Difference Between NEMMS Immediate Price Increase Case and DRI Immedlate Price Increase Case

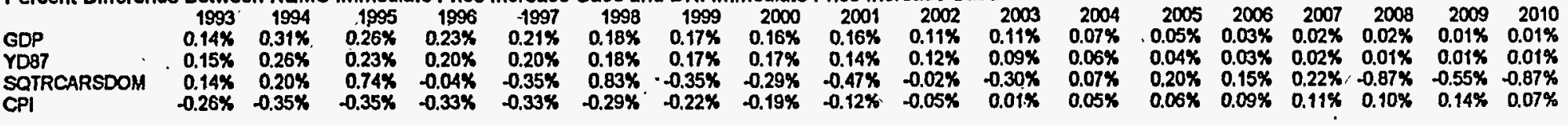


E

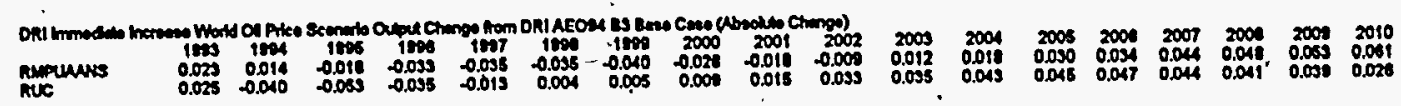
Sehated Euxtchy Estmmes: NEMS

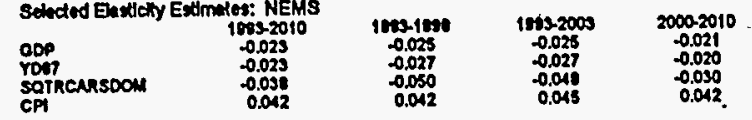

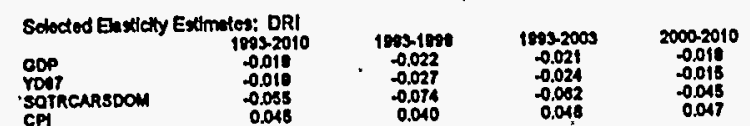

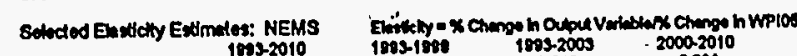

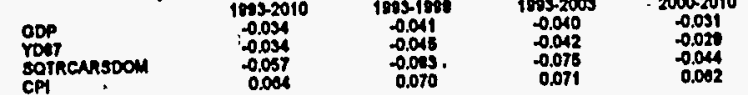

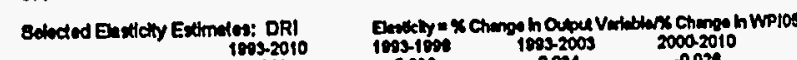

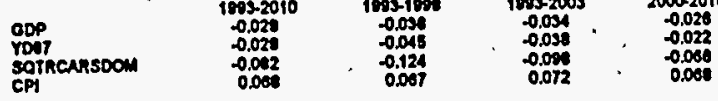

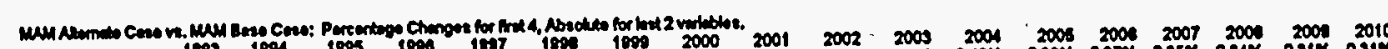

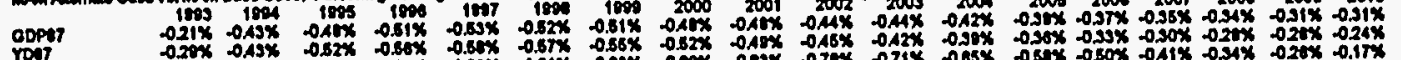

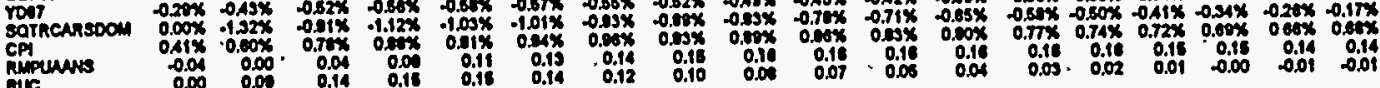
Rue

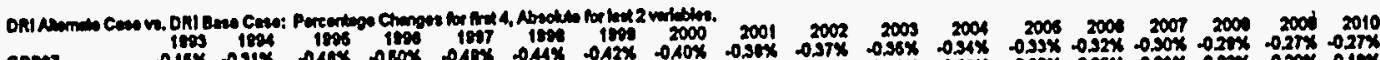

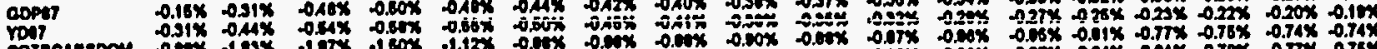

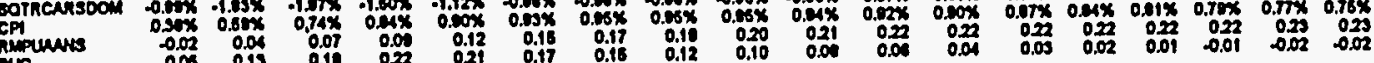

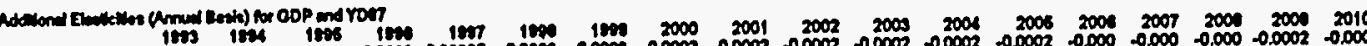

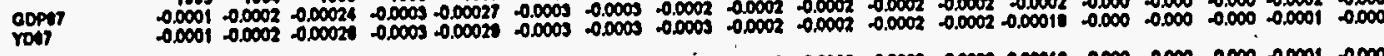

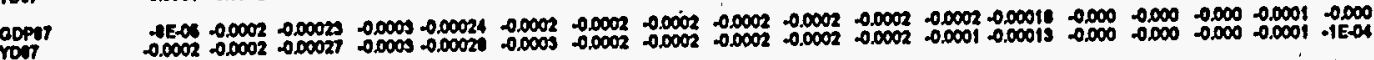




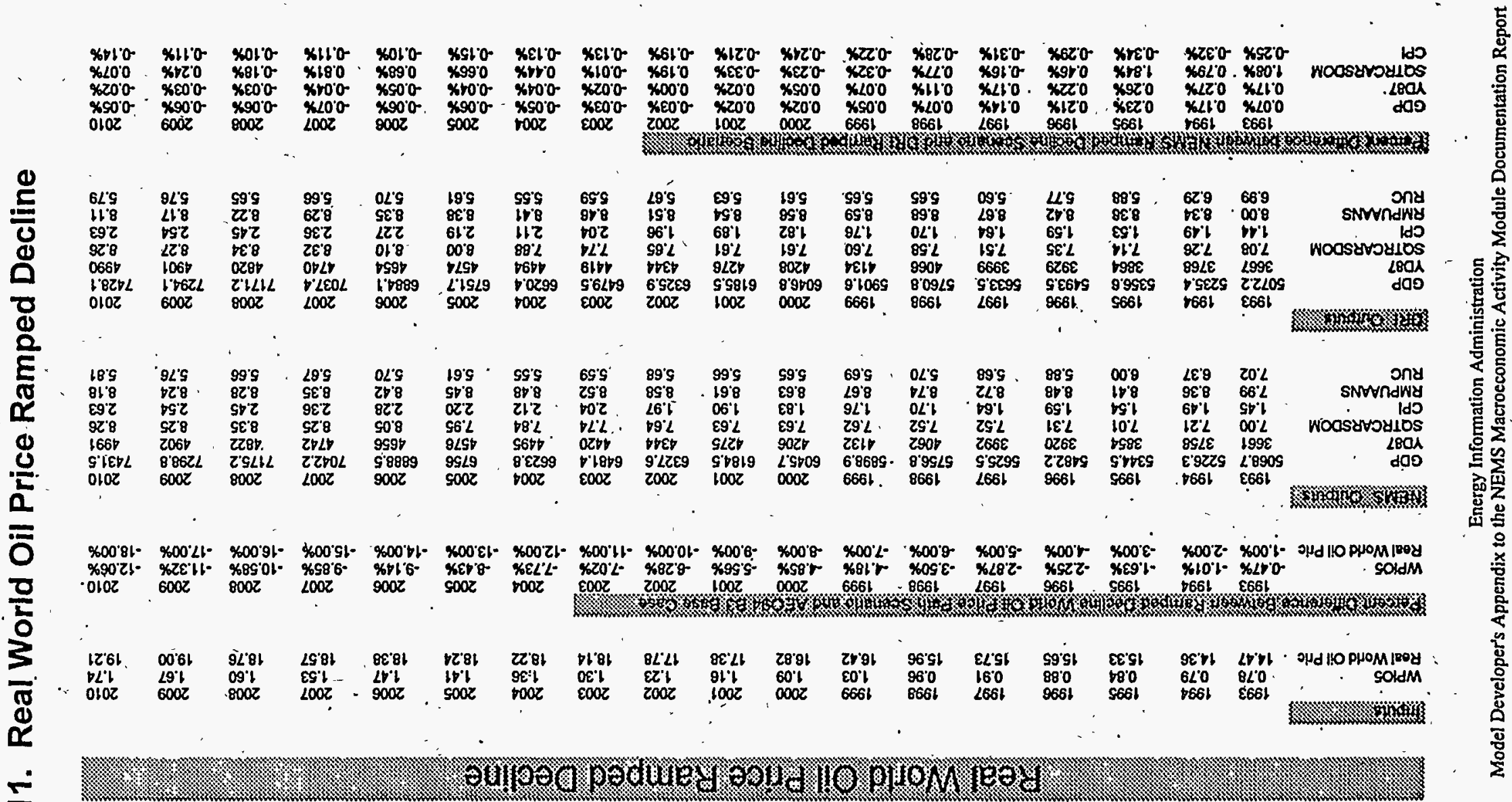




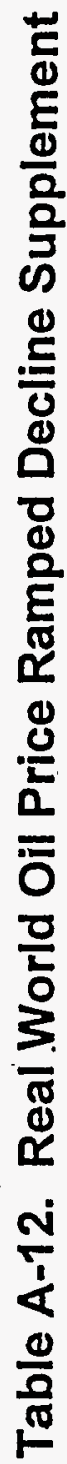

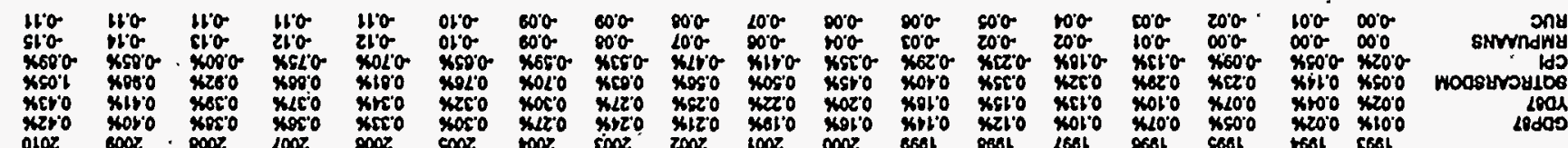

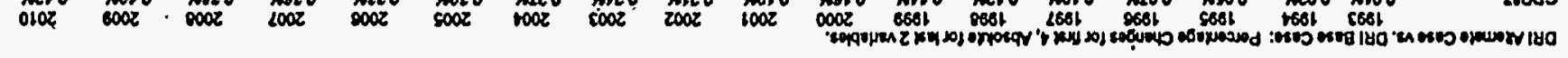

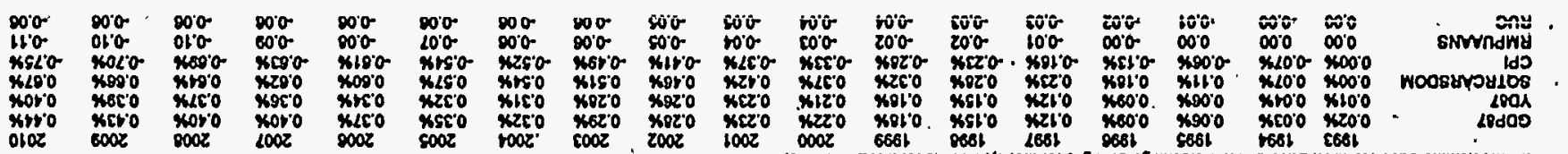

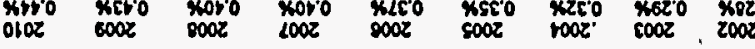
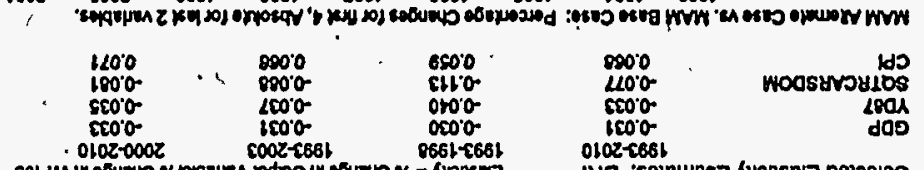

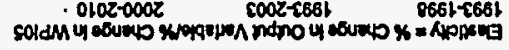

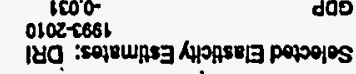

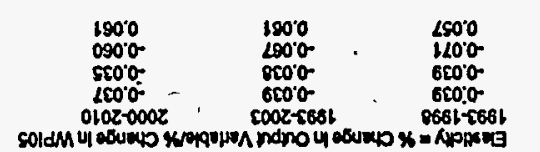

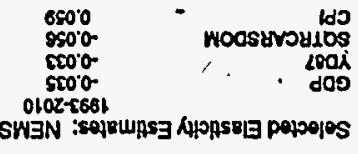
SOldM 4 I DSU

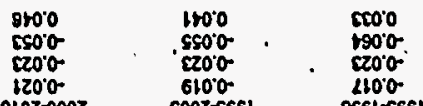

120.0

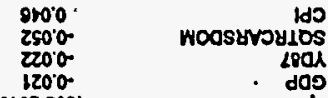

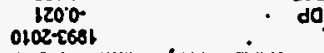

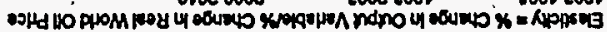

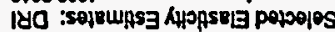

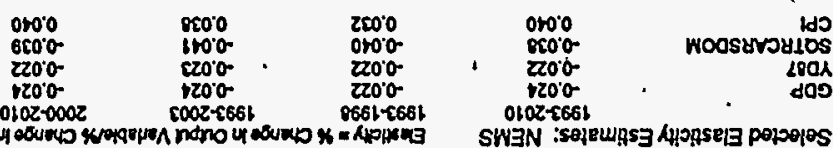

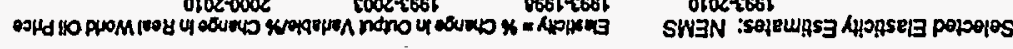

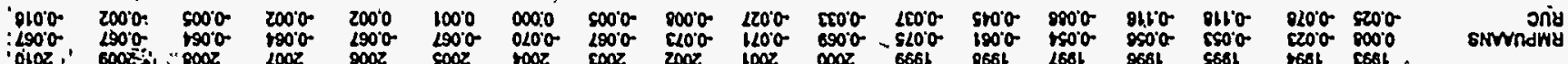

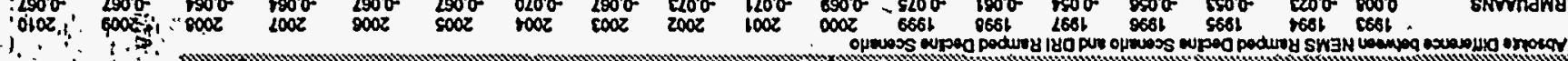

